EUROPEAN SUMMER SCHOOL IN LINGUISTIC TYPOLOGY

Porquerolles, September 2016

\title{
TRANSITIVITY, VALENCY, AND VOICE
}

\author{
Denis Creissels \\ DDL (UMR 5596) \& Université Lyon 2 \\ denis.creissels@univ-lyon2.fr \\ http://deniscreissels.fr
}





\section{TABLE OF CONTENTS}

\section{Abbreviations \\ Lesson 1: Transitive coding and other verbal predicative constructions}

\subsection{Some terminological clarifications}

\subsubsection{Arguments and adjuncts}

1.1.2. Valency, transitivity and voice

1.1.2.1. Valency, argument structure, coding frames

1.1.2.2. Transitivity

1.1.2.3. Voice

1.1.3. Syntactic transitivity

1.1.3.1. Core transitive verbs

1.1.3.2. Syntactically transitive verbs

1.1.4. Basic transitive coding

1.1.4.1. TAM/polarity-conditioned transitive coding

1.1.4.2. Differential coding of agents or patients

1.1.4.3. Basic transitive construction and intransitive constructions of transitive verbs 1.1.4.4. Multiple transitive coding

1.1.5. Direct/inverse marking in transitive constructions

1.1.5.1. Definition

1.1.5.2. The domains of direct/inverse marking

1.1.5.3. Rigid vs. flexible systems of direct/inverse marking

1.1.6. Core arguments vs. obliques

1.1.6.1. Core arguments

1.1.6.2. Obliques

\subsubsection{Alignment}

\subsubsection{Zero case}

\subsection{Transitive coding typology}

\subsubsection{Introductory remarks}

1.2.2. Joint vs. disjoint $A / P$ coding

1.2.3. Symmetrical vs. asymmetrical transitive constructions

1.2.4. Subtypes of symmetrical transitive constructions 
1.2.5. Subtypes of fully asymmetrical transitive constructions

1.2.6. Subtypes of partially asymmetrical transitive constructions

1.2.7. Transitive constructions with conflicting asymmetries

1.2.8. Variation in transitive coding and the characterization of the transitive coding system of individual languages as A- or P-centered

1.2.8.1. Variation in transitive coding that does not affect the possibility of characterizing the transitive coding system as a whole as A-or P-centered

1.2.8.2. Variation in transitive coding making impossible the characterization of the transitive coding system as a whole as A-or P-centered

\subsection{The Obligatory Coding Principle}

1.3.1. The Obligatory Coding Principle as a reformulation of the distinction between morphologically accusative and morphologically ergative languages

1.3.2. Impersonality and the Obligatory Coding Principle

1.3.2.1. Introductory remarks

1.3.2.2. Impersonal constructions

1.3.2.3. Anti-impersonal constructions

\subsection{Relationship between types of transitive coding and types of alignment}

1.4.1. Correlation between transitive coding typology and the Obligatory Coding Principle

1.4.2. A-unmarked vs. P-unmarked systems of argument coding

1.4.3. Atypical systems of argument coding

\subsection{Transitive coding and valency}

1.5.1. Bivalent verbs and transitivity

1.5.2. Trivalent verbs and transitivity

1.5.2.1. Extended-transitive coding and double-transitive coding

1.5.2.2. Indirective vs. secondative alignment

1.5.2.3. Hierarchy in double-transitive constructions

1.5.2.4. Dative coding

1.5.3. Monovalent verbs and transitivity

1.5.3.1. Light verb constructions

1.5.3.2. Cognate $P$ constructions with intransitive verbs

1.5.3.3. Other types of atypical P's: the case of Soninke and Manding

1.5.3.4. Time phrases encoded as the A term of a transitive construction

\section{Lesson 2: Valency-decreasing voices}




\subsection{A/U-demoting voices}

\subsubsection{Canonical passive constructions}

2.1.1.1. Passive constructions including an oblique agent phrase

2.1.1.2. Agentless passives

2.1.1.3. Constraints on the use of passive constructions

\subsubsection{Impersonal passives from transitive verbs}

2.1.3. Extension of passive morphology to U-demotion

2.1.3.1. Oblique passives

2.1.3.2. Impersonal passives from intransitive verbs

2.1.3.3. The adversative passive of Japanese

2.1.4. Syncretic passives and the origin of passive constructions

2.1.4.1. The passive-resultative syncretism

2.1.4.2. The passive-middle syncretism

2.1.4.3. The passive-antipassive syncretism

2.1.4.4. The passive-causative syncretism

2.1.4.5. Others

2.1.5. Impersonal voices

2.1.6. Oblique voices

\subsection{P-demotion: the antipassive voice}

\subsubsection{Definition}

\subsubsection{Typology of antipassive derivations}

2.2.3. The functions of antipassive derivations, and the relationship between antipassive and the Obligatory Coding Principle

2.2.4. Antipassives in Obligatory A Coding languages: evidence from Subsaharan languages

2.2.4.1. Introductory remarks

2.2.4.2. Bantu antipassives

2.2.4.3. West African antipassives

2.2.5. Dedicated vs. syncretic antipassive voices, and the origin of antipassive voices 2.2.5.1. Antipassive, reflexive, and reciprocal

2.2.5.2. Other possible sources of antipassive markers

2.2.5.3. The antipassive-causative syncretism

2.2.5.4. Antipassive markers also found in constructions involving no valency change

2.2.6. Non-canonical antipassives

\subsection{Reflexive and reciprocal}


2.3.1. Reflexive events, reflexive construction, reflexive voice

2.5.1.1. Quasi reflexive events and the notion of middle voice

2.5.1.2. From reciprocal to middle

2.5.1.3. Further extensions

2.3.2. Reciprocal events, reciprocal constructions, reciprocal voice

2.3.3. The reflexive-reciprocal syncretism

2.3.4. Reciprocity, co-participation, and antipassive

2.4. Anticausative and resultative

2.4.1. Anticausative

2.4.2. The resultative

2.5. The middle

2.5.1. Quasi reflexive events and the notion of middle voice

2.5.2. Passive middles

2.5.3. Antipassive middles

2.5.4. Impersonal middles

2.5.5. Middle marking without reduction of the number of arguments

2.5.6. Lexicalized middles

\section{Lesson 3: Valency-increasing voices and voice combinations}

\subsection{The causative voice}

\subsubsection{Definitions}

3.1.2. Direct vs. indirect causation

3.1.3. Restrictions on causative derivations, double causatives

3.1.4. The causee in the construction of causative verb forms

3.1.5. Possible sources of causative voices

3.1.5.1. The grammaticalization path causation verb $>$ causative auxiliary $>$ causative derivational affix

3.1.5.2. Others 
3.1.6. Non-canonical causatives, lexicalized causatives

3.1.6.1. Causative voice and underspecified transitivization

3.1.6.2. Causative voice and perspectivization

3.1.6.3. Causative voice encoding an increase in the agentivity of a participant

3.1.7. Syncretic causatives

3.1.7.1. The passive-causative syncretism

3.1.7.2. The antipassive-causative syncretism

3.1.7.3. The causative-applicative syncretism

3.1.7.4. The causative-iterative syncretism

\subsection{The applicative voice}

\subsubsection{Definition}

\subsubsection{Optional applicatives}

\subsubsection{Obligatory applicatives}

3.2.4. The treatment of the initial $P$ in applicatives from transitives

\subsubsection{Semantically specialized vs. unspecified applicatives}

3.2.6. Applicatives in diachrony

3.2.6.1. Adposition incorporation as a possible source of applicatives

3.2.6.2. Applicative periphrases

\subsubsection{The causative-applicative syncretism}

3.2.8. Non-canonical applicatives: the case of Tswana

3.2.8.1. Applicative derivation and the promotion of instrumental adjuncts

3.2.8.2. Applicative derivation and the semantic role of locative phrases: general remarks

3.2.8.3. Verbs of movement that cannot assign the role of source or destination

3.2.8.4. Verbs of movement that can assign the role of source

3.8.2.5. Verbs that do not express movement

3.2.8.6. Applicative derivation and the focalization of locative phrases

3.2.8.7. Discussion

\subsection{Some rare types of valency increasing derivations}

3.3.1. The possessive voice of Wolof

\subsubsection{Others}

\subsection{Voice combinations}

3.4.1. Combinations of voices with a compositional meaning

3.4.2. Combinations of voices with non-compositional interpretations 


\section{Lesson 4: Morphologically undirected valency alternations}

\subsection{Equipollent derivation in valency alternations}

4.2. Inflectional classes of verbs and valency (inflectional voices)

4.3. Auxiliary selection and valency

4.4. A note on unexpressed arguments

\subsection{Ambitransitivity}

4.5.2. Major types of ambitransitivity

4.5.3. A typology of ambitransitivity

4.5.3.1. Introductory remarks

4.5.3.2. A-lability, P-lability, reflexive lability, and reciprocal lability

4.5.3.3. Argument structure preserving vs. argument structure modifying ambitransitivity

4.5.3.4. Weak vs. strong ambitransitivity

4.5.4. Two semantic types of P-lability

4.5.5. Two semantic types of A-lability

4.5.6. Underspecified ambitransitivity

4.6. A-P reversal

4.7. A X lability

4.8. Locative lability

4.9. Impersonal lability

4.9.1. Unmarked impersonalization of transitive constructions with demotion of $A$ to oblique

4.9.2. Impersonal lability in presentational constructions

4.9.3. Other instances of impersonal lability

4.10. G-lability

4.11. Alternations between terms of predicative constructions and adnominal possessors

4.11.1. External possession 
4.11.2. 'Indirect object lowering'

Lesson 5: Incorporation and transitivity

5.1. Incorporation as a morphological operation

5.2. Argument incorporation

5.3. Possessive incorporation

5.4. Modifying incorporation

5.5. Classificatory incorporation

5.6. Incorporation in diachrony

5.7. Incorporation and transitivity marking: the case of Soninke

5.7.1. Introductory remarks

5.7.2. Functional subtypes of incorporation in Soninke

5.7.3. Possessive incorporation

5.7.4. $P$ incorporation

5.7.5. Oblique incorporation

5.7.5.1. Similative incorporation

5.7.5.2. Incorporation of temporal adjuncts

\section{Bibliography}





\section{Abbreviations}

A (a) the term of the basic transitive construction that represents the agent in the construction of core transitive verbs

(b) in the glossing of argument indexes in languages in which indexing is not limited to one argument, index belonging to a series used for (but not necessarily restricted to) the A term of the basic transitive construction

ABL ablative (case)

ABS adposition flagging nouns in 'absolutive' ( $\mathrm{P}$ or $\mathrm{U}$ ) role

ACC accusative (case)

ADJ adjective

ALL allative

ANTIPASS antipassive

APPL applicative

BEN benefactive

CAUS causative

CL noun class

CLF classifier

CONTINT continuative-intensive

CONV converb

COP copula

CPL completive

CSTR construct form marker

D default determiner (determiner that may mark definiteness or referentiality in limited contexts, but whose combination with nouns often acts as the semantically less-specified form of nouns)

DAT dative case marker, or dative index

DECL declarative

DEF definite

DEM demonstrative

DETR detransitivizer

DIR direct

DOM differential object $(\mathrm{P})$ marking

EP epenthetic

ERG ergative

EXCL exclusive

$\mathrm{F} \quad$ feminine

FOC focalization marker

FUT future

FV final vowel (in Bantu languages, a vowel analyzable as inflectional ending of verbs)

GEN genitive

GER gerundive

$\mathrm{H}$ (superscript) high morphotoneme

HON honorific

ICPL incompletive

IMPERS impersonal

INDEF indefinite

INF infinitive 


$\begin{array}{ll}\text { INSTR } & \text { instrumental (case) } \\ \text { INTR } & \text { intransitive } \\ \text { INV } & \text { inverse } \\ \text { IPF } & \text { imperfective } \\ \text { IPRF } & \text { imperfect } \\ \text { L } & \text { (superscript) low morphotoneme } \\ \text { LH } & \text { (superscript) low-high morphotoneme } \\ \text { LK } & \text { linker } \\ \text { LOC } & \text { locative } \\ \text { M } & \text { masculine } \\ \text { MDPASS } & \text { mediopassive } \\ \text { MID } & \text { middle voice marker } \\ \text { N } & \text { neuter (gender) } \\ \text { NEG } & \text { negative } \\ \text { NFUT } & \text { non-future } \\ \text { NP } & \text { noun phrase } \\ \text { NPL } & \text { non-human plural } \\ \text { NPST } & \text { non-past } \\ \text { OBL } & \text { oblique (case marker or adposition) }\end{array}$

$\mathrm{P} \quad$ (a) the term of the basic transitive construction that represents the patient in the construction of core transitive verbs

(b) in the glossing of argument indexes in languages in which indexing is not limited to one argument, index belonging to a series used for (but not necessarily restricted to) the $\mathrm{P}$ term of the basic transitive construction

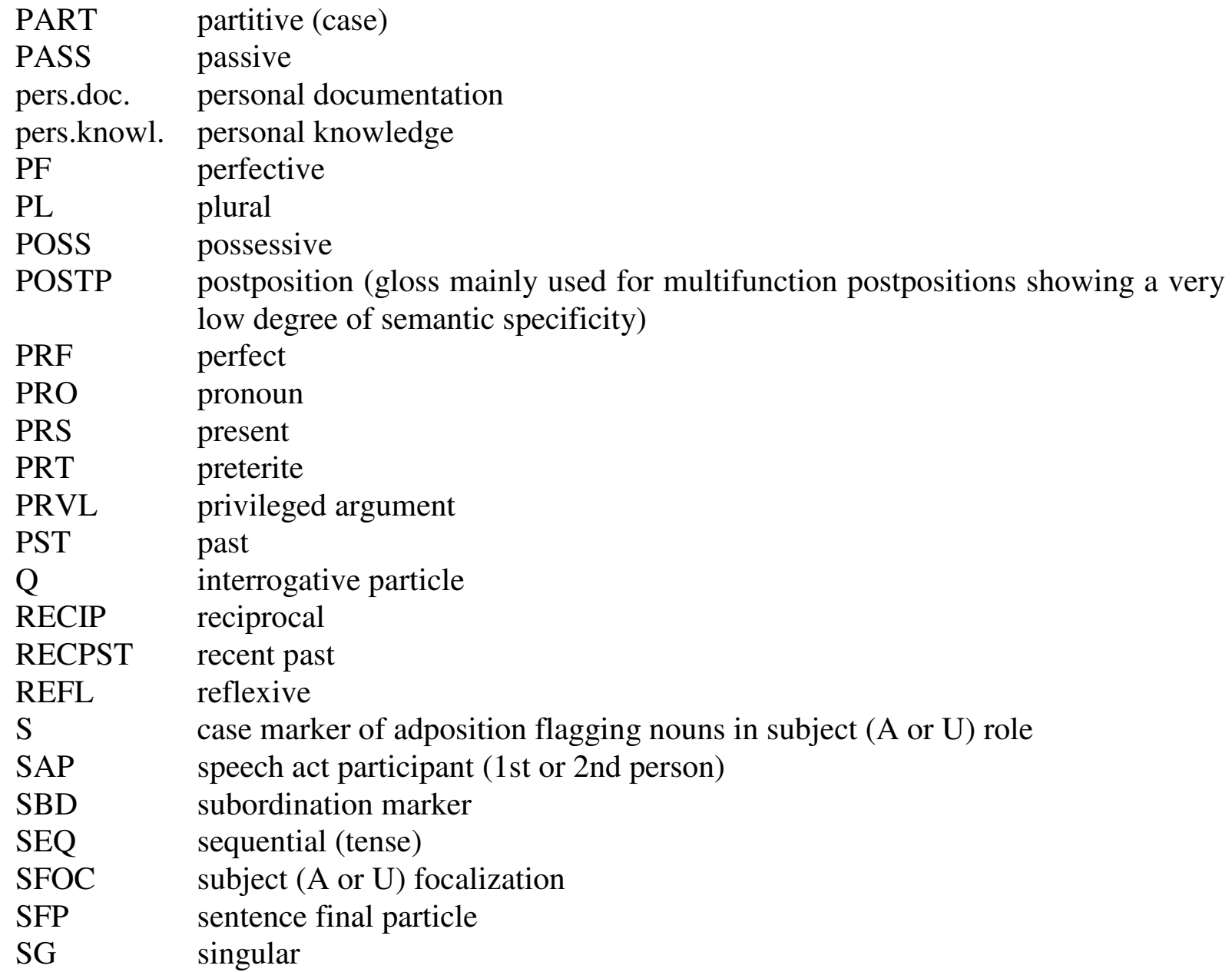


TAM tense-aspect-modality marker

TOP topicalization marker

TR transitive

(a) sole argument of semantically monovalent verbs

(b) core argument in a predicative construction that does not include an $\{\mathrm{A}, \mathrm{P}\}$ pair

(c) in the glossing of argument indexes in languages in which indexing is not limited to one argument, index belonging to a series used specifically for the $U$

$\mathrm{V}$ argument of intransitive verbs

VFOC verb focalization marker 



\section{Lesson 1 \\ Transitive coding and other verbal predicative constructions}

\subsection{Some terminological clarifications}

\subsubsection{Arguments and adjuncts}

The noun phrases involved in verbal predicative constructions are commonly divided into two broad types designated in most recent works as arguments and adjuncts. Arguments are characterized by their relatively tight semantic relationship to the verb, whereas adjuncts are characterized by a looser type of semantic relationship to the verb.

The argument vs. adjunct distinction has sometimes been discussed (in particular, in descriptions of individual languages) in such a way that it is not clear whether the authors conceive this distinction as referring to syntax, to the conceptualization of events, or to both at the same time.

The notion of argumenthood has been discussed, and argumenthood tests have been proposed, in classical works such as Jackendoff (1977), Marantz (1984), Pollard and Sag (1987), Grimshaw (1990). Schütze (1995) provides both a detailed survey and an interesting discussion in which he argues in favor of a scalar conception of argumenthood. However, the detailed discussions of argumenthood one can find in the literature almost always deal exclusively with English (or other well-described languages such as French or German), and it is not difficult to find languages to which the argumenthood tests put forward in the literature cannot be transposed. A cross-linguistic approach to argumenthood can only be based on semantic considerations.

Semantic argumenthood can be defined in terms of degree of involvement of participants in the event. Two types of participants can be viewed as showing a high degree of involvement: those without which the event cannot be conceived (for example, the lexical meaning of 'eat' cannot be defined without mentioning an eater and a thing being eaten), and those whose participation conditions that of other participants. Note that this notion of semantic argumenthood is gradient rather than categorical. For example, phrases representing beneficiaries or instruments, although commonly classified as adjuncts, are clearly less adjunct-like than for example phrases referring to the location of the event. The point is that instruments facilitate the actions performed by agents, and events implying beneficiaries are typically motivated by another participant's desire to act in favor of the beneficiary. And among agents, a semantic distinction can be made between those (for example, eaters) without which the process undergone by the patient is simply impossible to conceive, and those (for example, breakers) controlling processes that are also conceivable as occurring more or less spontaneously.

Crucially, there is no straightforward correspondence between essential participants in a given type of event and obligatory NPs in the construction of the verb encoding the event.

A particularly clear case is that of the verbs of eating. The act of eating cannot be defined without mentioning two essential participants, but many languages have two 'eat' verbs, one of them transitive and the other intransitive, that cannot be analyzed as related to each other via some morphological operation, as illustrated by Akhvakh $\overline{\mathbf{q}} \mathbf{a m}$ - (quoted in the infinitive as $\overline{\mathbf{q}} \mathbf{\overline { o } n u L a}$ ) 'eat (transitive)' vs. ũk- (quoted in the infinitive as ũkunuLa) 'eat (intransitive)' - Ex. (1). Crucially, in this example, sentence (d) cannot be used in the same meaning as (b), 
and is acceptable only if the unexpressed participant can be identified to a referent retrievable from the context or the situation.

(1) Akhvakh (pers.doc.)

(1a) Riē'i $\overline{\mathbf{q}}$ 'am-a!

meat eat-IMPER

'Eat (tr.) the meat!'

(1b) Ĩ ̌́ci ũk-a!

first eat-IMPER

'Eat (intr.) first!'

(1c) *Rī̄'i ũk-a!

meat eat-IMPER

*'Eat (intr.) the meat!'

(1d) Ĩ č'i $\overline{\mathbf{q}}$ 'am-a!

first eat-IMPER

'Eat it/that first!'

In the case of 'eat', it is absolutely uncontroversial that an eating event is a two-participant event, whatever the syntactic properties of the verbs used to encode it in individual languages. Things are not always so simple, an many verbs cannot be unambiguously characterized as mono- or bivalents, or as bi- or trivalents. However, in the framework developed in this course, this is not a problem, since none of the definitions that will be put forward presupposes the possibility of identifying the number of arguments of each individual verb with precision.

At this point, it is important to emphasize that a crucial advantage of the framework developed in this course, in comparison with other possible frameworks, is that the analytical decisions it implies are not conditioned by decisions about the status of participants in the argument structure of individual verbs as arguments or adjuncts. The crucial distinction in this framework is not the argument vs. adjunct distinction briefly commented in this section, but rather the distinction between core arguments and obliques introduced in Section 1.1.6 below, which logically follows from the notions defined in sections 1.1.2 to 1.1.4.

\subsubsection{Valency, transitivity and voice}

\subsubsection{Valency, argument structure, coding frames}

The notion of valency encompasses the argument structure of verbs (i.e. the involvement of a given number of participants in the event encoded by a given verb, and the roles they fulfill in this event), and the mapping of argument structure onto syntactic roles. For example, the argument structure of the English verb break in the clause The child broke the glass includes a breaker, encoded as the subject, and a thing broken, encoded as the object. The clause The glass was broken by the child expresses the same argument structure with a different mapping of participant roles onto syntactic functions (the thing broken is encoded as the subject, and the breaker as an oblique). A clause like The child saw a dog has the same syntactic structure as The child broke the glass, but it expresses a different type of argument structure, since break refers to an action performed by an agent and resulting in a change of 
state in the other participant (the patient), whereas see refers to a perception, and the participants are better characterized as an experiencer (or perceiver) and a stimulus.

Note that a given verb does not necessarily have the same argument structure in all its possible uses. For example, in The glass broke, break does not refer to an action performed by an agent, but to a process whose possible causes are left unspecified, and consequently the argument structure includes just one participant (the entity affected by the process in question).

Each language has an inventory of possible coding frames through which verbs express their argument structure. Formal contrasts between arguments may involve flagging, indexation, and linear order.

For example, Basque ${ }^{1}$ has three basic types of canonical coding frames that differ in the presence $v s$. absence of terms marked by one of the two morphological cases Zero (alias Absolutive $)^{2}$ and Ergative, and of the corresponding indexes on the verb form:

$$
\begin{array}{lll}
- & <\varnothing> & - \text { Ex. (1a); } \\
- & <\text { ERG }> & - \text { Ex. (1b); } \\
- & <\text { ERG, } \emptyset> & - \text { Ex. (1c). }
\end{array}
$$

Each of these basic types can be expanded by the addition of a term in the Dative case, which shares with terms in the Zero case and in the Ergative case the property of being obligatorily indexed on the verb form - Ex. (2d-f), and also by the addition of oblique arguments, i.e. NPs representing arguments but coded like typical adjuncts.

(2) Basque (pers.doc.)

(2a) Ispilu-a erori da.

mirror-SG fall.CPL PRS.P. $3 \mathrm{SG}^{3}$

'The mirror has fallen down.'

(2b) Ur-ak irakin du.

water-SG.ERG boil.CPL PRS.A.3SG.P.3SG

'The water has boiled.'

\footnotetext{
${ }^{1}$ Throughout this course, unless otherwise specified, language names must be understood as referring to the standard variety of the languages in question.

${ }^{2}$ On the term/notion of zero case, and on the use of $\varnothing$ in the schematization of coding frames, see Section 1.1.8. The convention for the glosses is that, in languages in which nouns are marked for case, the absence of any overt indication of case means that the noun in question is in the Zero case.

${ }^{3}$ In the languages that have two or more series of argument indexes, the glossing convention is as follows: indexes belonging to a series used to index the A term of the basic transitive construction are glossed A (even if they are used to index the $U$ term of an intransitive construction); indexes belonging to a series used to index the $P$ term of the basic transitive construction are glossed $P$ (even if they are used to index the $U$ term of an intransitive construction); indexes belonging to a series specifically used for the $U$ term of an intransitive construction are glossed $\mathrm{U}$; in languages that have a third set of indexes for the third argument of trivalent verbs, the indexes of this set are glossed DAT.

${ }^{4} \mathrm{Du}$ is a form of the so-called transitive auxiliary, which in principle indexes two arguments. Verbs with a sole core argument in the Ergative case are conjugated by means of this auxiliary, and their sole core argument is represented by an index of the A series, whereas the index that normally representss an argument in the Zero case takes the default value $3 \mathrm{SG}$.
} 
(2c) Haurr-ek ispilu-a puskatu dute.

child-PL.ERG mirror-SG break.CPL PRS.A.3PL.P.3SG

'The children have broken the mirror.'

(2d) Jon-i liburu-ak gustatzen zaizkio.

Jon-DAT book-PL please.ICPL PRS.P.3PL.DAT.3SG

'Jon likes books.'

(2e) Otso-ek ardi-ei esetsi zieten

wolf-PL.ERG sheep-PL.DAT attack.CPL PST.A.3PL.P.3SG.DAT.3PL ${ }^{5}$

'The wolves attacked the sheep.'

(2f) Haurr-ek Jon-i ispilu-a eman zioten.

child-PL.ERG Jon-DAT mirror-SG give.CPL PST.A.3PL.P.3SG.DAT.3SG

'The children gave the mirror to Jon.'

\subsubsection{Transitivity}

The notion of transitivity encompasses semantic transitivity and syntactic transitivity. There is a relationship between semantic and syntactic transitivity, since logically, syntactic transitivity can only be defined with reference to semantic transitivity. However, it is crucial to distinguish them carefully, since they do not necessarily coincide: transitive constructions do not necessarily refer to transitive events (cf. The child saw a dog), and transitive events are not necessarily encoded by transitive constructions (cf. The glass was broken by the child).

Semantic transitivity refers to the type of interaction between participants in twoparticipant events. As a semantic notion, it is gradient rather than categorical: two-participant events should not be characterized as transitive vs. non-transitive, but rather as more or less transitive. Prototypical transitive events (or events characterized by the highest possible degree of transitivity) involve a change of state or position undergone by one of the two participants (the patient) and triggered by the action of the other participant (the agent); moreover, prototypical transitivity implies that the action of the agent is conscious and voluntary, and aims at changing the state of the patient or controlling its position.

For example, the lexical meaning of break is compatible with the highest possible degree of semantic transitivity, but this is not the case for hit or eat. Hitting events are not prototypically transitive events, because the affected (or non-agentive) participant in a hitting event does not undergo a change of state or position, and consequently is not a typical patient. As regards eating events, the point is that the primary motivation of the action performed by the active participant in an eating event is not to change the state of the other participant or control its position, but rather to satisfy a physiological need, and consequently, the active participant in an eating event is not a typical agent.

The notion of syntactic transitivity will be defined and commented in Section 1.1.3.

\footnotetext{
${ }^{5}$ Zieten is a form of the so-called transitive-plus-dative auxiliary, which in principle indexes three arguments. Verbs with two arguments to which they assign the Ergative case and the Dative case are conjugated by means of this auxiliary, and the index corresponding to NPs in the Zero case takes the default value 3SG.
} 


\subsubsection{Voice}

There is no generally accepted definition of voice, although in all traditions, 'voice' refers to regularities in the relationship between argument structure and morphosyntax. For example, the particular type of alternation in the mapping of participant roles onto syntactic constructions illustrated by The child broke the glass $\sim$ The glass was broken by the child is traditionally described as a choice between 'active' and 'passive' voice.

When it comes to descriptions of previously undescribed languages, or to cross-linguistic comparisons, some authors use a very broad notion of voice, including all possible types of valency alternations, even those involving no morphological marking, whereas others use definitions of 'voice' that exclude valency-increasing mechanisms, and still others use definitions that exclude valency alternations involving no change in the semantic role assigned to the subject.

The definition of voice adopted in this course is that first proposed by Xolodovič (1970), according to which 'voice' is an abbreviation for 'morphologically coded valency alternation', without any additional condition on the valency alternations designated as voices. According to this definition, the mechanisms presented in Lessons 2 and 3 and in Sections 1 and 2 of Lesson 4 qualify as voices, whereas the alternations presented in the remainder of Lesson 4 are not voices.

\subsubsection{Syntactic transitivity}

\subsubsection{Core transitive verbs}

In this course, verbs encoding events involving one, two, or three essential participants are designated as monovalent, bivalent, and trivalent. Transitive and intransitive do not refer to the number of essential participants in the events denoted by verbs, but to the fact that they select a coding frame identical to that of verbs encoding a particular type of event. The delimitation of the set of transitive verbs is language-specific and relies on formal criteria, but the sets of transitive verbs of the individual languages are universally defined as including a particular semantic class of verbs, the core transitive verbs, defined as bivalent verbs that can head clauses encoding events characterized by a maximum degree of semantic transitivity as defined in Section 1.1.2.2 above.

In other words, a core transitive verb is a bivalent verb that has the ability to refer to twoparticipant events involving two well-individuated participants, a typical agent (i.e. a human participant consciously and willingly controlling an activity oriented towards the other participant), and a typical patient (i.e. a participant undergoing a change of state or position triggered by the activity of an agent). Break is a good example of a core transitive verb. By contrast, as already commented in Section 1.1.2.2, hit is not a core transitive verb (and in many languages, hittees are coded differently from typical patients), and eat is not a core transitive verb either (which explains why many languages have two totally different translational equivalents of English eat, one of them transitive and the other intransitive, a situation that seems to never occur with core transitive verbs).

It is commonly assumed that, in the languages of the world, the set of the verbs recognizable as core transitive verbs according to the restrictive definition posited above shows a high degree of formal homogeneity, in the sense that, in each individual language, all core transitive verbs, or almost all, assign the same coding characteristics to their agents and patients. By contrast, cross-linguistically, as discussed among others by Tsunoda (1985) and Lazard (1994) and confirmed by Hartmann et al. (2013), no other class of verbs defined in terms of semantic role assignment shows a comparable propensity to group together into the 
same valency class. This suggests a cognitive prominence of this semantic class of verbs, and justifies giving it a central status in a typology of argument coding and in a typology of the interface between argument structure and morphosyntax.

\subsubsection{Syntactically transitive verbs}

In all languages, many verbs that are not core transitive verbs according to the definition put forward in Section 1.1.3.1 select a type of argument coding identical to that selected by core transitive verbs. The term transitive verb without further specification refers to verbs whose construction includes two terms coded like the two arguments of core transitive verbs, whatever their semantic roles. For example, English see is not a core transitive verb, but the coding it assigns to its arguments identifies it as transitive, since verbs such as break or fix assign the same coding to their arguments. Basque ikusi 'see' is also a transitive verb, since its coding frame $<$ ERG, $\varnothing>$ is the same as that of puskatu 'break' - Ex. (3). By contrast, Akhvakh hariguruLa 'see' is not transitive, since its coding frame $\langle\mathrm{DAT}, \emptyset\rangle$ is different from the coding frame $<E R G, \emptyset>$ selected in Akhvakh by biq'ōruLa 'break' - Ex. (4).

(3) Basque (pers.doc.)

(3a) Haurr-ek ispilu-a puskatu dute.

child-PL.ERG mirror-SG break.CPL PRS.A.3PL.P.3SG

'The children have broken the mirror.'

(3b) Haurr-ek ispilu-a ikusi dute.

child-PL.ERG mirror-SG see.CPL PRS.A.3PL.P.3SG

'The children have seen the mirror.'

(4) Akhvakh (pers.doc.)

(4a) Mik'i-de istaka biq'wāri.

child-ERG glass break.CPL

'The child broke the glass.'

(4b) Mik'i-La istaka harigwari.

child-DAT glass see.CPL

'The child saw the glass.'

Ex. (5) shows that, contrary to their English of French equivalents, the Mandinka verbs làfí 'want' and ñìná 'forget' are not transitive, since constituent order in Mandinka clauses is absolutely rigid, and the verbs in question select a coding frame N1 V N2 Postp different from the coding frame N1 N2 V typical for transitive clauses.

(5) Mandinka (pers.doc.)

(5a) Kèwôo yè fòolèesúwòo dádáa.

man.D CPL bicycle.D repair

'The man repaired the bicycle.' 
(5b) Kèwôo làfí-tà kód-òo lá. man.D want-CPL money.D POSTP

'The man wants money.'

(5c) Kèwôo ñìná-tà í kòntóyò lá. man.D want-CPL 1SG name.D POSTP 'The man has forgotten my name.'

Similarly, French regarder 'look at' is transitive, but its English equivalent look (at) is not transitive. Its coding frame can be designated as extended intransitive, and its second argument can be characterized as an oblique argument - see section 1.1.6.

As illustrated by the examples above, there is cross-linguistic variation in the extension of the set of bivalent verbs selecting coding frames different from those typical for core transitive verbs (we will return to this question in Section 1.5), but transitive coding is universally the default type of coding for bivalent verbs.

\subsubsection{Basic transitive coding}

The notion of basic transitive coding is central throughout this course. The basic transitive coding is a construction involving a verb and two NP's designated as A and P, whose coding is identical to that of the agent and the patient when the verb heading the construction is a core transitive verb.

The question discussed in this section is that the coding of agents and patients in the construction of core transitive verbs may show different types of variation which do not have the same consequences for the identification of a particular construction as the basic transitive construction in a given language. In some cases, an analysis in terms of conditioned variation within the frame of a single construction is possible (Sections 1.1.4.1 and 1.1.4.2). Sometimes, the variation is better analyzed in terms of choice between the basic transitive construction and detransitivized variants (Section 1.1.4.3), but it may also happen that it must be analyzed in terms of choice between two or more constructions that equally deserve being recognized as transitive (Section 1.1.4.4).

\subsubsection{TAM/polarity-conditioned transitive coding}

It may happen that the variation in the coding of $\mathrm{A}$ and $\mathrm{P}$ is conditioned by the TAM or polarity value of the clause, commonly (but not necessarily) expressed through verb morphology. Ex. (6) illustrates this phenomenon: in the Kurmanji variety of Kurdish, with the verb in the incompletive aspect, $\mathrm{A}$ is in the Zero case and $\mathrm{P}$ in the so-called Oblique case, whereas with the verb in the completive aspect, $\mathrm{P}$ is in the Zero case, and $\mathrm{A}$ in the Oblique case; as regards indexation, the verb invariably indexes the argument in the Zero case, i.e. A in the incompletive aspect, and $\mathrm{P}$ in the completive aspect.

(6) Kurmanji (Blau and Barak 1999)

$\begin{array}{llllllll}\text { (6a) } & \text { Ez } & \text { Sînem-ê } & \text { dibîn-im } & \text { (6e) } & \text { Min } & \text { Sînem } & \text { dît-Ø. } \\ \text { 1SG } & \text { Sinem-OBL } & \text { see.ICPL-1SG } & & \text { 1SG.OBL } & \text { Sinem } & \text { see.CPL-3SG } \\ \text { 'I see } & \text { Sinem.' } & & & \text { 'I saw Sinem.' } & \end{array}$


(6b)

$\begin{array}{lll}\text { Sînem } & \text { min } & \text { dibîn-e } \\ \text { Sinem } & \text { 1SG.OBL } & \text { see.ICPL-1SG } \\ \text { 'Sinem } & \text { sees me.' }\end{array}$

(6c) $\mathbf{E z}$ tê-m

1SG come.ICPL-1SG

'I am coming.'

(6d) Sînem tê-Ø

Sinem come.ICPL-3SG

'Sinem is coming.' (6f) Sînem-êe ez dît-im.

Sinem-OBL 1SG see.CPL-3SG

'Sinem saw me.'

(6g) Ez hat-im

1SG come.CPL-1SG

'I came.'

(6h) Sînem hat-Ø

Sinem come.CPL-3SG

'Sinem came.'

\subsubsection{Differential coding of agents or patients}

I designate as differential coding or agents and patients a phenomenon more widely known as 'differential marking of subjects or objects'. This phenomenon may occur in flagging or indexation. For example, in (7), the P argument of Spanish atropellar 'run over' is flagged by the preposition a (which in most of its uses corresponds to English to) in sentence (a), but is left unflagged in sentence (b).

(7) Spanish (pers.knowl.)

(7a) El coche atropelló a un peatón.

the car ran_over to a pedestrian

'The car ran over a pedestrian.'

(7b) El tren atropelló un tractor.

the train ran_over a tractor

'The train ran over a tractor.

The term of differential argument coding as I use it in this course applies to variation in the coding characteristics of $\mathrm{A}$ or $\mathrm{P}$ exclusively conditioned by features inherent to the argument in question, or by its function in information structure. This means that alternations conditioned by features of the verb such as TAM, by features of the co-argument, or implying variation in semantic role assignment, do not meet the definition of differential argument coding.

Differential coding may be rigid or flexible. Rigid differential coding is conditioned by inherent grammatical or semantic features of NPs (pronoun vs. noun, animate vs. inanimate), whereas flexible differential coding is conditioned by their discourse status. ${ }^{6}$ Many languages have differential argument coding mechanisms combining rigidity and flexibility. For example, in Sinhala, accusative flagging is optional for animate patients, whereas inanimate patients are obligatorily unflagged.

It is commonly assumed that the differential coding of agents and the differential coding of patients are each other's mirror image, but as argued by Fauconnier and Verstraete (2014), this idea can be criticized. What seems to me particularly important is that, once the definition of differential coding is made explicit, it turns out that most of the cases of 'differential

\footnotetext{
${ }^{6}$ On the role of information structure in differential P coding, see Iemmolo $(2010,2011)$ and Dalrymple \& Nikolaeva (2011).
} 
marking of agents' mentioned in the literature must be discarded as involving a change in semantic role affecting the features that define typical agents.

For example, involuntary agents are not typical agents, and consequently involuntary agent constructions are not instances of differential agent coding, and must rather be analyzed as coding frame alternations triggered by a change in argument structure. Evidence that involuntary agents imply a change in argument structure rather than differential agent marking is provided by languages like Akhvakh, where a verb like biq'uruLa 'break, intr.' / biq'ōruLa 'break, tr. (causative form of biq'uruLa)' occurs in the causative form in combination with a typical agent, and in the intransitive form in combination with an 'involuntary agent' - Ex. (8).

Akhvakh (pers.doc.)

(8a) Mik'i-de istaka b-iq'wāri.

child-ERG glass N-break.CAUS.CPL

'The child broke the glass.'

lit. 'The child made the glass break.'

(8b) Mik'i-gune istaka b-iq'wari.

child-ABL glass N-break.CPL

'The child broke the glass unintentionally.' lit. 'The glass broke from the child.'

Similarly, some languages have a more or less strict ban on the use of inanimates as A arguments of transitive verbs, and use various types of constructions to express the equivalent of English sentences such as The wind broke the branch. In such languages, the constructions used with inanimates fulfilling an agent-like role must be analyzed as alternative constructions whose selection is triggered by a change in argument structure, rather than instances of differential agent marking within the transitive construction, since inanimates cannot be typical agents.

\subsubsection{Basic transitive construction and intransitive constructions of transitive verbs}

It may happen that the variation observed in the coding of the arguments of core transitive verbs is best analyzed as reflecting an alternation between a construction that qualifies as basic transitive coding and one or more constructions involving detransitivization. This is particularly obvious in the case of constructions (irrespective of whether they involve morphological coding on the verb or not) that semantically imply that the agent is removed from the argument structure: anticausative constructions (The glass broke), P-oriented resultatives (The glass is broken).

There are also less obvious cases in which the argument structure is not affected, but the status of one of the alternative constructions as the basic transitive construction can nevertheless be established on the basis of the following two criteria: the basic transitive construction is less marked than the other(s) in terms of discursive or semantic conditioning (and consequently much more frequent in texts), and the morphosyntactic properties of the alternative construction(s) of core transitive verbs provide evidence of demotion of either the agent (passivization) of the patient (antipassivization). Note that the choice between the alternative constructions may imply the use of a distinct form of the verb (voice), but it may also happen that the alternative constructions use the same verb forms (lability).

Ex. (9b) illustrates the cross-linguistically rare phenomenon of a passive construction without passive morphology, and Ex. (10b) illustrates an antipassive construction without 
antipassive morphology. Both Bambara and Supyire have a rigid APVX constituent order in the basic transitive construction, and in both examples, $\mathrm{P}>\mathrm{X}$ demotion is marked by the change in the linear order of constituents and the presence of a postposition.

(9) Bambara (pers.doc.)

(9a) Sékù má nègèsô dílán.

Sékou CPL.NEG bicycle repair

'Sékou did not repair the bicycle.'

(9b) Nègèsô má dílán Sékù fè̀.

bicycle CPL.NEG repair Sékou by

'The bicycle was not repaired by Sékou.'

(10) Supyire (Carlson 1994)

(10a) U a m̀̀àà-bíí bò.

3SG CPL sheep.PL-DEF kill

'He killed the sheep.'

(10b) $\mathbf{U}$ a bò m̀̀àà-bíl-ê.

3SG CPL kill sheep.PL-DEF-in

'He killed some of the sheep.'

lit. 'He killed in the sheep.'

\subsubsection{Multiple transitive coding}

In some of the languages that have two or more alternative constructions for transitive verbs, no obvious candidate for the status of basic transitive construction emerges. I will refer to this phenomenon as multiple transitive coding.

The case of the languages with the Philippine-type of voice system has been widely discussed in the literature. Ex. (11) illustrates three verbal voice forms in Tagalog. Each clause has a privileged argument marked by the preposition ang, ${ }^{7}$ and this privileged argument is the only one having access to some operations (for example, questioning). The preposition ang provides no indication about the semantic role of the privileged argument, but this information is given by the voice form of the verb. The other nominal terms of the clause are marked by prepositions whose choice reflects the argument structure of the verb and the semantic roles of adjuncts: ng (used to mark adnominal possessors, but also agents and patients when they are not promoted to privileged argument), sa (dative), etc. The functions of these voice alternations are quite similar to those of the alternations described in terms of passive or antipassive voices in other languages, but there is no clear asymmetry that could justify analyzing (a) as basic and (b) as passive, or (b) as basic and (a) as antipassive.

\footnotetext{
${ }^{7}$ This preposition is commonly designated as 'nominative preposition', but this term is potentially misleading, since the Tagalog system is basically different both from those for the description of which the term 'nominative' is traditionally used (Latin, Greek, etc.) and from those to the description of which the use of the term 'nominative' has been extended in more recent times (for example, Japanese, or the 'marked-nominative' languages of East Africa).
} 
(11) Tagalog (Latrouite 2001: 123-4)

(11a) Nagbigay ang babae ng liham sa kapit-babay. VOICE.give PRVL woman CORE letter DAT neighbour 'The woman gave a letter to the neighbour.'

(11b) Ibinigay ng babae ang liham sa kapit-babay. VOICE.give CORE woman PRVL letter DAT neighbour 'The woman gave a letter to the neighbour.'

(11c) Binigyan ng babae ng liham ang kapit-babay.

VOICE.give CORE woman CORE letter PRVL neighbour

'The woman gave a letter to the neighbour.'

A similar problem arises with other languages that have alternative constructions of transitive verbs expressing alternative perspectivizations of the event comparable to those expressed by passive or antipassive derivations, without however clear evidence that one of the alternative constructions should be considered as basic, and the other as a detransitivized variant.

Uduk (Koman) is a case in point. In this language, the unique argument of monovalent verbs is invariably in immediate preverbal position, devoid of case marking and crossreferenced on the verb. Obliques follow the verb, or precede the unique argument in case of topicalization.

(12) Uduk (Koman - Killian 2015: 218)
à 'cí 'kút-úd.
CL2 child cough.IPF-3SG
'The child is coughing.'

Transitive verbs have two alternative constructions, designated by Killian as 'A-voice' and 'O-voice' ${ }^{8}$ Although the choice between these two constructions may be functionally similar to the choice between the basic transitive construction and a detransitivized variant (passive or antipassive) in other languages, the position defended by Killian (2015) is that both are transitive.

In the A-voice, the agent of typical transitive verbs occupies the immediate preverbal position. It is in the same Zero case as the unique argument of monovalent verbs, whereas $\mathrm{P}$ in postverbal position is marked for the Accusative case if it belongs to the gender designated by Killian as 'class 2'. Class 1 P's are in the Zero case but trigger a change in the indexation of A: A is indexed for all persons with class 2 P's, whereas class 1 P's inhibit the indexation of $\mathrm{A}$ in all persons except for $1 \mathrm{SG}, 1 \mathrm{PL}$, and INCL.

(13) Uduk (Koman - Killian 2015: 218)

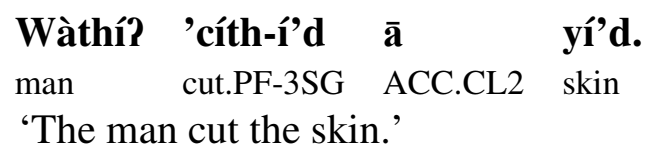

\footnotetext{
${ }^{8}$ Note that, according to the terminology adopted in this course, these two alternative constructions of Uduk transitive verbs do not qualify as 'voices', since they do not involve any specific morphological marking.
} 
In the O-voice, A is case-marked with the Ergative case, and is always in immediate postverbal position. There is no argument indexation on the verb. $\mathrm{P}$ is usually found in immediate preverbal position, but its position is relatively flexible.

(14) Uduk (Koman - Killian 2015: 218)

$\begin{array}{llll}\text { Tāshá wò'c mà } & \text { 'ká. } \\ \text { snake bite.IPF } & \text { ERG.CL2 } & \text { dog } \\ \text { 'The dog bit the snake.' } & \end{array}$

\subsubsection{Direct/inverse marking}

\subsubsection{Definition}

The notion of direct/inverse marking refers to languages in which the verb forms heading transitive constructions include a marker encoding the relative ranking of $\mathrm{A}$ and $\mathrm{P}$ according to some referential hierarchy. The referential hierarchies conditioning direct/inverse marking variously involve factors such as person (SAP > 3), ${ }^{9}$ animacy (human $>$ nonhuman animate $>$ inanimate), grammatical features (unpossessed $>$ possessed), and discursive features (salient within a given stretch of discourse $>$ non-salient).

In such systems, the transitive verb forms encoding that $\mathrm{A}$ ranks higher than $\mathrm{P}$ on the hierarchy in question are called direct, and those used when $\mathrm{P}$ ranks higher than A are called inverse.

Although this is not necessarily the case, it is interesting to observe that, in transitive constructions involving direct/inverse marking, the presence of a direct or inverse marker in the verb form may constitute the only clue to the identification of one of the participants as the agent, and the other as the patient, as in Ex. (15). In the hierarchy underlying direct/inverse marking in Plains Cree, SAP's rank higher than non-SAP's, and non-SAP's marked as obviatives (non-salient) rank lower than 'proximate' non-SAP's (salient, and morphologically unmarked).

(15) Plains Cree (Haude \& Zúñiga 2016 quoting Wolfart 1996: 410)

(15a) Ni-sêkih-â-nân atim.

1-scare.TA-DIR-1PL.EXCL dog

'We scare the dog.'

(15b) Ni-sêkih-iko-nân atim.

1-scare.TA-INV-1PL.EXCL dog

'The dog scares us.'

(15c) Sêkih-ê-w nâpêw atim-wa.

scare.TA-DIR-3 man dog-OBV

'The man (salient) scares the dog (non-salient).'

(15d) Sêkih-ikw-w nâpêw atim-wa.

scare.TA-INV-3 man dog-OBV

'The dog (non-salient) scares the man (salient).'

\footnotetext{
${ }^{9} \mathrm{SAP}$ is an abbreviation for 'Speech Act Participant' (i.e. 1st or 2nd person).
} 


\subsubsection{The domains of direct/inverse marking}

In a given language, direct/inverse marking must not necessarily be found in all possible agent-patient combinations. Three types of configurations must be distinguished:

- local scenarios: both A and P are SAP's;

- mixed scenarios: one of the protagonists is a SAP, the other is not;

- non-local scenarios: neither A nor P is a SAP.

It seems that direct/inverse marking in local scenarios is only found in systems that also have direct-inverse marking in mixed scenarios, with SAP's ranking higher than non-SAP's. Moreover, the extension of direct-inverse marking to local scenarios often shows various types of idiosyncrasies and irregularities. In particular, ranking among SAP's is languagespecific (1>2 in some languages, $2>1$ in others). Consequently, what is really important for a typology of direct/inverse marking systems is the distinction between the following three types of systems:

- systems with direct/inverse marking both in mixed and non-local scenarios;

- systems with direct/inverse marking in mixed scenarios only;

- systems with direct/inverse marking in non-local scenarios only.

\subsubsection{Rigid vs. flexible systems of direct/inverse marking}

Systems in which direct/inverse marking does not concern non-local scenarios may be morphologically very complex and difficult to analyze, but in other respects they are quite straightforward, since in such systems, the choice between direct and inverse marking automatically follows from a hierarchy of person.

By contrast, in systems with direct/inverse marking in mixed and non-local scenarios, or in non-local scenarios only, the criteria determining the relative ranking of non-SAP's in the hierarchy governing the choice between direct and inverse marking may involve a complex interplay of grammatical, semantic, and discursive factors. In particular, such systems may be more or less rigid or flexible, depending on the importance of grammatical or semantic criteria, and the place left to discourse factors in the definition of the hierarchy.

\subsubsection{Core arguments vs. obliques}

As already announced in Section 1.1.1, the crucial distinction in the framework developed in this course is not the argument vs. adjunct distinction, but rather the distinction between core arguments and obliques.

\subsubsection{Core arguments}

The first observation underlying the definition of core arguments put forward in this section is that, in the languages of the world, the overwhelming majority of monovalent verbs divide into a small number of classes as regards the coding of their unique argument. Most of the time, there is just one major class of monovalent verbs to which almost all monovalent verbs belong, regardless of the semantic role of their unique argument. Some languages have two major classes of monovalent verbs, but languages with three or more classes of monovalent verbs including more than a handful of members each are quite exceptional. 
Moreover, as a rule, intransitive predications with non-monovalent verbs include an argument encoded like the unique argument of (a major class of) monovalent verbs.

On this basis, a notion of core argument transcending the distinction between transitive and intransitive predication can be defined as follows:

- in transitive predication, the core arguments are A (the argument encoded like the agent of core transitive verbs) and $\mathrm{P}$ (the argument encoded like the patient of core transitive verbs);

- in intransitive predications, the core argument is the argument whose coding coincides with that of the unique argument of (a major class of) monovalent verbs.

In the remainder of this course, $U$ is used as an abbreviation for the argument in an intransitive predication whose coding coincides with that of the unique argument of (a major class of) monovalent verbs.

Note that, according to this definition, a language may have statistically marginal types of intransitive predication including no core argument.

\subsubsection{Obliques}

By definition, all the terms of verbal predicative constructions that are not core arguments according to the definition given in 1.1.6.1 are obliques, regardless of their status according to the argument vs. adjunct distinction.

Terms that are analyzable semantically as arguments, but do not show the type of coding that would justify identifying them as core arguments, will be designated as oblique arguments.

\subsubsection{Alignment}

The term 'alignment' refers to similarities between two terms belonging to two different constructions: ${ }^{10}$

\section{A TERM $\mathrm{T}_{1}$ OF A CONSTRUCTION $\mathrm{C}_{1}$ AND A TERM $\mathrm{T}_{2}$ OF $\mathrm{A}$ CONSTRUCTION $\mathrm{C}_{2}$ ARE ALIGNED WITH RESPECT TO A GIVEN FEATURE IF THEY SHARE THE SAME VALUE OF THE FEATURE IN QUESTION.}

For example, in Ex. (1), reproduced here as (16), the coding of the unique core argument of erori 'fall' is aligned with that of the $\mathrm{P}$ argument of puskatu 'break', whereas the coding of the unique core argument of irakin 'boil' is aligned with that of the A argument of puskatu 'break'.

\footnotetext{
10 Unfortunately, one can find some uses of the term 'alignment' in the typological literature that are not consistent with this definition. In particular, in 'hierarchical alignment' as introduced by Nichols (1992), 'alignment' does not refer to properties shared by terms belonging to different constructions, but to the mapping from the semantic roles of agent and patient to morphosyntactic slots. The misnamed 'hierarchical alignment' is rather a type of transitive coding in which the coding characteristics of $\mathrm{A}$ and $\mathrm{P}$ are determined by their relative ranking with respect to the indexability hierarchy. It is true that this type of transitive coding raises specific problems for alignment typology, since from a strictly logical point of view, it is difficult to compare the coding of the unique argument of monovalent verbs to that of $\mathrm{A}$ or $\mathrm{P}$ in languages in which it is impossible to define types of coding assigned to A and P independently from each other. It should, however, be clear that considering this situation as a particular type of 'alignment' makes no sense.
} 
(16) Basque (pers.doc.)

(16a) Ispilu-a erori da.

mirror-SG fall.CPL PRS.P.3SG

'The mirror has fallen down.'

(16b) Ur-ak irakin du.

water-SG.ERG boil.CPL PRS.A.3SG.P.3SG

'The water has boiled.'

(16c) Haurr-ek ispilu-a puskatu dute.

child-PL.ERG mirror-SG break.CPL PRS.A.3PL.P.3SG

'The children have broken the mirror.'

The alignment of the unique argument of a monovalent verb with the agent of the basic transitive construction is commonly designated as accusative alignment (or nominativeaccusative alignment), whereas the alignment of the unique argument of a monovalent verb with the patient of the basic transitive construction is commonly designated as ergative alignment (or absolutive-ergative alignment). ${ }^{11}$ Note that this example shows that both types of alignment may co-exist in the same language.

\subsubsection{Zero case}

In the languages in which nouns are inflected for case, I designate as zero case (and I represent as $\varnothing$ in the schematization of coding frames) the case form of nouns that coincides with the form used in isolation for quotation and labeling, whatever the distribution of this form in syntactic contexts. By labeling, I refer for example to nouns accompanying a picture representing a possible referent, nouns written on signal boards, nouns describing the content of a box on which they are written, etc.

In most languages, the zero case is characterized by the absence of an overt case marker, but there are exceptions, and the absence of an overt marker is not essential in the notion of zero case. What is essential is the ability to be used, not only as the quotation form of nouns in elicitation contexts, but also as a pure label in the absence of any syntactic context. For example, the Zero case of Latin (traditionally called Nominative) has a zero ending with some nouns (puer 'child'), but an overt ending with some others (domin-us 'master'). In Russian, nouns like devušk-a 'girl' have an ending -a in the Zero case in the singular, but a zero ending in the Genitive plural. Similarly, in Icelandic, hatt-ur 'hat' has an overt ending -ur in the Zero case in the singular, but a zero ending in the Accusative singular (hatt). With such nouns, flagging may involve deletion of morphological material present in the syntactically unmarked form of nouns.

\footnotetext{
${ }^{11}$ In the typological literature, the abbreviation commonly used for the unique core argument of monovalent verbs is $\mathrm{S}$, but this is potentially misleading, since $\mathrm{S}$ is also commonly found as the abbreviation for 'subject'. The two notions should not be confused, and this is the reason why I will not follow this convention. As already commented in Section 1.1.6.1, the abbreviation $U$ will be used with the slightly different (although clearly related) meaning of 'argument in an intransitive predication whose coding coincides with that of the unique argument of (a major class of) monovalent verbs'.
} 


\subsection{Transitive coding typology}

\subsubsection{Introductory remarks}

In this section, I propose a typology of transitive coding based on the notion of symmetry $v s$. asymmetry in the coding of A and P. This is a typology of constructions, not of languages, which means that the transitive coding of individual languages does not necessarily belong straightforwardly to a given type, and may involve variously conditioned alternations between two or more types. This remark applies not only to languages with multiple transitive coding, but also to languages with differential coding of agents or patients, and to languages in which the coding of $\mathrm{A}$ and $\mathrm{P}$ is conditioned by the TAM and/or polarity value of the clause.

For example, as 'ergative' as Dyirbal may be in its syntax, its transitive coding cannot be straightforwardly identified as the type of transitive coding normally expected in 'ergative' languages, since it involves an alternation between four different types. The only constant thing in the transitive coding of Dyirbal is the absence of indexation. As regards flagging, Dyirbal can be described as having two core cases in addition to the Zero case, Ergative (not available for 1st and 2nd person pronouns) and Accusative (available for 1st and 2nd person pronouns only), and a system of differential coding of agents and patients conditioned by the distinction between pronouns referring to SAP's and all other nominals: in A role, 1st and 2nd person pronouns show Zero flagging and other nominals Ergative flagging, whereas in P role, 1st and 2nd person pronouns show Accusative flagging and other nominals Zero flagging. Consequently, four configurations are possible depending on the nature of A and P. Two of them are illustrated in Ex. (17): in (17a), flagged A contrasts with unflagged $\mathrm{P}$, whereas in (17b), unflagged A contrasts with flagged $\mathrm{P} .^{12}$

Dyirbal (Dixon 1994:161)

(17a)

Duma yabu-ngu bura-n.
father mother-ERG
'Mother saw father.'

(17b) Dana jurra-na bura-n.

1PL 2PL-ACC see-NFUT

'We saw you all.'

\subsubsection{Joint vs. disjoint $\mathrm{A} / \mathrm{P}$ coding}

The notion of joint vs. disjoint $A / P$ coding is not of the same nature as those discussed in the remainder of Section 1.2, since it characterizes the transitive coding system as a whole, whereas the other distinctions discussed in this section apply to characteristics of transitive constructions that must not necessarily be uniquely determined in a given language.

Joint A/P coding refers to transitive coding systems in which the coding characteristics of $\mathrm{A}$ and $\mathrm{P}$ cannot be described separately, because the nature of one of the core terms of the

\footnotetext{
12 Alternatively, Dyirbal can be analyzed as having the same case inventory for all nominals, whith both the Ergative and the Accusative case partially homonymous with the Zero case. According to this analysis, the Ergative case has the allomorphs zero and -ngu, and the Accusative case has the allomorphs -na and zero. Interestingly, this analysis preserves the unity of transitive coding, although in a somewhat artificial way, but leads to the conclusion that the argument coding system of Dyirbal departs from the 'ergative' canon even more radically than commonly assumed, with both $\mathrm{A}$ and $\mathrm{P}$ flagged in transitive coding, and 'tripartite' alignment (A consistently in the Ergative case, $\mathrm{P}$ consistently in the Accusative case, and $\mathrm{U}$ in the Zero case).
} 
transitive construction conditions the coding of the other. This phenomenon is also referred to as co-argument sensitivity.

In this respect, there is a sharp contrast between flagging and indexation: joint $\mathrm{A} / \mathrm{P}$ flagging (or co-argument sensitivity in flagging) is quite exceptional, whereas joint $\mathrm{A} / \mathrm{P}$ indexation (or co-argument sensitivity in indexation) is very common.

The two cases of joint A/P flagging I am aware of are Sahaptin, with an ergative case used only when P is a SAP (1st or 2nd person), and Ik, with an accusative case used only when A is not a SAP (i.e. belongs to 3rd person).

In systems in which both $\mathrm{A}$ and $\mathrm{P}$ are indexed, disjoint indexation means that there is a dedicated slot for A indexes, another dedicated slot for $\mathrm{P}$ indexes, and they are filled independently from each other. Quite obviously, many indexation systems do not meet this characterization. The notion of joint $\mathrm{A} / \mathrm{P}$ indexation subsumes hierarchical $\mathrm{A} / \mathrm{P}$ indexation, indexation in direct/inverse marking systems, and $\mathrm{A} / \mathrm{P}$ indexation by means of portmanteau indexes.

For example, Guarani has two sets of person markers for verbs. One of them indexes the A argument of transitive verbs and the $U$ argument of intransitive verbs that assign a relatively agentive role to $\mathrm{U}$, the other one indexes the $\mathrm{P}$ argument of transitive verbs and the $\mathrm{U}$ argument of intransitive verbs that assign a relatively patientive role to U. However, transitive verbs cannot have more than one person agreement prefix, and the choice of the person agreement prefix illustrates the notion of hierarchical A/P indexation:

- in all combinations of $1 \mathrm{st} / 2$ nd person and 3rd person, the agreement prefix indexes the 1st/2nd person argument, whatever its semantic role - Ex. (18a-b);

- in $2>1$ combinations ( 2 nd person $A+1$ st person $P$ ), the agreement prefix indexes the 1 st person $\mathrm{P}$, resulting in ambigüity with $3>1$ combinations - Ex. (18c);

- in $1>2$ combinations (1st person $\mathrm{A}+2$ nd person $\mathrm{P})$, special portmanteau prefixes are used - Ex. (18d) ${ }^{13}$

- if both $\mathrm{A}$ and $\mathrm{P}$ are 3rd person, the verb bears the 3rd person prefix of the agentive series.

(18) Guarani (Tonhauser 2006: 132-3)

(18a) A-hecha Juan.

A.1SG-see Juan

'I see Juan.'

(18b) Che-hecha Juan.

P.1SG-see Juan

'Juan sees me.'

(18c) Che-su'u-ta.

P.1SG-bite-FUT

'You will bite me.'

or 'He/she/it/they will bite me.'

\footnotetext{
${ }^{13}$ Interestingly, the portmanteau prefix ro(i)- ' $1>2 \mathrm{SG}$ ' has the same form as the $1 \mathrm{EXCL}$ prefix of the agentive series.
} 
(18d) Roi-su'u-ta.

1>2SG-bite-FUT

'I will bite you.'

Joint A/P coding is not problematic for the typology of transitive constructions sketched in sections 1.2.3 to 1.2.7. The problem is that, in systems with joint $\mathrm{A} / \mathrm{P}$ coding, the recognition of alignment relationships between transitive coding and non-transitive coding frames necessitates an adaptation of the notion of alignment. I will not discuss this question further, since it is not directly relevant to the topic of this course.

\subsubsection{Symmetrical vs. asymmetrical transitive constructions}

Transitive constructions may involve a greater or lesser degree of symmetry between the coding characteristics of $\mathrm{A}$ and $\mathrm{P}$, and I propose to relate this variation to the tendencies observed cross-linguistically in the encoding of core terms and obliques: indexation is not a universal phenomenon, but it is common for core syntactic terms, whereas the indexation of obliques, although found to a limited extent in some languages, is relatively exceptional; conversely, flagging by means of non-zero case forms or adpositions is more common for obliques than for core syntactic terms. Nothing similar can be observed for constituent order, which consequently will play no role in this typology.

The combination of four binary features ( \pm A flagging, \pm A indexation, $\pm \mathrm{P}$ flagging, $\pm \mathrm{P}$ indexation) gives sixteen logically possible types. They are not evenly distributed in the languages of the world, and some of them seem to be found only in languages whose transitive coding involves variously conditioned alternations with other types. A is more often indexed than $\mathrm{P}, \mathrm{P}$ is more often flagged than $\mathrm{A}$, and the indexation of both $\mathrm{A}$ and $\mathrm{P}$ in the same construction is much more common than the flagging of both A and P. However, I have not done the kind of investigation that would allow me to give a precise quantitative evaluation of these tendencies, and I will just propose a classification of the possible types.

I first propose to characterize as symmetrical the transitive constructions in which $\mathrm{A}$ and $\mathrm{P}$ do not differ in the extent to which they show core-like or oblique-like coding characteristics. I further propose to characterize the transitive constructions in which A shows more core-like coding characteristics than $\mathrm{P}$ as A-centered, and those in which the term showing more corelike coding characteristics is $\mathrm{P}$, as $P$-centered.

The possible subtypes of transitive constructions are enumerated in Sections 1.2.4 to 1.2.7, with the indication of languages in which they can be found, alone or in alternation with other subtypes. Question marks indicate configurations that are not attested in the documentation I have been able to consult.

\subsubsection{Subtypes of symmetrical transitive constructions}

There are four logical possibilities of symmetrical transitive constructions:

- neither A nor P is flagged or indexed (Bambara, Vietnamese);

- both $\mathrm{A}$ and $\mathrm{P}$ are indexed, neither $\mathrm{A}$ nor $\mathrm{P}$ is flagged (K'iche', Abkhaz, Nahuatl, Lakota);

- both A and P are flagged, neither A nor P is indexed (Japanese, Tongan); ${ }^{14}$

- both A and P are flagged and indexed (Udi, Kanuri, Choctaw, some Basque varieties). ${ }^{15}$

\footnotetext{
${ }^{14}$ Like the other types in which both $\mathrm{A}$ and $\mathrm{P}$ are flagged, this type seems to be attested only in languages that have differential flagging of $\mathrm{A}$ and/or P.
} 


\subsubsection{Subtypes of fully asymmetrical transitive constructions}

In fully asymmetrical transitive constructions, the asymmetry is found in both flagging and indexation, with two logical possibilities:

- fully A-centered constructions: A is not flagged whereas $\mathrm{P}$ is flagged, A is indexed whereas $\mathrm{P}$ is not indexed (Latin, Turkish);

- fully P-centered constructions: $\mathrm{P}$ is not flagged whereas $\mathrm{A}$ is flagged, $\mathrm{P}$ is indexed whereas $\mathrm{A}$ is not indexed (Avar).

\subsubsection{Subtypes of partially asymmetrical transitive constructions}

In partially asymmetrical transitive constructions, the asymmetry is found in one coding characteristic only, which gives eight logical possibilities. ${ }^{16}$ Four of them can be characterized as partially A-centered:

- neither A nor P is flagged, only A is indexed (French);

- both A and P are flagged, only A is indexed (?);

- neither A nor P is indexed, only P is flagged (Mongolian, Sinhala);

- both A and P are indexed, only P is flagged (Hungarian, Quechua).

The following four can be characterized as partially P-centered:

- neither A nor P is flagged, only P is indexed (!Xoon);

- both $\mathrm{A}$ and $\mathrm{P}$ are flagged, only $\mathrm{P}$ is indexed (?);

- neither A nor P is indexed, only A is flagged (Lezgi);

- both $\mathrm{A}$ and $\mathrm{P}$ are indexed, only $\mathrm{A}$ is flagged (Basque).

\subsubsection{Transitive constructions with conflicting asymmetries}

Two logically possible types of transitive constructions involve asymmetries in flagging and indexation that do not converge in characterizing one of the arguments as more core-like or more oblique-like than the other in its coding characteristics:

- A is both marked and indexed, whereas P is neither marked nor indexed (Oromo);

- A is neither marked nor indexed, whereas $\mathrm{P}$ is both marked and indexed (?).

\subsubsection{Variation in transitive coding and the characterization of the transitive coding system of individual languages as A- or P-centered}

In many languages, the basic transitive construction has variously conditioned variants that differ with respect to at least one of the four features on which the typological grid put forward in the previous sections is based ( \pm A flagging, $\pm \mathrm{A}$ indexation, $\pm \mathrm{P}$ flagging, $\pm \mathrm{P}$

\footnotetext{
15 The Western Basque varieties illustrating the type of transitive construction with both A and P flagged and indexed have a system of differential patient coding with an alternation between Zero case and Dative case (and the corresponding indexes) in the coding of the patient.

${ }^{16}$ In Sections 3.6 and 3.7, the question marks signal types for which I have no illustration to propose, which of course does not imply that illustrations could not be found in a wider and more systematic language sample.
} 
indexation). However, in a broad typological perspective, the crucial distinction is between systems of transitive coding in which the variants of the basic transitive construction do not instantiate two opposite values of the A-centered vs. P-centered parameter, and systems of transitive coding that, taken as a whole, cannot be unambiguously characterized as A- or P-centered.

\subsubsection{Variation in transitive coding that does not affect the possibility of characterizing the transitive coding system as a whole as A-or P-centered}

This situation can be illustrated by the Romance transitive coding systems. Across Romance languages, the details of $\mathrm{A}$ indexation vary, and $1 \mathrm{st} / 2 \mathrm{nd}$ person pronouns may behave in this respects differently from other nominals; there is also important variation in the obligatoriness / optionality of $\mathrm{P}$ indexation, depending on the nature of the $\mathrm{P}$ argument, and differential $\mathrm{P}$ flagging in found in some Romance varieties only. However, A is uniformly unflagged and obligatorily indexed, and consequently, in spite of the unquestionable variation, the Romance systems of transitive coding can be unambiguously characterized as A-centered.

\subsubsection{Variation in transitive coding making impossible the characterization of the transitive coding system as a whole as A-or P-centered}

Kurmanji Kurdish (cf. Ex. (4) above) provides a straightforward illustration of this kind of situation, since one of the two variants of transitive coding in Kurmanji Kurdish is fully Acentered (A unflagged and indexed, $P$ flagged and not indexed), whereas the other one is fully $\mathrm{P}$-centered (A flagged and not indexed, P unflagged and indexed).

\subsection{The Obligatory Coding Principle}

\subsubsection{The Obligatory Coding Principle as a reformulation of the distinction between morphologically accusative and morphologically ergative languages}

The usual definition of accusative / ergative alignment has been given in Section 1.1.4. However, as regards alignment relationships in the coding properties of core arguments (morphological accusativity / ergativity), the traditional distinction between predominantly accusative and predominantly ergative languages is best understood with reference to a very general (although violable) constraint on the possible coding frames in a given language, for which I propose the term of Obligatory Coding Principle.

In the languages that have coding frame inventories fully consistent with the Obligatory Coding Principle, every coding frame must include an argument showing a given type of coding that can be viewed as the default or unmarked argument coding for a given language.

Given the definition of $\mathrm{A}$ and $\mathrm{P}$, this constraint leaves just two logical possibilities: in a language whose argument coding system does not violate the Obligatory Coding Principle, the type of coding that must be found in every possible coding frame must necessarily coincide, either with A coding (obligatory A coding languages), or with $\mathrm{P}$ coding (obligatory $P$ coding languages). Consequently, in a language whose argument coding system does not violate the Obligatory Coding Principle, all intransitive constructions include a core argument whose coding uniformly coincides, either with the coding of A (in obligatory A coding languages), or with the coding of $\mathrm{P}$ (in obligatory $\mathrm{P}$ coding languages).

The notion of obligatory A coding language is consequently a reformulation of the notion of language consistently accusative in the coding properties of core arguments, and the notion 
of obligatory $\mathrm{P}$ coding language is a reformulation of the notion of language consistently accusative in the coding properties of core arguments.

However, many languages have statistically marginal classes of intransitive verbs that violate the Obligatory Coding Principle, and in some languages, intransitive verbs divide into valency classes in a way that radically violates the Obligagory Coding Principle. For example, Basque has monovalent verbs assigning $\mathrm{P}$ coding to their sole argument - Ex. (19c), and others assigning A coding - Ex. (19b), and in most Basque varieties, none of these two classes of intransitive verbs can be considered marginal.

(19) Basque (pers.doc.)

(19a) Haurr-ak ur-a ekarri du.

child-SG.ERG water-SG bring.CPL PRS.A.3SG.P.3SG

'The child brought the water.'

(19b) Ur-ak irakin du.

water-SG.ERG boil.CPL PRS.A.3SG.P.3SG ${ }^{17}$

'The water boiled.'

(19c) Haurr-a etorri da.

child-SG come.CPL PRS.P.3SG

'The child came.'

\subsubsection{Impersonality and the Obligatory Coding Principle}

\subsubsection{Introductory remarks}

Impersonality has been a regular topic of investigation in Indo-European linguistics, but until very recently it was not the subject of detailed cross-linguistic or typological research. This is the obvious consequence of the difficulties involved in identifying instances of impersonality on a cross-linguistic basis.

A major problem in a cross-linguistic investigation of impersonality is that no clear definition emerges from the inventories of phenomena viewed as instances of impersonality in different traditions. Moreover, it turns out that none of the traditional inventories of phenomena presented as instances of impersonality is fully consistent, and the same can be said of most of the recent works that have tried to define a cross-linguistically valid notion of impersonality. Some of the phenomena currently viewed as instances of impersonality have a clear structural basis, but others can only be identified as instances of impersonality on a purely functional basis, and any functional definition making it possible to group them together would unavoidably lead to extend the label 'impersonal' to many phenomena, such as canonical passives, indefinite subject NPs, non-agentive but otherwise canonical subjects, non-topical but otherwise canonical subjects, reference to kinds, etc., which most authors do not include in impersonality.

In this course, the label 'impersonal' is restricted to impersonal constructions in the strict sense of this term. The definition that will be put forward and commented in Section 1.3.2.2 excludes from impersonality a number of phenomena commonly viewed as instances of impersonality, such as:

\footnotetext{
${ }^{17}$ See Footnote 4.
} 
- the unspeficied interpretation of null subjects;

- the unspecified interpretation of 3rd person plural pronouns;

- the generic use of the 2 nd person;

- generic/vague human pronouns such as German man or French on;

- demonstratives encoding vague reference to inanimate entities (French ça).

The point is that such phenomena, although commonly considered instances of impersonality, occur in constructions that, as constructions, are not really different from canonical verbal predication. Given the topic of this course, it is not necessary to discuss them further. By contrast, impersonal constructions in the strictest sense of this term play an important role in the valency system of many languages.

\subsubsection{Impersonal constructions}

An important advantage of the Obligatory Coding Principle is that it provides at the same time a very simple way of defining impersonal constructions, and a good basis for discussing the possible extension of this notion to languages other than obligatory A coding languages.

The languages in the description of which the notion of impersonal construction has been used by traditional grammarians are obligatory A coding languages with more or less marginal exceptions to the rule of obligatory A coding. In such languages, an impersonal construction can be defined as a construction that does not include a slot for an argument encoded in the same way as the agent in the basic transitive construction.

For example, in French, in a clause like Il est venu deux femmes, lit. 'It came two women' the 3rd person masculine $\mathrm{A} / \mathrm{U}$ index il is a mere place-holder devoid of any reference, since the sole argument of venir 'come' is represented by the NP in postverbal position, and the gender-number values normally expressed by il (singular masculine) are in contradiction with those of this NP (plural feminine).

Note that, as illustrated by this example, an impersonal construction may include a dummy element that in other constructions would be interpreted as representing an A argument. Conversely, a clause including no A-like NP is not necessarily impersonal: what is crucial for distinguishing canonical constructions with a null A from impersonal constructions is the possibility to introduce an NP coded like the A term of the basic transitive construction without modifying the argument structure, and without modifying the rest of the construction either.

In the perspective of this course, it is important to distinguish two types of impersonal constructions: those constituting the only available option for a given verb and a given argument structure, and those in competition with a canonical predicative construction expressing the same argument structure. Ex. (20) illustrates the second possibility.

(20) French

(20a) Il est venu deux femmes.

A.3SGM be.PRS.3SG come.PTCP.SGM two woman.PL

'Two women came.' (impersonal construction)

(20b) Deux femmes sont venues.

two woman.PL be.PRS.3PL come.PTCP.PLF

'Two women came.' (canonical predication) 
The French verb falloir 'need' illustrates the possibility of an impersonal construction that does not alternate with a canonical predicative construction: in Modern French, this verb can only be used with the dummy A index il 'he', and its two arguments are obligatorily expressed in the same way as the non-A arguments of typical trivalent verbs - Ex. (21).

\section{(21) French}

$\begin{array}{lllll}\text { Il } & \text { nous } & \text { faut } & \text { ces } & \text { livres. } \\ \text { A.3SGM } & \text { DAT.1PL } & \text { need.PRS.3SG } & \text { DEM.PL } & \text { book.PL } \\ \text { 'We need these books.' lit. 'It needs us these books.' }\end{array}$

\subsubsection{Anti-impersonal constructions}

The term anti-impersonal construction was coined by Gilbert Lazard (1985, 1995) to designate the mirror-image of impersonal constructions in obligatory $\mathrm{P}$ coding languages that have more or less marginal exceptions to the general rule of obligatory $\mathrm{P}$ coding. In such languages, an anti-impersonal construction can be defined as a construction that, exceptionally, does not include a slot for an argument encoded in the same way as the patient in the basic transitive construction.

For example, in several Nakh-Daghestanian languages, bivalent verbs whose arguments can be characterized resp. as aimer and target are often found in the anti-impersonal construction illustrated by ex. (22), with an Ergative-marked argument (the aimer) and a Lative-marked argument (the target), but no slot for a Zero-marked NP (i.e. an NP casemarked like the patient in the basic transitive construction).

(22) Akhvakh (pers.doc.)

$\begin{array}{llll}\text { Wašo-de } & \text { jašo-ga } & \text { ēaje } & \text { godi. } \\ \text { boy-ERG girl-LAT look_at.CVB } & \text { COP.SGN } \\ \text { 'The boy looked at the girl.' } & \end{array}$

Interestingly, impersonal and anti-impersonal constructions are the mirror-image of each other, but functionally, they are not found with the same semantic types of verbs. For example, constructions of aiming verbs in which the aimer has the coding characteristics of the agent in the basic transitive construction, but the target has the coding characteristics of locative or allative obliques, are cross-linguistically very common, irrespective of alignment patterns. In obligatory A coding languages, as illustrated by English look at, this does not contradict the rule according to which verbal predicative constructions must include a term showing A coding, whereas in obligatory $\mathrm{P}$ coding languages, this violates the constraint according to which verbal predicative constructions normally include a term showing $\mathrm{P}$ coding.

Additional data on obligatory $\mathrm{P}$ coding languages corroborate the propensity of verbs of aiming to occur in anti-impersonal constructions (see among others, on Australian languages, Tsunoda (1981) on Djaru, and Hale (1982) on Warlpiri).

Diachronically, it is interesting to observe that, in obligatory $\mathrm{P}$ coding languages, the univerbation of light verb compounds in which the non-verbal element of the compound is a noun encoded like the $\mathrm{P}$ term of a transitive construction mechanically creates intransitive verbs violating the principle of obligatory $\mathrm{P}$ coding, whereas in obligatory A coding language, the intransitive verbs resulting from the same evolution do not violate the rule of obligatory A coding - for more details, see Creissels (2015a). 


\subsection{Relationship between types of transitive coding and types of alignment}

\subsubsection{Correlation between transitive coding typology and the Obligatory Coding Principle}

Quite obviously, the A-centered type of transitive coding strongly correlates with obligatory A coding (or, in other words, with the 'accusative' alignment $A=U \neq P$ ), whereas the Pcentered type of transitive coding strongly correlates with obligatory $\mathrm{P}$ coding (or, in other words, with the 'ergative' alignment $\mathrm{A} \neq \mathrm{U}=\mathrm{P}$ ).

Interestingly, the languages with symmetrical transitive coding do not show a clear preference for $\mathrm{A}$ or $\mathrm{P}$ as the default type of argument coding. Among languages with symmetrical transitive coding it is equally easy to find examples of languages with obligatory A coding (in which $\mathrm{U}$ consistently aligns with A), such as Nahuatl, and of languages with obligatory P coding (in which $\mathrm{U}$ consistently aligns with P), such as K'iche'. It is also among such languages that it is possible to find the less controversial examples of split-U languages, in which a class of intransitive verbs with $\mathrm{U}$ coded like A and a class of intransitive verbs with $\mathrm{U}$ coded like $\mathrm{P}$ are roughly equal in size.

\subsubsection{A-unmarked vs. P-unmarked systems of argument coding}

The combination of A-centered transitive coding with obligatory A coding and the combination of P-centered transitive coding with obligatory P coding define prototypes corresponding to what seems to be the most widespread (although generally implicit) conception of what may be 'typical accusative languages' and 'typical ergative languages' respectively. This correlation is, however, not absolute, hence the terminological and conceptual problems raised by the indiscriminate use of 'ergative' with reference to a type of transitive coding and a type of alignment. In order to avoid the misunderstandings resulting from this terminological practice, I propose to call A-unmarked systems of argument coding the systems of argument coding that combine A-centered transitive coding with obligatory A coding (i.e., the systems found in 'typically accusative' languages), and P-unmarked systems of argument coding those combining P-centered transitive coding with obligatory P coding (i.e., the systems found in 'typically ergative' languages).

\subsubsection{Atypical systems of argument coding}

Atypical systems of argument coding are systems of argument coding that depart from the prototypes defined in 1.4.2 in one of the following ways:

- systems involving multiple transitive coding;

- systems involving a type of transitive coding that cannot be unambiguously characterized as symmetrical, A-centered, or P-centered;

- systems that cannot be unambiguously characterized as obligatory A coding or obligatory P coding systems;

- systems contradicting the tendency to associate A-centered transitive coding with obligatory A coding, and P-centered transitive coding with obligatory P coding. 


\subsection{Transitive coding and valency}

\subsubsection{Bivalent verbs and transitivity}

Languages differ in the extent to which they make use of transitive coding, in other words, in their degree of transitivity prominence. For example, like English or French, Wolof (Atlantic) extends the transitive coding typically found with verbs such as 'break' to a verb like 'forget' (whose arguments cannot be described as an agent and a patient), whereas in Mandinka (Mande), 'forget' has an extended intransitive construction in which one of the arguments is an oblique argument.

(23) Wolof (Atlantic - pers.doc.)

(23a) Xale bi toj na weer bi.

child CLb.DEF break PRF.3SG glass CLb.DEF

'The child has broken the glass.'

(23b) Xale bi fàtte na sama sant

child CLb.DEF forget PRF.3SG my name

'The child has forgotten my name.'

(24) Mandinka (Mande - pers.doc.)

(24a) Díndínò yè wéeròo tèyí.

child.D CPL.TR glass.D break

'The child has broken the glass.'

(24b) Díndínò ñìná-tà í kòntóyò lá.

child.D forget-CPL.INTR 1 SG name.D POSTP

'The child has forgotten my name.'

It has long been known that English or French have a much stronger tendency to employ transitive verbs than for example German or Russian. Say (2014) provides a precise picture of the variation in transitive prominence across European languages. As regards the languages of the world, some precise data are now available due to the Leipzig Valency Classes Project, whose database contains data from 36 languages world-wide. Haspelmath (2015) discusses the classification of the 36 languages according to their degree of transitivity prominence on the basis of the sample of 80 verb meanings that were systematically collected for all the languages of the project. For example, in this classification, Mandinka (illustrated in Ex. (24)) ranks 20th on 36, immediately after Italian, which means that its moderate degree of transitivity prominence is comparable to that of West European languages. More generally, it seems that, in the languages of the world, the low degree of transitivity prominence that characterizes the languages of Eastern Europe and of the Caucasus is exceptional, whereas languages with a degree of transitive prominence higher than that found in West European languages are common. 


\subsubsection{Trivalent verbs and transitivity}

\subsubsection{Extended-transitive coding and double-transitive coding}

As a rule, trivalent verbs such as 'give', 'show', 'send', 'sell', etc. select either extendedtransitive coding frames, or double-transitive coding frames. ${ }^{18}$ In both cases, the most agentive participant is encoded like the A term of the basic transitive construction. In the extended-transitive type of coding, illustrated by Ex. (25) and (26), one of the other two arguments is encoded like the $\mathrm{P}$ term of the transitive construction, and the third one is assigned a distinct coding. In the double-transitive type of coding, illustrated by Ex. (27), two arguments show coding characteristics identical to those of the P term in the basic transitive construction. Note that the double-transitive type of coding, relatively marginal in the languages of Europe, is common in the languages of the world.

(25) Hungarian (pers.doc.)

(25a) János pénz-t keresett.

János money-ACC earn.PST.3SG

'János earned money.'

(25b) János pénz-t adott Bélá-nak.

János money-ACC give.PST.3SG Béla-DAT

'János gave money to Béla.'

(26) Chamorro (Topping 1973: 241, 251)

(26a) Ha tuge' i kannastra.

3SG.ERG weave ABS basket

'He wove the basket.'

(26b) Ha na'i i patgon ni leche.

3SG.ERG give ABS child OBL milk

'He gave the child milk.'

(27) Panyjima (Dench 1991: 195)

(27a) Ngunha parnka ngarnarta mantu-yu.

DEM lizard eat.FUT meat-ACC

'That lizard will eat the meat.'

(27b) Ngatha yukurru-ku mantu-yu yinyanha.

1SG dog-ACC meat-ACC give.PF

'I gave the dog meat.'

\footnotetext{
${ }^{18}$ I introduce the term of 'double-transitive' coding frame in order to avoid the ambiguity of 'ditransitive' : in principle, given its etymology, 'ditransitive' should be restricted to verbs selecting a coding frame with two terms showing the same coding properties as the $\mathrm{P}$ term of the basic transitive construction. Unfortunately, in recent typological literature, 'ditransitive' is commonly used as synonymous with 'trivalent', even by authors that distinguish 'transitive' from 'bivalent' in the way adopted in this course.
} 


\subsubsection{Indirective vs. secondative alignment}

As can be seen from Ex. (25) and (26), in the extended-transitive type of coding of the trivalent verbs whose argument structure includes a recipient and a 'theme' (gift, etc.), there is cross-linguistic variation in the choice of the argument encoded like the $\mathrm{P}$ term of the basic transitive construction. In the recent typological literature, the alignment $\mathrm{T}=\mathrm{P} \neq \mathrm{R}$ (as in Ex. (25)) is designated as indirective alignment, and the alignment $\mathrm{R}=\mathrm{P} \neq \mathrm{T}$ (as in Ex. (26)) as secondative alignment.

Ex. (28) illustrates the fact that indirective and secondative alignment may co-exist in the same language. Soninke has two quasi-synonymous verbs kínì and 'kú 'give'. With kínì, the position immediately to the left of the verb, which characterizes the $\mathrm{P}$ term of the basic transitive construction, is occupied by the theme phrase (and the recipient is encoded as an oblique), whereas with 'kú, the same position is occupied by the recipient phrase (and the theme phrase is encoded as an oblique).

Soninke (pers.doc.)

(28a) Múusá dà qálìsî-n kínì Dénbà yí.

Moussa TR money-D give Demba POSTP

'Moussa gave the money to Demba.'

\section{(28b) Múusá dà Dénbà kú qálìsí yà.}

Moussa TR money-D give Demba POSTP

'Moussa gave the money to Demba.'

\subsubsection{Hierarchy in double-transitive constructions}

In double-transitive constructions, there is no morphological evidence of a hierarchy between the theme phrase and the recipient phrase. However, as regards the behavioral properties typical for the patient in the basic transitive construction of a given language, the theme phrase and the recipient phrase do not always show the same degree of assimilation to the monotransitive patient. In other words, in this respect, double-transitive constructions are frequently more or less asymmetric.

For example, in the languages that have both passive constructions and a double-transitive construction for trivalent verbs, it is not rare that the recipient and the theme, in spite of their identical coding, do not have equal access to the function of $U$ term of a passive construction.

It seems that, in the double-transitive constructions showing this kind of assymetry, it is most of the time the recipient phrase that shows more resemblance in its behavior with the $\mathrm{P}$ term of the basic transitive construction.

\subsubsection{Dative coding}

The traditional descriptions of constructions of trivalent verbs with the recipient treated differently from the monotransitive patient (as in (25b) and (28a) above) often use terms such as 'dative' or 'indirect object', and suggest that, in some respects at least, this argument shows more affinities with core syntactic terms than with obliques. In some languages, for example Basque, or Georgian, such an analysis is solidly motivated by properties such as obligatory indexation, or involvement in case alternations. In French, the fact that some phrases introduced by the preposition à behave exactly like $\mathrm{P}$ phrases in reflexivization is a strong argument for giving them a special status. However, this is clearly not always the case. For 
example, in Latin, or in Hungarian, the dative-marked recipients do not seem to have properties justifying to classify them apart from the other obliques.

\subsubsection{Monovalent verbs and transitivity}

There is a variety of ways in which monovalent verbs may be found in constructions including two terms with the coding characteristics of the A and P terms of the basic transitive construction. However, with monovalent verbs, one of the two terms (most commonly, the Plike term) cannot represent a participant, and consequently this term, in spite of its coding, must not be expected to behave in all respects like typical patients. For example, in the languages that have passive constructions, the atypical P's found in transitive constructions of monovalent verbs must not be expected to have the ability to be converted into the $\mathrm{U}$ term of a passive construction.

\subsubsection{Light verb constructions}

Light verb constructions such as English have a look, do a dance, or take a plunge, depart from the canonical situation in which NP's in a direct syntactic relationship to verbs represent participants in an event encoded by the verb. Light verb constructions are a particular type of complex predicate, in which a given type of event is lexified as the combination of a verb and a non-verbal word, the verb being semantically 'light' in the sense that its contribution to the conceptualization of an event is relatively small in comparison with that of the non-verbal element of the complex predicate. As illustrated by Ex. (29), the non-verbal element of complex predicates of this type is often a noun, and it is particularly common that the light verb construction has the coding characteristics of a transitive construction with the noun that constitutes the non-verbal element of the complex predicate in $\mathrm{P}$ role. This results in constructions in which the unique argument of monovalent predicates is expressed as the A term of a transitive construction, as in (a), and one of the arguments of bivalent predicates can only be expressed as an oblique, as in (b).

(29) Basque (pers.doc.)

(29a) Haurr-ek lo egiten dute.

child-PL.ERG sleep do.ICPL PRS.A.3PL.P.3SG

'The children are sleeping (lit. are doing sleep).'

$\begin{array}{lllllll}\text { Gizon } & \text { horr-ek } & \text { ez } & \text { du } & \text { euskar-az } & \text { hitz } & \text { egiten. } \\ \text { man } & \text { DEM.SG-ERG } & \text { NEG } & \text { PRS.A.3SG.P.3SG } & \text { Basque-SG.INSTR } & \text { word } & \text { do.ICPL } \\ \text { 'This man does not speak Basque (lit. does not do word in Basque).' } & \end{array}$

Light verb constructions are probably universal, but some languages use them with great frequency and systematically, and thus have a relatively limited number of verbal lexemes, in some cases less than a hundred. Some languages have a particularly high proportion of predicates expressed as light verb compounds in which the light verb is a transitive verb (most often a verb with the meaning 'do, make', as in Ex. (29)), and the non-verbal element is a noun encoded like the $\mathrm{P}$ argument of transitive verbs.

Languages in which light verb constructions are particularly frequent include languages with A-unmarked systems of argument coding, such as Japanese, Turkish, Persian or Ewe, languages with P-unmarked systems of argument coding, such as Tibetan or Lezgi, and languages with atypical systems of argument coding, such as Basque. Examples (30) and (31) 
illustrate the use of 'do' as a light verb in Turkish and Basque.

(30) Turkish (pers.doc.)

$\begin{array}{llll}\text { hayret etmek } & \text { astonishment } & + \text { do } \rightarrow \text { be astonished } \\ \text { istirahat etmek } & \text { rest (noun) } & + \text { do } \rightarrow \text { rest (verb) } \\ \text { kabul etmek } & \text { acceptance } & + \text { do } \rightarrow \text { accept } \\ \text { şüphe etmek } & \text { doubt (noun) } & + \text { do } \rightarrow \text { doubt (verb) } \\ \text { taksim etmek } & \text { division } & + \text { do } \rightarrow \text { divide } \\ \text { vefat etmek } & \text { death } & + \text { do } \rightarrow \text { die }\end{array}$

(31) Basque (pers.doc.)

$\begin{array}{llll}\text { agur egin } & \text { greeting } & + \text { do } \rightarrow \text { greet } \\ \text { barre egin } & \text { laugh (noun) } & + \text { do } \rightarrow \text { laugh (verb) } \\ \text { amets egin } & \text { dream (noun) } & + \text { do } \rightarrow \text { dream (verb) } \\ \text { leher egin } & \text { explosion } & + \text { do } \rightarrow \text { explode } \\ \text { lo egin } & \text { sleep (noun) } & + \text { do } \rightarrow \text { sleep (verb) } \\ \text { negar egin } & \text { tear } & + \text { do } \rightarrow \text { cry }\end{array}$

Crosslinguistically, the nouns combining with light verbs usually exhibit morphosyntactic properties different from those of ordinary nominal arguments. For instance, in Basque and other languages where determiners are obligatory, light verb constructions are often characterized by the use of bare nouns. And in languages with a relatively flexible constituent order, the nouns in light verb constructions tend to exhibit limited mobility in relation to the verb.

Creissels (2015) discusses the consequences of the evolution of light verb constructions for the typology of argument coding systems.

\subsubsection{Cognate $P$ constructions with intransitive verbs}

A cognate $P$ construction (or cognate object construction, cognate accusative construction) is a construction in which a verb is used transitively with a cognate noun in $\mathrm{P}$ role. Cognate $\mathrm{P}$ constructions are found with transitive verbs as a possible strategy for avoiding the specification of the $\mathrm{P}$ argument (see Section 4.4), but they are also found with verbs that cannot be constructed transitively with a participant encoded as P - Ex. (32).

\section{(32) English}

\section{He slept a troubled sleep. \\ He laughed a bitter laugh. \\ He died a painful death. \\ He smiled a charming smile. \\ He danced a cheerful dance. \\ He walked their walk and talked their talk. (i.e., He walked and talked as they did.)}

In some of the languages that make a particularly wide use of such constructions, many monovalent predicates can only be expressed as a cognate P construction. 
The cognate $\mathrm{P}$ contruction may also be motivated by the expression of verb focus. In the languages that use this strategy, the meaning expressed in English as 'He did sleep' is rendered literally as It's sleep that he slept.

\subsubsection{Other types of atypical P's: the case of Soninke and Manding}

Mande languages are particularly interesting for a study of atypical P's, since in Mande languages, verbal predication is organized in such a way that there cannot be any ambiguity between phrases in $\mathrm{P}$ role and oblique phrases.

In Mande morphosyntax, the $A$ term in the basic transitive construction and the $\mathrm{U}$ term in intransitive constructions are immediately followed by a 'predicative marker' expressing grammaticalized TAM distinctions and polarity, and also involved in transitivity marking. The position between the predicative marker and the verb unambiguously characterizes the $P$ term of the basic transitive construction. However, this position may also be occupied by atypical P's, i.e. noun phrases that do not represent a participant, and nevertheless are encoded in the same way as typical patients, in particular phrases that provide information about the duration of an activity, as in (33b).

(33) Soninke (pers.doc.)

(33a) Hàatú dà kónpè-n céllà.

Fatou TR room-D sweep

'Fatou swept the room.'

(33b) Hàatú dà kòotá-n mùumâ-n céllà.

Fatou TR day-D whole-D ${ }^{\mathrm{LH}}$ sweep

'Fatou spent the whole day sweeping.'

In Ex. (33), the verb is transitive, and the atypical $\mathrm{P}$ expressing duration of an activity occupies the syntactic position normally occupied by the patientive argument of the transitive verb. ${ }^{19}$ However, as illustrated by Ex. (34), the same construction is also found with otherwise strictly intransitive verbs, i.e. with verbs that cannot be found in a transitive construction with a noun phrase representing a participant in the $\mathrm{P}$ slot, and nevertheless can be constructed transitively with a duration phrase in the $\mathrm{P}$ slot.

(34) Soninke (pers.doc.) ${ }^{20}$

(34a) Ń yàtí yérú.

1SG be_sick last_year

'I was sick last year.'

(34b) Ń dà qású-báané wàtí.

1SG TR month-one be_sick

'I was sick during a whole month.'

\footnotetext{
${ }^{19}$ In Lesson 5, we will see how the patientive argument can be expressed when the P slot in the construction of a transitive verb is occupied by such a non-argumental phrase.

${ }^{20}$ In this example, 'be sick' appears as yàtí in (a) and wàtí in (b), but this alternation is automatically triggered by the presence/absence of a nasal at the end of the preceding word..
} 
With some intransitive verbs denoting activity, this construction triggers a vowel alternation that can be analyzed as encoding transitivization. This phenomenon clearly supports the distinction between semantic transitivity and syntactic transitivity, since the presence of an atypical $P$ has no impact on semantic transitivity.

(35) Soninke (pers.doc.)

\section{(35a) Tógáanà-n tèré léerì-nú sìkkì.} hunter-D walk hour-D three ${ }^{\mathrm{L}}$ 'The hunter walked three hours.'

(35b) Tógáanà-n dà léerì-nú sìkkì tèrá.

hunter-D TR hour-D three ${ }^{\mathrm{L}}$ walk.TR

'The hunter spent three hours walking.'

Intransitive verbs denoting manner of movement, such as wùrú 'run' or tèré 'walk' can be used transitively with a duration phrase in the $\mathrm{P}$ slot, but the same position may also be occupied by a phrase denoting the interval covered. In this use, they show the same possibility of transitivization marking.

(36) Soninke (pers.doc.)

(36a) ó wùrú léerí-báané.

$1 \mathrm{PL}$ run hour-one

'We ran one hour.'

(36b) Ó dà léerí-báané wùrá.

1PL TR hour-one run.TR

'We spent one hour running.'

(36c) Ó dà kílóméetàrá-nú sìkkì wùrá.

1PL TR kilometer-PL three ${ }^{\mathrm{L}}$ run.TR

'We ran three kilometers.'

The third type of phrases that do not refer to a participant and can feature in the $\mathrm{P}$ slot of a transitive construction of otherwise strictly intransitive verbs is the noun hó 'thing', interpreted in this construction as expressing intensity of the activity - Ex. (32).

(37) Soninke (pers.doc.)

\section{Lémínè-n Đá hó qènqè-né. \\ child-D ICPL thing sleep-GER \\ 'The child sleeps so much.'}

Hó 'thing' as an atypical $\mathrm{P}$ expressing intensity may trigger the same transitivization marking as described above. 
(38) Soninke (pers.doc.)

Yàxàrê-n yá hó tèrà-ná.

woman-D ICPL thing walk.TR-GER

'The woman walks so much.'

The same types of atypical P's are found in Mandinka, and in addition to that, as illustrated by Ex. (39a), Mandinka has atypical P's referring to the cause of the event. In particular, with verbs that cannot be constructed transitively with a participant in $\mathrm{P}$ role, a transitive construction with the interrogative mŭy 'what' in the $\mathrm{P}$ slot is possible, as in $(39 \mathrm{~b})$, and mŭy is then interpreted as 'why'.

(39) Mandinka (pers.doc.)

(39a) Wùlôo kà làpìrìndínò lè yúurà.

dog.D ICPL small_blow.D FOC growl

'It's for a small blow that the dog growls.'

(39b) Í kà mŭy nè mée jěe?

2SG ICPL what FOC spend_time there

'Why are you always spending time there?'

\subsubsection{Time phrases encoded as the A term of a transitive construction}

Many languages have sentences like The storm found me in the middle of the forest with the meaning 'I was in the middle of the forest when the storm burst'. West African languages make a particularly wide use of this kind of construction. Ex. (40) illustrates this construction in Mandinka with the transitive verb 'create' and the P-labile verb 'finish'.

(40) Mandinka (pers.doc.)

Bǔi mây dúníyáa dáa, buii fánán té
today CPL.NEG world
create today also ICPL.NEG world fit. 'Today did not create the world, today will not finish the world either.'
> 'The world was not created today, it will not finish today either.'

Ex. (41) illustrates a construction of this type in Bambara with an intransitive verb.

(41) Bambara (pers.doc.)

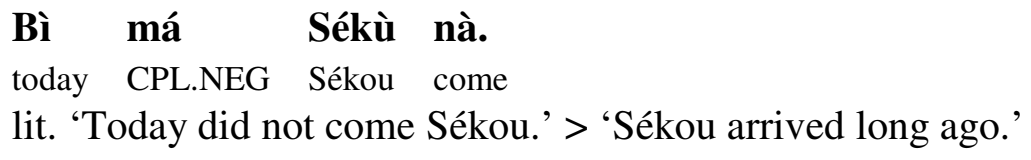




\section{Lesson 2 \\ Valency-decreasing voices}

In the valency alternations described in this lesson, the less valent verb form is more complex than the more valent one. In the simple cases, either the less valent verb form differs from the more valent one by the addition of a derivational affix, or the less valent verb form is an analytic verb form combining a voice auxiliary and a non-finite form of the auxiliated verb.

\subsection{A/U-demoting voices}

By demotion (or backgrounding), I mean an operation that deprives an argument from its syntactic status of core argument, without however removing it from the argument structure. In the description of valency-decreasing mechanisms, it is crucial to distinguish between argument-backgrounding mechanisms (which change the mapping of semantic roles onto syntactic functions but leave the argument structure unchanged, even if the demoted argument is not expressed) and argument-removing mechanisms (which modify the argument structure).

\subsubsection{Canonical passive constructions}

\subsubsection{Passive constructions including an oblique agent phrase}

Ex. (1b) illustrates the kind of constructions for which there is consensus on the use of the label 'passive'.

(1) Tswana (pers.doc.)

(1a) Kítsó ‘ó-tláà-kwál-á lơ-kwâ:lò.

(CL1)Kitso A.CL1-FUT-write-FV CL11-letter

'Kitso will write the letter.'

(1b) Lò-kwáló ${ }^{\dagger} l o ́$-tláà-kwál-w-à $\quad$ (kí ${ }^{\dagger}$ Kî̀tsò).

CL11-letter A.CL11-FUT-write-PASS-FV by (CL1)Kitso

'The letter will be written (by Kitso).

In addition to the presence of a suffix -w- providing evidence that (1b) derives from (1a), the crucial characteristics of clause (1b), in comparison with the transitive clause (1a), are that the argument structure of kwálá 'write' is not affected in (1b), but the mapping of semantic roles onto syntactic functions is different:

- in (1b), the writer is not one of the two core terms (A) of a transitive predication, as in (1a); it may be left unexpressed, or encoded as an oblique;

- in (1b), the thing written is not the P term of a transitive predication, but the $\mathrm{U}$ term of an intransitive predication.

To summarize, the valency change in (1b) can be summarized as combining the demotion of $\mathrm{A}$ and the promotion of $\mathrm{P}$.

Functionally, the observation of the contexts in which passive constructions are particularly frequent leads to the conclusion that they can be characterized as presenting the 
construction that, originally, was something like 'The letter will be written, it is Kitso [who will write it]'.

\subsubsection{Constraints on the use of passive constructions}

It has been mentioned above that, in some languages, the use of the basic transitive construction is limited by constraints on the inherent topicality of the A term that make the passive construction obligatory in some conditions. Conversely, it may happen that the use of the passive construction is limited by constraints related to constrasts in the inherent topicality of the $\mathrm{P}$ argument promoted to $\mathrm{U}$. Constraints on the animacy or person of the $\mathrm{P}$ argument promoted to $\mathrm{U}$ or of the demoted $\mathrm{A}$ are just a particular case.

For example, in Nahuatl, the active-passive alternation is only possible with animate P's. With inanimate P's, the active-passive alternation is not possible, but middle verb forms can be used with a passive reading - Example (4).

(4) Classical Nahuatl (Launey 1980)

(4a) Ø-Itta-lō-c in cihuātl.

A.3-see-PASS-CPL DEF woman

'The woman was seen.'

(4b) Ø-Mo-tta-c in cihuātl.

A.3-MID-see-CPL DEF woman

'The woman saw herself (e.g. in a mirror).'

(4c) *Ø-Itta-lō-c in calli.

A.3-see-PASS-CPL DEF house

*'The house was seen.'

(4d) Ø-Mo-tta-c in calli.

A.3-MID-see-CPL DEF house

'The house was seen.' (lit. 'saw itself')

In K'ichee', passive constructions with an agent phrase are not possible with 1st or 2nd person A's.

(5) K'ichee' (Campbell 2000)

(5a) X-Ø-kunax ri ak'aal r-umal ri ixoq.

CPL-P.3SG-treat.PASS DEF child 3SG-by DEF woman

'The child was treated by the woman.'

$(5 b)$

\begin{tabular}{|c|c|c|c|}
\hline *X-Ø-kunax & & ak'aal & w-umal. \\
\hline
\end{tabular}

Conversely, in some languages, pragmatic factors may result in a preference for passive constructions. For example, depending on the relationship between the speech act participants, transitive constructions with 1 st or $2 \mathrm{~d}$ person A's may be considered rude. It has been argued that the development of this kind of use of passive constructions may lead to the 
obsolescence of the original transitive construction, and consequently to the reanalysis of the former passive construction as the basic transitive construction (Queixalós 20013).

\subsubsection{Impersonal passives from transitive verbs}

In many languages, the verb forms found in canonical passive constructions are also found in constructions in which the A-argument is demoted exactly as in a canonical passive construction, but the P-argument is encoded as in the basic transitive construction. Such constructions are commonly termed 'impersonal passives'.

(6) French

(6a) Le president a pris une décision.

the president has taken a decision

'The president took a decision.'

(6b) Une décision a été prise (par le president). a decision has been taken by the president 'A decision was taken (by the president).' (canonical passive)

(6c) Il a été pris une décision.

it has been taken a decision

'A decision was taken.' (impersonal passive)

Ex. (7) illustrates an impersonal passive construction including an agent phrase.

(7) German

In der Küche wurde von vielen Leuten
in the keraucht.

'There was smoking by many people in the kitchen.'

\subsubsection{Extension of passive morphology to U-demotion}

\subsubsection{Oblique passives}

Oblique passives are constructions in which an intransitive verb undergoes a morphological operation identical to that marking $\mathrm{A}$ demotion and $\mathrm{P}$ promotion with transitive verbs. The unique core argument $U$ of the intransitive verb is demoted exactly like the A argument of a transitive verb, and a term encoded as an oblique in the construction of the underived form of the intransitive verb is promoted to U. Ex. (8) is a classical example of oblique passive.

(8) English

This bed has been slept in.

Sambou (Forthcoming) shows that Joola languages (Atlantic) have a type of oblique passive, illustrated by Ex. (9b), which as far as I know has not been mentioned so far in the literature on passives. In (9b), e-bool-yu 'the bowl' in U role governs verb agreement, but is also resumed by a pronoun in the position it would occupy in the corresponding active sentence. 
(9) Kuwaataay (Joola, Atlantic - Sambou Forthcoming)

(9a) Sana a-ñoofo-a-ñoofo ti e-bool-yu.

Sana CLa-eat-VFOC-eat in CLe-bowl-CLe.D

'Sana has eaten in the bowl.'

\section{(9b) E-bool-yu e-ñoofo-ee-ñoofo ti e-yo.}

CLe-bowl-CLe.D CLe-eat-VFOC.PASS-eat in CLe-PRO

lit. 'The bowl ${ }_{i}$ has been eaten in $i_{i}$.'

Although this is not a common type of passive construction, it is not difficult to imagine a plausible grammaticalization path. Since impersonal passives (i.e. constructions in which the demotion of $\mathrm{A}$ or $\mathrm{U}$ is not accompanied by the promotion of any other term) are crosslinguistically very common, one can imagine that the source of this construction was an impersonal passive with a dummy $\mathrm{A} / \mathrm{U}$ index, something like It-has been eaten in this bowlwith a non-referential reading of $i t$, which in combination with the topicalization of the oblique phrase may have given something like This bowl $\mathrm{l}_{\mathrm{i}}$, it-has been eaten in $i_{\mathrm{i}}$. Then the topicalized phrase was reinterpreted as occupying an argumental position, and the dummy index of the impersonal passive construction was replaced by a index expressing agreement with the NP to its left: This bowl ${ }_{\mathrm{i}} i t_{\mathrm{i}}$-has been eaten in $i t_{\mathrm{i}}$.

\subsubsection{Impersonal passives from intransitive verbs}

In impersonal passives from intransitive verbs, passive morphology (identified as such by reference to its function with transitive verbs) encodes the demotion of the $U$ term of an intransitive construction without promotion of any other term.

Ex. (10) \& (11) illustrate the impersonal passive of Tswana, a language in which the use of impersonal passives is fully productive not only with transitive verbs - Ex. (10), but also with intransitive verbs - Ex. (11). In the impersonal passive constructions of Tswana, the morphological slot in the verb form normally devoted to $A / U$ indexation is occupied by a dummy element which is etymologically a locative index.

(10) Tswana

(10a) Mà-búrú †á-rék-íl-é dí-q⿳亠口冖̀:mó.

CL6-Afrikaner A.CL6-buy-PRF-FV CL10-cow

'The Afrikaners have bought (the) cows.'

(10b) Dì-qhòmó dí-rèk-íl-w-è (kí Mà-bû:rù).

CL.10-cow A.CL10-buy-PRF-PASS-FV by CL6-Afrikaner

'The cows have been bought (by the Afrikaners).' (canonical passive)

(10c) Xú-rék-íl-w-é dí- q⿳ò:mó.

A.CL17-buy-PRF-PASS-FV CL10-cow

'Some cows have been bought.' (impersonal passive)

lit. 'There has been bought cows.' 
(11) Tswana

(11a) Kítsó ó-bù-î:l-è.

(CL1)Kitso A.CL1-speak-PRF-FV

'Kitso has spoken.'

(11b) Xú-bù-î:l-w-è.

A.CL17-speak-PRF-PASS-FV

'People have spoken.' (impersonal passive)

lit. 'There has been spoken.'

\subsubsection{The adversative passive of Japanese}

In Japanese, the verb forms found in canonical passive constructions can also be found in a construction equally available for transitive and intransitive verbs, in which the A/U argument is demoted to oblique, and the $\mathrm{A} / \mathrm{U}$ position (marked as such by the particle ga, glossed ' $\mathrm{S}$ ') is occupied by a noun phrase representing a person negatively affected by the event. The difference with the constructions described in the previous sections is that the rest of the construction remains unchanged, whereas the $\mathrm{A} / \mathrm{U}$ role in the adversative passive construction is occupied by a term that could not feature as a term of the construction of the base verb, and could only be encoded as a possessor. In other words, adversative passives can be viewed as a particular variety of external possession, a family of constructions whose common feature is that they put some emphasis on the affectedness of the external possessor (on external possession, see also 4.11, 5.3).

A remarkable feature of the adversative passive construction is that, in this particular use, passive morphology does not encode a valency decrease, but rather a valency increase reminiscent of that observed in causative constructions, since the $\mathrm{A} / \mathrm{U}$ slot is occupied by an NP referring to a participant that could not feature as a term of the construction of the base verb.

In Ex. (12), sentence (a) illustrates the canonical passive construction, and sentences (b-e) illustrate the adversative passive.

(12) Japanese

(12a) Kodomo-ga otoosan-ni yob-are-ta.

child-S father-OBL call-PASS-PST

'The child was called by [his] father.'

(12b) Kodomo-ga otoosan-ni shin-are-ta.

child-S father-OBL die-PASS-PST

'The child was affected by the death of his father.'

lit. 'The child was dead by [his] father.'

(12c) Taroo-ga Ziroo-ni saihu-o nusum-are-ta.

Taroo-S Ziroo-OBL purse-ACC steal-PASS-PST

'Taroo had his purse stolen by Ziroo.'

lit. 'Taroo was stolen the purse by Ziroo.' 


\section{(12d) Taroo-ga Reiko-ni kao-o tatak-are-ta.}

Taroo-S Reiko-OBL face-ACC hit-PASS-PST

'Taroo was hit in the face by Reiko.'

lit. 'Taroo was hit the face by Reiko.'

\section{(12e) Taroo-ga sensei-ni kodomo-o sikar-are-ta. \\ Taroo-S teacher-OBL child-ACC scold-PASS-PST \\ 'Taroo had his child scolded by the teacher.' \\ lit. 'Taroo was scolded the child by the teacher.'}

\subsubsection{Syncretic passives and the origin of passive constructions}

By syncretic passives, I mean the use of the same morphological marking in canonical passive constructions and in constructions expressing other kinds of valency operations or involving no valency change. Note that the impersonal passives and oblique passives presented in 2.1.2 and 2.1.3 can be viewed as instances of voice syncretism, since in some languages, the same valency changes are encoded by dedicated voices (impersonal voices -2.1 .5 - and oblique voices - 2.1.6).

The remainder of this section is devoted to other types of syncretisms in which the verb forms found in canonical passive constructions may be involved. They have their explanation in the grammaticalization processes in which passive constructions are involved.

\subsubsection{The passive-resultative syncretism}

Resultative constructions are a common source of passive constructions. This explains why many European languages have analytic passives in which a 'be' verb combines with a nonfinite verb form also used in noun-modifying function with a clearly resultative semantics (commonly designated as 'past participle'). In some languages, passive and resultative are distinguished by the use of two distinct auxiliaries (Spanish ser vs. estar, German werden vs. sein), but in others (French, English), if no agent phrase is present, 'be + past participle' may be ambiguous between an agentless passive reading and a resultative reading.

\subsubsection{The passive-middle syncretism}

On the passive-middle syncretism, see Section 2.5.2.

\subsubsection{The passive-antipassive syncretism}

In Soninke, some transitive verbs have a detransitivized form equally available for passive and antipassive uses - Ex. (13). ${ }^{21}$

\footnotetext{
${ }^{21}$ In this example, it is not immediately obvious why the transitive form yígá (whose initial $\mathbf{y}$ is realized $\tilde{\mathbf{n}}$ in contact with a nasal) should be considered as the base form from which the intransitive form yígé is derived. In fact, this derivation involves a ditransitivizing suffix -i which is realized as a distinct segment with monosyllabic stems, but fuses with the last vowel of non-monosyllabic stems, converting a final $\mathbf{a}$ or $\mathbf{o}$ into $\mathbf{e}$, and a final $\mathbf{u}$ into i.
} 
(13) Soninke (pers.doc.)

(13a) Lémúnù-n dà tíyè-n ñígá.

child.PL-D TR meat-D eat

'The children ate the meat.'

(13b) Lémúnù-n ñígé.

child.PL-D eat.DETR

'The children ate.'

(13c) Tíyè-n ñígé.

meat-D eat.DETR

'The meat was eaten.'

In many cases (in particular, in the case of Soninke), a plausible explanation is that a reflexive construction has been the source of both middle, passive, and antipassive constructions - see Sections 2.5.2 and 2.5.3. Another possible explanation is that a sociative-reciprocal derivation has developed not only an antipassive function, but also middle functions, from which a passive function may have developed - see Sections 2.3.4 and 2.5.2.

\subsubsection{The passive-causative syncretism}

On the passive-causative syncretism, see Section 3.1.8.1.

\subsubsection{Others}

The languages of South East Asia have constructions sometimes analyzed as passive periphrases, which however are just a particular case of benefactive / adversative periphrases that also have uses that do not lend themselves to a passive analysis.

For example, in Vietnamese, duoc 'receive, enjoy' and bi 'suffer' can be used as benefactive / adversative auxiliaries in combination with other verbs, and it is tempting to analyze them as passive auxiliaries when the construction has the following shape:

$\mathrm{P}$ duoc (A) $\mathrm{V}$ 'P is V-ed (by A)' (benefactive passive)

$\mathrm{P}$ bi (A) $\mathrm{V} \quad$ 'P is $\mathrm{V}$-ed (by A)' (adversative passive)

This analysis is however problematic in many respects, since the verbs involved in duoc/bi periphrases are not necessarily transitive, the NP preceding the benefactive / adversative auxiliary is not necessarily an argument of the second verb, and even when a passive analysis seems possible, the A argument of the transitive verb does not show evidence of having been demoted - Bruening \& Tran (2015).

\subsubsection{Impersonal voices}

Some languages have derived verb forms found exclusively in the types of constructions described in Sections 2.1.3 (impersonal passives from transitive verbs) and 2.1.4.2 (impersonal passives from intransitive verbs). I propose the term of impersonal voice for such verb forms. This raises however a terminological problem, because in some traditions, they are designated as 'passive', which implies a definition of passive broader than that adopted in this course. 
Ex. (14c) illustrates the impersonal voice of Finnish (commonly called 'passive' in Finnish grammars) in the case of a transitive verb. Ex. (15) illustrates impersonal derivation from an intransitive verb. The impersonal nature of the construction follows from the inability of the verb form to express agreement with any of its arguments.

(14) Finnish (pers.doc.)
(14a) Minä tunne-n sinut
1SG speak.PRS-1SG 2SG.ACC
'I know you.'

(14b) Sinä tunne-t minut

2SG speak.PRS-2SG 1SG.ACC

'You know me.'

(14c) Sinut tunne-taan siellä

1SG speak-IMPERS there

'You are known there. / They know you there.'

(15) Finnish (pers.doc.)

Täällä puhu-taan saksaa

here speak-IMPERS German

'German is spoken here. / They speak German here.'

As evidenced by Lunda, Kimbundu and other South West Bantu languages (Givón 2001, vol. 2:149-151, Kawasha 2007), a possible evolution resulting in the emergence of an impersonal voice is the reanalysis of a constructions with a 3rd person plural referring to an unspecified $\mathrm{A} / \mathrm{U}$ : in clauses that, initially, were something like 'They killed the lion', it became possible to add an oblique representing a specific $\mathrm{A} / \mathrm{U}$ (something like 'They killed the lion by the hunter', interpreted as 'The hunter killed the lion'), which implies the reanalysis of the former pronoun or index or of 3rd person plural as a voice marker devoid of any reference.

\subsubsection{Oblique voices}

Some languages have derived verb forms found exclusively in the types of constructions described in Section 2.1.3.1 (oblique passives). I designate such verb forms as oblique voices. Malagasy is a case in point. In Malagasy, $\mathrm{A}$ in transitive clauses and $\mathrm{U}$ in intransitive clauses are identified as such by their final position, and as illustrated by Ex. (16), distinct verb forms are used to promote patients (passive voice, sentence (b)) and instruments (oblique voice, sentence $(d))$ to the status of $A / U$.

(16) Malagasy (pers.doc.)

(16a) Manasa ny lamba Rasoa.

PRS.wash DEF cloth Rasoa

'Rasoa is washing the clothes.' 


\section{(16b) Sasan -dRasoa ny lamba. \\ PRS.be_washed Rasoa DEF cloth \\ 'The clothes are washed by Rasoa.'}

\section{(16c) Manasa lamba amin' ny savony Rasoa.}

PRS.wash cloth with DEF soap Rasoa

'Rasoa is washing clothes with the soap.'

(16d) Anasan -dRasoa lamba ny savony.
PRS.be_used_to_wash Rasoa cloth with soap
'The soap is used by Rasoa to wash the clothes.'

\subsection{P-demotion: the antipassive voice}

\subsubsection{Definition}

Like the passive, the antipassive does not affect the argument structure of the verb. In canonical antipassive constructions, a transitive verb undergoes a morphological operation encoding $\mathrm{P}$ demotion: the $\mathrm{P}$ argument of the transitive verb is either left unexpressed or encoded as an oblique, whereas the A argument of the transitive verb is treated as the U term of an intransitive predication.

For example, K'ichee' has two distinct antipassive suffixes that differ in the details of their syntactic properties and of their functions. Note that in the basic transitive construction, both $\mathrm{A}$ and $\mathrm{P}$ are obligatorily indexed, whereas in the antipassive construction, the $\mathrm{P}$ argument demoted to oblique is not indexed, and the A argument is indexed as the $\mathrm{U}$ term of an intransitive construction (and consequently, like the $\mathrm{P}$ term in the basic transitive construction, since K'ichee' is an obligatory P coding ('ergative') language).

(17) K'ichee' (Campbell 2000)

(17a) X-Ø-ki-loq' ixim ri ixoqiib'. CPL-P.3SG-A.3PL-buy maize DEF woman.PL 'The women bought some maize.'

(17b) X-e-loq'-on ri ixoqiib'. CPL-P.3PL-buy-ANTIPASS DEF woman.PL

'The women bought [unspecified things].'

(17c) Aree ri ixoqiib' x-e-loq'-ow reech ri ixim.

FOC DEF woman.PL CPL-P.3PL-buy-ANTIPASS 3SG-for DEF maize

'THE WOMEN bought the maize.'

\subsubsection{Typology of antipassive derivations}

Cross-linguistically, antipassive derivations vary along the following parameters:

- the demoted $\mathrm{P}$ argument may be optionally expressed as an oblique, but in some antipassive constructions, it is obligatorily left unexpressed; 
- the verb forms found in antipassive constructions may be dedicated antipassive forms, or forms also found in constructions expressing other types of valency operations, or even in constructions involving no change in the valency (see Section 2.2.6.4);

- there is also some cross-linguistic variation in the functions of the constructions meeting the definition formulated in Section 2.2.1.

\subsubsection{The functions of antipassive derivations, and the relationship between antipassive and the Obligatory Coding Principle}

Very generally, the demotion of the $\mathrm{P}$ argument results in an increase of the relative topicality of the A argument, and in a decrease in the relative topicality of the P argument. This results in a general tendency to favor the use of antipassive constructions with indefinite or nonreferential P's, and consequently with reference to habitual rather than specific events.

For example, in Yup'ik, the $\mathrm{P}$ term of the transitive construction can only be interpreted as definite. Some Yup'ik verbs are A-labile, and allow for the expression of indefinite $\mathrm{P}$ arguments as obliques in an intransitive construction without changing their form - Ex. (18ab), but with other verbs, a morphologically unmarked intransitive construction can only have an anticausative or passive interpretation, and antipassive derivation is required to express indefiniteness of the P argument - Ex. (18c-e).

Yup'ik (Mithun 2000)

$\begin{array}{lll}\text { Arna-m } & \text { tangrr-aa } & \text { taqukaq. } \\ \text { woman-ERG } & \text { see-DECL.A.3SG.P.3SG } & \text { bear } \\ \text { 'The woman } & \text { sees the bear.' } & \end{array}$

(18b) Arnaq tanger-tuq taquka-mek. woman see-DECL.U.3SG bear-ABL 'The woman sees a bear.'
Arna-m
allg-aa
'lumarraq.
woman-ERG tear-DECL.A.3SG.P.3SG shirt
'The woman tears the shirt.'

(18d) 'Lumarraq alleg-tuq.

shirt tear-DECL.U.3SG

'The shirt gets torn.' or 'The shirt is being torn.'

(18e) Arnaq allg-i-uq

'lumarra-mek.

woman tear-ANTIPASS-DECL.U.3SG shirt-ABL

'The woman tears a shirt.'

In the languages that have strict constraints on the expression of the $\mathrm{P}$ argument in the basic transitive construction, the antipassive is a possible strategy for leaving the $\mathrm{P}$ argument unexpressed (see the example of Soninke in Section 2.2.4).

Finally, in 'deep-ergative' languages in which the A term of the transitive construction is not accessible to some operations (focalization, relativization, questioning, etc.) to which P's and U's lend themselves, the conversion of $\mathrm{A}$ into $\mathrm{U}$ by means of antipassive derivation makes it accessible to the operations in question. 
Antipassive derivations have long been observed by linguists describing individual languages, but no cross-linguistic generalization had been proposed. For example, the antipassive prefixes of Nahuatl where just called 'unspecified object prefixes' in Nahuatl grammars. The systematic cross-linguistic investigation of the antipassive started 40-50 years ago in connection with the cross-linguistic study of ergativity, and a correlation was immediately proposed between the alignment properties of languages and the presence of passive or antipassive voices. According to this hypothesis, obligatory A coding ('nominative-accusative') languages would have an passive voice, whereas obligatory $\mathrm{P}$ coding ('absolutive-ergative') languages would have an antipassive voice. However, this hypothesis does not stand up to scrutiny:

- antipassive voices, either syncretic or dedicated, are quite common in obligatory A coding languages (see Section 2.2.4 for more details),

- passive voices are not rare in obligatory P coding languages either,

- many languages, whatever their status with respect to the Obligatory Coding Principle, have both a passive and an antipassive voice (K'ichee', Yup'ik, Soninke, etc.).

In fact, as regards the antipassive voice, the only differences between obligatory A coding and obligatory $\mathrm{P}$ coding languages are that:

- the antipassive voice is more visible in obligatory $\mathrm{P}$ coding languages, since the conversion of $\mathrm{A}$ into $\mathrm{U}$ changes its coding characteristics, whereas in obligatory $\mathrm{A}$ coding languages, the conversion of $A$ into $U$ triggers no change in its coding characteristics;

- making the A argument accessible to operations to which it does not have access as the A term of a transitive construction is a possible function of the antipassive voice in some 'ergative' languages which has no equivalent in 'accusative' languages.

Janic (2013) provides a general survey of antipassive constructions in accusative languages, and a general discussion of this question.

\subsubsection{Antipassives in obligatory A coding languages: evidence from Subsaharan languages}

\subsubsection{Introductory remarks}

In the long-standing debate about the relationship between antipassive and accusativity / ergativity, a number of Subsaharan languages belonging to various families and areas provide crucial evidence against the hypothesis of a privileged relationship between antipassive as a type of valency change and ergativity, and provide strong support to the view that accusative languages may have fully productive antipassive derivations. The languages in question have 'accusative' alignment in core argument coding, and also have antipassive derivations.

Ex. (19) illustrates this situation in Tennet (Surmic, Eastern Sudanic): Tennet uses the same 'marked-nominative' case (glossed ' $S$ ') for noun phrases in A or U role, and requires the addition of a special antipassive suffix to transitive verbs in unspecified-P constructions. 
(19) Tennet (Surmic, Eastern Sudanic - Randall 1998: 245)

(19a) Á-dáh dọẹéc áhát.

IPF-eat child.S asida

'The child is eating asida.'

(19b) Á-dáh-ye dọe

IPF-eat-ANTIPASS child.S

'The child is eating.'

Koyraboro Senni (Songhay - Heath 1999: 166-167) has a detransitivizing suffix -a which, depending on the individual verbs, may encode valency changes of the mediopassive or antipassive type. This latter possibility can be illustrated by haabu 'sweep (tr.)' > haab-a 'do the sweeping'.

In the remainder of this section, I briefly present some Bantu and West African illustrations.

\subsubsection{Bantu antipassives}

The reciprocal-antipassive syncretism, widely attested outside Africa (in particular among Austronesian and Turkic languages) is also typically found among Bantu languages, where the verbal suffix -an- traditionally designated as reciprocal extension has more or less productive uses that depart from the notion of reciprocal, and rather fall under the notion of antipassive. In some of them (for example, Tswana), the antipassive uses of -an-, although unquestionably attested, have a very low productivity. In others (for example, Kirundi), the reciprocal and antipassive uses of -an- seem to have a comparable degree of productivity, resulting in a systematic ambiguity between the antipassive and reciprocal readings of anforms with plural NP's in U role - Ex. (20)

(20) Kirundi (Bantu - Ndayiragije 2006: 275)

(20a) Abanyéeshuúle baatukye umwarimu.

students insulted teacher

'Students insulted the teacher.'

(20b) Abanyéeshuúle baatukanye

students insulted.RECIP/ANTIPASS

(a) 'Students insulted each other.' (reciprocal reading)

(b) 'Students insulted [people].' (antipassive reading)

\subsubsection{West African antipassives}

Antipassive derivations with a limited degree of productivity are common among Atlantic and Mande languages. For example, Ganja (Balant, Atlantic) has 11 transitive verbs that cannot be used in a null-P construction, and whose intransitive use with reference to no specific patient requires the use of an antipassive form. Five of them involve a special suffix, whereas the antipassive form of the other six verbs is formed by means of a reciprocal or mediopassive suffix. Ex. (21) illustrates antipassive derivation with wom 'eat'. 
(21) Ganja (Balant, Atlantic - Creissels and Biaye 2016: 251-252)

(21a)

$\begin{array}{llll}\text { À-wôm } & \text { tîw. } \\ \text { CLha-eat } & \text { (CLu)meat } \\ \text { 'He/she ate meat' } & \text { vs. } & * \text { À-wóm-t̀̀ } & \text { CLha-eat-ANTIPASS }\end{array} \quad \begin{aligned} & \text { tîw. } \\ & \text { (CLu)meat }\end{aligned}$

(21b)
À-wóm-t-ò.
vs. * *̀̀-wóm-ò.
CLha-eat-ANTIPASS-FV
CLha-eat-FV

'He/she ate.'

The antipassive is more productive in Wolof (Atlantic). It involves a suffix -e also used in reciprocal function. Ex. (22) illustrates the antipassive use of this suffix.

Wolof (Atlantic - Nouguier-Voisin 2002:310)

(22a) Xaj a ko màtt.

dog FOC 3SG bite

'A DOG bit him/her.'

(22b)
Xaj bi du
màtt-e.
dog CLb.DEF ICPL.NEG.3SG bite-ANTIPASS
'[You should not be afraid,] the dog doesn't bite.'

Interestingly, in Wolof, antipassive -e is particularly productive with verbs that have a doubletransitive construction. In that case, it invariably encodes the demotion of the recipient / beneficiary argument. This is consistent with the general tendency of this argument to act as the primary $\mathrm{P}$ in the double-transitive constructions of Subsaharan languages.

A similar situation is described by Renaudier (2012) for Sereer (Atlantic).

Among Atlantic and Mande languages, Soninke (Mande) distinguishes itself by the very high degree of productivity of its antipassive derivation. Moreover, in Soninke, the productivity of antipassive derivation relies essentially on the use of a dedicated antipassive suffix.

Soninke has a particularly clear-cut distinction between transitive and intransitive predication, even in comparison with other Mande languages, and very strict constraints on the intransitive use of transitive verbs. With the only exception of a handful of A-labile verbs, transitive verbs in their underived form cannot be found in constructions in which the $\mathrm{P}$ argument would not be expressed. The discourse frequency of antipassive constructions in which the verb is overtly marked as detransitivized follows from the fact that, in Soninke, they constitute the usual strategy to encode two-participant events lexicalized as transitive verbs without mentioning the patient. With the only exception of ten A-labile verbs or so, the Soninke verbs that can be used transitively have an antipassive form. A minority of transitive verbs have an antipassive form marked by a multifunction detransitivizing suffix -i also found with the same verbs with an anticausative or passive function, but most transitive verbs use a dedicated antipassive suffix -ndì -ndí.

Soninke has no constraint restricting the use of the antipassive form of transitive verbs to stereotyped activities or habitual events. Antipassive verb forms can refer to specific events, provided no specific patient is mentioned - Ex. (23) below. Most of the time, the participant that would be encoded as the $\mathrm{P}$ term of the transitive construction is not mentioned at all, but as shown by Ex. (23c), constructions in which it is expressed as an oblique are also possible: 
(23) Soninke (pers.doc.)

(23a) Hàatú dà yúgó sàará.

Fatou TR male give_birth

'Fatou gave birth to a boy.' (transitive construction)

(23b) Hàatú sàaré.

Fatou give_birth.DETR

'Fatou had a baby.' (antipassive construction with unexpressed $\mathrm{P}$ argument)

(23c) Hàatú sàaré tì lénñúgó yì.

Fatou give_birth.DETR with son POSTP

'Fatou gave birth to a son.' (antipassive construction with demoted P argument)

Interestingly, Soninke also has a productive mechanism of P-incorporation which semantically triggers a non-specific reading of the incorporated noun, and morphologically implies detransitivization marking on the verb. However, as a rule, incorporation requires the multifunction detransitivizing suffix -i - Ex. (24b), where gáagè < gáagà+i - even with verbs whose antipassive form is formed by means of the dedicated antipassive suffix - Ex. (24c).

(24) Soninke (pers.doc.)

(24a) ì wá yìràamû-n gáagà-ná.

3SG ICPL cloth.PL-D sell-GER

'(S)he sells (the) clothes.'

(24b) ì wá yìràn-gáagè-né.

3SG ICPL cloth-sell.DETR-GER

'(S)he sells clothes.'

or 'She does cloth selling.'

(24c) ì wá gáagá-ndì-ní.

3SG ICPL sell.ANTIPASS-GER

'(S)he sells things.'

or 'She does selling.'

As regards the origin of the two suffixes involved in Soninke antipassivization, comparative evidence suggests that the multifunction detransitivizing suffix was originally a reflexive marker that developed anticausative / passive and antipassive uses, whereas the dedicated antipassive suffix might be the reflex of a former verb 'do' in an antipassive periphrasis ('do V-ing').

\subsubsection{Dedicated vs. syncretic antipassive voices, and the origin of antipassive voices}

\subsubsection{Antipassive, reflexive, and reciprocal}

As alluded to earlier in the previous section, reflexive and reciprocal constructions are particularly common sources of antipassives, hence the frequent reflexive-antipassive and reciprocal-antipassive syncretisms. 
The evolution from reflexive to antipassive is well-attested with the reflexes of the IndoEuropean reflexive pronoun *se in Romance and Slavic languages, but the evolution from reciprocal to antipassive seems to be more widespread in the languages of the world. Of course, antipassive voices resulting from the evolution of reflexive construction can be syncretic with other types of voices historically related to reflexive constructions (anticausative, passive).

In Section 2.3.4, we will return to the question of the reciprocal-antipassive syncretism, in relationship with the reciprocal-pluractional syncretism.

\subsubsection{Other possible sources of antipassive markers}

Other possible sources of antipassive markers are:

- the grammaticalization of hypernymic nouns in P role ('buy thing' > buy.ANTIPASS, 'help person' > help.ANTIPASS),

- the grammaticalization of a light verb 'do' in an antipassive periphrasis ('do buying' > buy.ANTIPASS).

\subsubsection{The antipassive-causative syncretism}

On the antipassive-causative syncretism, see Section 3.1.8.2.

\subsubsection{Antipassive markers also found in constructions involving no valency change}

Avar has a verbal derivation, designated as 'continuative-intensive' by Charachidzé (1981), which with transitive verbs triggers a valency change of the antipassive type - Ex. (25).

Avar (Charachidzé 1981)

(25a) Musa-ca kasat qwa-na

Musa-ERG lettre write-CPL

'Musa wrote a letter.'

(25b) Musa qwa-dar-na

3SG write-CONTINT-CPL

'Musa was busy writing.'

The same derivation is available for the intransitive verbs, but with intransitive verbs, no valency change occurs.

\subsubsection{Non-canonical antipassives}

As illustrated by Ex. (17c) above, the derived verb forms of K'ichee' marked by the suffix -ow can be found in canonical antipassive constructions. However, the same forms can also be found in constructions involving a valency change that does not correspond to any wellidentified type of voice. In Ex. (26), sentence (b) is the canonical antipassive counterpart of the transitive sentence (a), whereas sentence (c) illustrates an alternative construction of the same antipassive form. In this variant, the sole index included in the verb form refers to the $\mathrm{P}$ argument, which suggests a passive rather than antipassive construction, but at the same time, the $\mathrm{A}$ argument is not flagged as could be expected in a passive construction. This alternative 
construction is conditioned by person hierarchy: the $\mathrm{P}$ argument must rank higher than $\mathrm{A}$ in the ' 1 st person $>2$ nd person $>$ 3rd person plural $>$ 3rd person singular' hierarchy.

(26) K'ichee' (Campbell 2000)

(26a) X-oj-u-ti' ri kumatz

CPL-P.1PL-A.3SG-bit DEF snake

'The snake bit us.'

(26b) Aree ri kumatz $\mathbf{x}$-Ø-ti'-ow q-eech

FOC DEF snake CPL-P.3SG-bite-ANTIPASS 1PL-for

'THE SNAKE bit us.'

(26c) Aree ri kumatz x-oj-ti'-owik

FOC DEF snake CPL-P.1PL-bite-ANTIPASS

'THE SNAKE bit us.'

\subsection{Reflexive and reciprocal}

Reflexive and reciprocal have in common with passive and antipassive that the argument structure of the verb is not affected. Their particularity is that the relationship between participants in the event and participant roles in the argument structure of the verb is not oneto-one.

\subsubsection{Reflexive events, reflexive construction, reflexive voice}

Reflexive events are events that can be conceptualized as involving a participant cumulating two participant roles normally assigned separately, as in (27b).

(27) English

\section{(27a) John injured Peter.}

\section{(27b) John injured himself.}

Ex. (27b) illustrates a cross-linguistically common way of coding reflexive events: the construction is the same as for the same event with distinct participants fulfilling each of the two roles, and one of the two syntactic roles is fulfilled by a pronoun interpreted as coreferent with another term of the construction.

Depending on the individual languages and the syntactic roles involved in the reflexive relation, this type of reflexivity coding may involve fully dedicated reflexive pronouns or other types of pronouns lending themselves to a reflexive interpretation. Intensive pronouns are particularly common in reflexive function, but in some languages, even ordinary third person personal pronouns in $\mathrm{P}$ role are ambiguous between a reflexive and a non-reflexive interpretation, if a pronoun expressing the same person and number values fulfills the A role.

The role of reflexive pronoun may also be fulfilled by forms that transparently result from the grammaticalization of nouns such as 'body' or 'head', alone of combined with possessives - Ex. (28). 
(28) Georgian (pers.doc.)

(28a) Vano-s bedžit st'udent'-ad vtvli.

Vano-ACC serious student-as consider.PRS.A.1SG.P.3SG

'I consider Vano a serious student.'

(28b) Čem-s tav-s bedžit st'udent'-ad vtvli.

POSS.1SG-ACC head-ACC serious student-as consider.PRS.A1SG.P3SG

'I consider myself (lit. I consider my head) a serious student.'

However, when the two roles assigned to the same participant are normally encoded as A and $\mathrm{P}$ in a transitive construction, many languages code the participant cumulating two roles as the $\mathrm{U}$ term of an intransitive predication involving a derived form ot the transitive verb - Ex. (29).

(29) Jóola Banjal (Bassène 2007)

(29a) Alafubbun a-sótten-e aare aku.

CLa.doctor A.CLa-treat-TAM CLa.woman CLa.DEF

'A doctor treated the woman.'

(29b) No ni-sómut-me ínje i-sótten-oro-e.

when A.1SG-be_sick-SBD 1SG A.1SG-treat-REFL-TAM

'When I was sick, I treated myself.'

This type of reflexive coding is quite widespread, but most of the time, the derived verb forms expressing reflexivization also have other possible functions, due to a widespread tendency to extend reflexive marking to the expression of other types of valency operations. We will return to this question in Sections 2.3.3 and 2.5.

\subsubsection{Reciprocal events, reciprocal constructions, reciprocal voice}

In prototypical reciprocal events, two participant roles are shared by two participants, as in (30b).

(30) English

(30a) John greeted Peter.

(30b) John and Peter greeted each other.

The definition of reciprocal events with more than two participants involved in the reciprocal relationship is less straightforward. For example, The guests greeted each other does not necessarily imply that each of the guests greeted all the others, but only that a sizeable proportion of the guests greeted another members of the group and were also greeted, not necessarily by the same persons.

Ex. (30b) illustrates a cross-linguistically common way of coding reciprocal events: the construction is the same as for the same event with distinct participants fulfilling each of the two roles, and one of the two syntactic roles is fulfilled by a reciprocal pronoun. Depending on the individual languages, this type of reciprocity coding may involve fully dedicated 
reciprocal pronouns or forms that transparently result from the grammaticalization of nouns such as 'like' or 'companion', or of word combinations such as 'one one' or 'one other'. $\mathrm{K}$ 'ichee' illustrates the case of a language using the same pronoun in reflexive and reciprocal function. Note that the 3rd person agreement triggered by this reflexive/reciprocal pronoun, even when it refers to a speech act participant, is consistent with its probable etymology as a former possessed noun.

(31) K'ichee' (Campbell 2000)

(31a) X-Ø-w-il jun kuuk.

CPL-P.3SG-A.1SG-see one squirrel 'I saw a squirrel.'

$\begin{array}{lllll}\mathbf{X}-\boldsymbol{\emptyset}-\mathbf{w}-\mathbf{i l} & \mathbf{w}-\mathbf{i i b} & \text { pa } & \text { le } & \text { ja'. } \\ \text { CPL-P.3SG-A.1SG-see } & \text { 1SG-REFL/RECIP } & \text { in } & \text { DEF } & \text { water } \\ \text { 'I saw myself in the water.' } & & & \end{array}$

(31c) X-e-ki-to' ri ixoqiib' ri alab'oom. CPL-P.3PL-A.3PL-help DEF woman.PL DEF child.PL 'The children helped the women.'

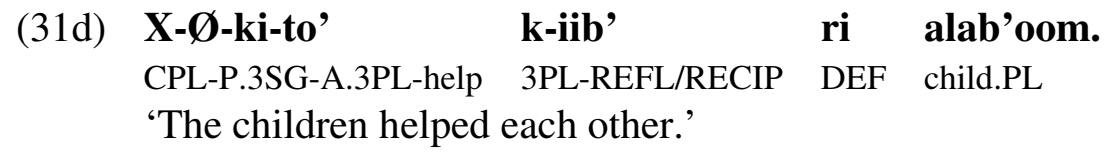

However, when the two roles shared by a group of participants are normally encoded as A and $\mathrm{P}$ in a transitive construction, many languages code the group of participants sharing two roles as the unique core argument of a derived intransitive verb form. It may also happen that part of the participants involved in the reciprocal relationship are encoded as the unique core argument of the derived verb forms, the others being encoded as a comitative adjunct, as in (32c). Note that verb agreement excludes considering that (32c) differs from (32b) in constituent order only.

(32) Tswana (pers.doc.)

(32a) Kítsó 'ó-rát-á Lòrátó thâ:tà.

(CL1)Kitso A.CL1-love-FV (CL1)Lorato much

'Kitso loves Lorato much.'

(32b) Kítsó lí-Lòrátó 'bá-rát-án-à

(CL1)Kitso with-(CL1)Lorato A.CL2-love-RECIP-FV much

'Kitso and Lorato love each other much.'

(32c) Kítsó ‘ó-rát-án-à lí-Lòrâ:tò

(CL1)Kitso A.CL1-love-FV (CL1)Lorato

'Kitso and Lorato love each other.'

lit. 'Kitso loves each other with Lorato.' 
Reciprocal constructions involving a derived intransitive form of transitive verbs are quite widespread, but most of the time, as developed in Sections 2.3.3 and 2.3.4, the derived verb forms expressing reciprocity also have other possible functions.

\subsubsection{The reflexive-reciprocal syncretism}

The reflexive-reciprocal syncretism does not seem to be particularly widespread in the languages of the world, but it is found in several branches of Indo-European (Romance, Slavic, etc.), in which it results from the extension of the uses of a former reflexive pronoun (Indo-European *se). A possible functional explanation is that a reciprocal event can be viewed as a reflexive event involving a plural individual.

\subsubsection{Reciprocity, co-participation, and antipassive}

The reciprocal-antipassive syncretism has been presented in Section 2.2.6.1. Another syncretism in which reciprocal voices are commonly involved is the syncretism with sociative derivations expressing joint action (co-participation) without changing the valency.

For example, Turkish grammars usually designate the verbal suffix -(I)s as 'reciprocal suffix', but define its meaning as indicating a reciprocal or mutual action. This suffix has a reciprocal interpretation in e.g. bak-ış 'look at one another', but with verbs whose argument structure excludes reciprocity, the same suffix indicates co-participation with identical roles: koş-uş 'run together', gül-üsş 'laugh together', etc. The notion of co-participation is crucial for a proper understanding of these two syncretisms:

- reciprocity can be viewed as a particular type of co-participation;

- co-participation can be viewed as an extension of the notion of reciprocity;

- co-participation marking can be interpreted as leaving open the question of semantic role assignment to individual participants, in which case contextual factors or our knowledge of the world constitute the basis on which particular semantic roles are assigned to individual participants.

The notion of co-participation can conveniently be defined as applying to constructions that imply a plurality of participants in the event they refer to without assigning them distinct roles. This definition groups together three types of situations that can be termed unspecified co-participation, parallel co-participation, and reciprocal co-participation.

In constructions with a meaning of unspecified co-participation, an event involves two or more participants that may assume distinct roles, but the construction by itself leaves open the precise role assumed by some of them, and role recognition crucially relies on lexical and/or pragmatic factors. Constructions with a meaning of parallel co-participation (typically expressed by together in English) imply that two or more participants share the same role, and constructions with a meaning of reciprocal co-participation imply a plurality of participants interacting in such a way that at least some of them fulfill two distinct roles in their interaction with the others.

Such definitions are necessary, but the linguistic manifestations of the different types of co-participation are not always easy to identify, and shifts are not rare, from one type of coparticipation to another one, or from co-participation to types of role assignment in which each participant receives a distinct role.

For example, many languages have markers such as English with, commonly defined as polysemous, with a comitative meaning and an instrumental meaning, and comitative > instrumental is a very common diachronic process. The notion of comitative is commonly 
defined in a way that makes it compatible the notion of parallel co-participation, whereas the notion of instrumental implies a conceptualization of the event in which each participant explicitly receives a distinct role, and consequently, cannot be included in co-participation. Moreover, the notion of parallel co-participation is too restricted to cover the variety of noninstrumental uses of with. For example, John came with Peter can indistinctly refer to situations that could be described in a more precise way by sentences such as John and Peter came together, John came and brought Peter with him, John came in the car driven by Peter, etc.

The distinction between abstract meaning and default interpretation provides a possible explanation of such facts. According to this kind of analysis, with has unspecified coparticipation as its abstract meaning, and parallel co-participation as its default interpretation. This definition of the meaning of with leaves open the possibility that contextual and/or pragmatic factors force interpretations of with whereby the noun phrase introduced by with represents a participant whose role is more or less distinct from those assumed by the other participants. For example, A came with $\mathbf{B}$ says nothing about the precise way the entity represented by the term B participates in the event. In the absence of any other indication, the default interpretation will therefore be A and B came together. But the construction by itself does not necessarily imply a meaning of parallel co-participation, even when A and B represent entities of the same type (as in John came with Peter). And in sentences in which $\mathrm{A}$ and $\mathrm{B}$ are necessarily assigned distinct semantic roles, such as Mary came with her baby (= Mary brought her baby) and Mary came with her bicycle (= Mary used her bicycle to come), it seems reasonable to posit that the difference in the interpretation is determined by the semantic nature of the entities denoted by the nominal terms of a construction whose abstract meaning is unspecified participation.

In this perspective, the diachronic shift comitative > instrumental can be analyzed as involving both the loss of the default interpretation of parallel co-participation and the semanticization of a contextually determined interpretation. The interest of this analysis is confirmed by the fact that, cross-linguistically, the use of comitative markers to code participants with specific roles recoverable from the context, and the tendency to semanticize such uses, are not limited to the expression of an instrumental meaning: some languages use comitative markers to retrieve the demoted agent in passive constructions, and the homonymy between causative markers and comitative markers observed in some languages (e.g., in the Mande language $\mathrm{Soso}^{22}$ ) can be viewed as an evidence that a possible origin of causative constructions is the semanticization of a particular use of constructions whose original meaning was unspecified participation.

Returning to verbal derivations currently identified as reciprocal in descriptive grammars, it is interesting to observe that derived verb forms used most commonly in a way compatible with the notion of reciprocity may also have more or less marginal uses that cannot be described as reciprocal. Such 'reciprocal' verb forms clearly have reciprocity as their default meaning, but can also be used with a meaning of unspecified or parallel co-participation in contexts that exclude a reciprocal interpretation.

Some Tswana data are particularly suggestive in this respect. The Tswana verbs derived by means of a suffix -an- are commonly termed reciprocal, and this designation is justified by the fact that, almost always, they unambiguously convey a reciprocal meaning. However, verbs derived by means of the suffix -an- are also found, although sporadically, in contexts in

\footnotetext{
${ }^{22}$ In Soso, N1 N2 ra-faa ' $\mathrm{N} 1$ brought N2', with the causative prefix ra- attached to the verb faa 'come', is synchronically distinct from $\mathbf{N 1}$ faa $\mathbf{N} 2$ ra 'N1 came with N2', with the comitative postposition ra taking $\mathrm{N} 2$ as its complement, but diachronically, these two constructions seem to originate from two different arrangements of the same morphological material.
} 
which speakers unanimously interpret them as non-reciprocal. For example, the only possible

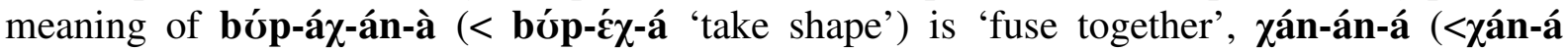
'refuse') is commonly interpreted as 'disobey', and in example (33), a reciprocal interpretation of (33a) is not excluded, but this 'reciprocal' clause is commonly understood as synonymous with the transitive clause (33b), in which the underived form of bàtt-à 'look for' combines with lìpòdísí 'policeman' in A role, and lìòdù 'thief' in $\mathrm{P}$ role.

Tswana (pers.doc.)

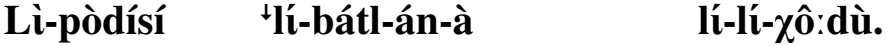 \\ CL5-policeman A.CL5-look_for-RECIP-FV with-CL5-thief}

abstract meaning: 'The policeman and the thief are both involved in a looking-for event.', preferred interpretation: 'The policeman is looking for the thief.'

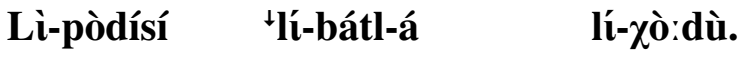 \\ CL5-policeman A.CL5-look_for-FV CL5-thief \\ 'The policeman is looking for the thief.'}

Such observations can easily be accounted for by positing that:

(a) reciprocity is the default interpretation of Tswana reciprocal verbs,

(b) the reciprocal interpretation of Tswana reciprocal verbs can be cancelled by the lexical meaning of the verb, or by pragmatic factors,

(c) the cancellation of the default interpretation of reciprocity results in activating an instruction to go back to the more abstract meaning of co-participation, and to construct an interpretation compatible with the factors that have led to the cancellation of the default meaning.

For example, a reciprocal interpretation of bớp-á $\boldsymbol{\chi}$-án-à 'fuse' is excluded, since bớp- $\boldsymbol{\varepsilon} \chi$-á 'take shape' has only one semantic role to assign, but a meaning of parallel co-participation ('take shape together' > 'fuse') is easy to imagine.

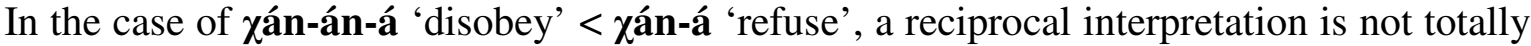
excluded, but one usually refuses a proposal, or a thing, not another person, which makes a reciprocal interpretation not very likely.

Finally, in the case of bàtt-àn-à, in principle, a reciprocal interpretation is perfectly possible, and what suggests to cancel it here is that policemen used to look for thieves, but thieves as a rule rather try to avoid policemen.

In Tswana, the interpretation of the reciprocal form of transitive verbs in a construction including a comitative adjunct seems to proceed as follows: the $U$ term is assigned the same semantic role as $\mathrm{A}$ in the transitive construction of the corresponding non-derived verb, and the recognition of the precise way its referent interacts with the participant represented by the comitative adjunct relies on lexical, contextual and pragmatic factors, the reciprocal interpretation being only the default interpretation. The example of bàtt-àn-à shows that interpretations of reciprocal verbs whereby a comitative adjunct is assigned the same semantic role as $\mathrm{P}$ in the transitive construction of the corresponding non-derived verb are not excluded. This results in sporadic antipassive uses of the reciprocal derivation of Tswana. 


\subsection{Anticausative and resultative}

Anticausative and resultative differ from the mechanisms described in the previous sections in that they involve a change in argument structure: in anticausative and resultative constructions, the A argument of a transitive verb is removed from argument structure. As already mentioned in Section 2.1.4 above, anticausatives and resultatives are equally common sources of passives.

\subsubsection{Anticausative}

The anticausative is similar to the passive in that the A argument loses its core syntactic term status and the $\mathrm{P}$ argument becomes the $\mathrm{U}$ term of an intransitive predication. However, in the passive, the agent is not removed, but only demoted. Semantically, a passive such as French La porte a été ouverte 'The door was opened' crucially differs from the anticausative La porte s'est ouverte 'The door opened' in that an agent is implied (though not mentioned explicitly) in the passive, whereas the event encoded by an anticausative construction is thought of as happening spontaneously. This explains the following two observations:

- agent-oriented adverbs can be inserted in passive constructions, as in La porte a été ouverte exprès 'The door was opened on purpose', but not in anticausative constructions (*La porte s'est ouverte exprès),

- adverbs highlighting the absence of involvement of an instigator can be inserted in anticausative constructions, as in La porte s'est ouverte toute seule 'The door opened by itself'), but not in passive constructions (*La porte a été ouverte toute seule).

Furthermore, contrary to the passive, which can generally be formed from the great majority of transitive verbs (if not all), anticausatives can be formed only from verbs expressing processes that can be thought of as happening more or less spontaneously, without a (human) agent's intervention.

Some languages (for example, Tswana) have derivational suffixes fully specialized in anticausative-marking function, but it is more common that anticausative is one of the possible functions of middle markers with a variety of detransitivizing functions. This situation often results from the evolution of constructions whose original function was the expression of reflexivity, but the development from reciprocal to anticausative is also attested in some Oceanic and Bantu languages. (see Section 2.5).

\subsubsection{The resultative}

The resultative is defined as a derivation that turns a verb referring to an event into a derived form (verb or participle) referring to the state resulting from that event.

Although the anticausative and the resultative have the same derived valency pattern, the two derivations are very different in nature. The anticausative has the removal of the agent as its primary function, whereas the primary function of the resultative is the expression of a state by means of an event word. The removal of the agent is a secondary effect of this primary function: states cannot have agents. Since the expression of a state is the primary function of the resultative, it can also be formed from intransitive verbs in many languages, and in resultatives of intransitive verbs, there is no valency change at all.

The problem with resultatives is that, in their predicative use, they are very unstable diachronically: when used predicatively, resultatives tend to re-activate the dynamic meaning of the verb from which they derive, and consequently to reintroduce the suppressed agent in 
their argument structure. Depending on the details of the constructions and the valency of the verbs involved in resultative constructions, this may lead to the reanalysis of resultatives as perfects or passives. Such evolutions have been extremely common in the history of IndoEuropean languages.

\subsection{The middle}

\subsubsection{Reflexive, reciprocal, and middle}

\subsubsection{Quasi-reflexive events and the notion of middle voice}

The notion of quasi-reflexive event is necessary to account for the cross-linguistically widespread use of reflexive forms or constructions to encode one-participant events that cannot be viewed as reflexive events stricto sensu, although they have an affinity with reflexive events that explains the tendency to use the same coding.

For example, in French, there is the same formal relationship between se lever 'stand up' and lever 'raise' as between se blesser 'injure oneself' and injure 'blesser', although the semantic relationship is not identical: a person who stands up cannot be described as performing on themself the same action as when raising another person or an object.

Consequently, I propose the term of quasi-reflexivity for the following type of relationship between one- and two-participant events:

- the action performed by the unique participant in the one-participant event can be assimilated to the process undergone by the patient in the two-participant event;

- this action is performed consciously and voluntarily, but in a way that cannot be assimilated to the action performed by the agent in the two-participant event.

Moreover, intermediate cases between uncontroversial reflexives and uncontroversial quasireflexives can be found. For example, wash stands closer to the reflexive prototype than stand up, but it cannot be viewed as a fully prototypical reflexive either, since washing oneself is not exactly performing on oneself an action one normally performs on other persons.

The fuzzy limit between typical reflexives and quasi-reflexives explains the development of middle voices in which the same morphological marking is typically used to encode events lending themselves to a reflexive, quasi-reflexive, or anticausative type of conceptualization. ${ }^{23}$

\subsubsection{From reciprocal to middle}

Detransitivization markers with functions including the expression of quasi-reflexivity and anticausativity may also develop from reciprocal markers that have no connection with reflexivity. This development is documented by the evolution of reciprocal markers in some Bantu and Oceanic languages.

\subsubsection{Further extensions}

Middle marking resulting from the evolution of a former reflexive or reciprocal construction may be syncretic with the marking of other varieties of valency reduction: passivization (see

\footnotetext{
${ }^{23}$ The term middle is used by most authors in this broad sense. Note however that some authors use it in a more restricted sense corresponding to what is called here 'quasi-reflexive'.
} 
2.5.2), antipassivization (see 2.5.3), impersonalization (see 2.5.4). Middle marking may also be found in constructions that do not imply a reduction of the number of core arguments but modify the semantic role of the A arguments (see 2.5.5). Finally, the lexicalization of middle marking is a very common phenomenon (see 2.5.6).

Interestingly, at some stage of their evolution, it is not rare that middle voices resulting from the grammaticalization of an initially reflexive construction lose the ability to encode typical reflexive events which constitutes their original function, subsisting only in other functions, due to the grammaticalization of a new way of encoding reflexivity.

\title{
2.5.2. Passive middles
}

European languages provide ample evidence for the diachronic development reflexive $>$ middle > passive. In some of the languages in question, the passive uses of the middle voice are more or less sporadic, or marginal (this is for example the case in French), whereas in others (Spanish, or Russian), the Indo-European reflexive pronoun *se converted into a middle voice marker has further acquired a productive passive use. In Example (34), (a) illustrates the original reflexive function of the middle marker of Russian -sja, whereas (b) illustrates the passive use of the same marker.

Russian (pers.knowl.)

\section{(34a) Ivan moet-sja \\ Ivan wash.PRS.3SG-MID \\ 'Ivan is washing.'}

$\begin{array}{llll}\text { (34b) Eto } & \text { javlenie issleduet-sja } & \text { učenymi. } \\ & \text { DEM.SG.N phenomenon investigate.PRS.3SG-MID } & \text { scientist.PL.INSTR } \\ \text { 'This phenomenon is investigated by scientists.' } & \end{array}$

\subsubsection{Antipassive middles}

Although the semantic aspects of this development are not well-understood, it is uncontroversial that middle voices resulting from the grammaticalization of a reflexive construction are very frequently also found with a more or less productive antipassive function. Ex. (35) illustrates the antipassive use of the middle marker of Russian -sja, illustrated above in reflexive and passive function, and Ex. (36) illustrates the antipassive use of Spanish se (Note that, in Spanish, the middle marker shows the same variation in personnumber as the reflexive clitic pronoun from which it originates). In the antipassive construction illustrated by (35), the demoted $\mathrm{P}$ is obligatorily left unspecified, whereas in (36), it surfaces at an oblique. This aspect of the antipassive use of middle marking is variously regulated in individual languages.

(35) Russian (pers.knowl.)

\author{
Beregite-s' sobaki, ona kusaet-sja. \\ beware-MID dog.GEN 3SG.F bite.PRS.3SG-MID \\ 'Beware of the dog, it bites.'
}


(36) Spanish (pers.doc.)

(36a) Aproveché

la confusión.

take_advantage_of.PRF.1SG DEF.SG.F confusion

'I took advantage of the confusion.'

(36b)

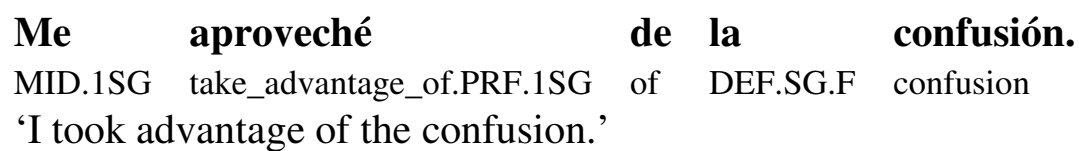

\subsubsection{Impersonal middles}

The extension of middle marking to impersonalization is found among others in Spanish. (37a) illustrates the canonical transitive construction of encontrar 'find'. In (37b), the construction is de-transitivized by the middle marker (originally, a reflexive clitic) se; the NP in post-verbal position governs verb agreement, and the construction is ambiguous between a reciprocal and a passive reading. In (37c), the NP in post-verbal position is introduced by the same preposition a as in (37a) and does not govern verb agreement, and there is no possibility to add an NP governing verb agreement. Consequently, the construction (37c) must be analyzed as including a slot for a term showing $\mathrm{P}$ coding, but no slot for a term showing $\mathrm{A}$ coding.

(37) Spanish (pers.doc.)

(37a) El policía encontró a los $\quad$ ladrones.

DEF.SG.M policeman find.PRF.3SG DOM DEF.PL.M thief.PL

'The policeman found the thieves.'

(37b) Se encontraron los ladrones.

MID find.PRF.3PL DEF.PL.M thief.PL

'The thieves met.' or 'The thieves were found.'

(37c) Se encontró a los ladrones.

MID find.PRF.3SG DOM DEF.PL.M thief.PL

'They (unspecified) found the thieves.'

Ex. (38) illustrates the use of middle marking in the impersonal variant of an intransitive construction in Portuguese.

(38) Portuguese

Aquí não se pode nadar.

here NEG MID be_able.PRS.3SG swim.INF

'One can't swim here.'

\subsubsection{Middle marking without reduction of the number of arguments}

Starting from the expression of agent-beneficiary reflexivization (or auto-benefactive), as in (39b), middle voices may develop uses marking no change in the number of arguments, their syntactic status, or the denotative meaning, in which middle marking just highlights the 
affectedness of the agent, as in (39d). ${ }^{24}$ Note that, in French, middle marking automatically triggers the use of 'be' (instead of 'have') in completive auxiliary function.

(39) French

(39a) Il a acheté des chaussures.

he has bought some shoes.

'He bought shoes.'

(39b) Il s'est acheté des chaussures.

he MID-is bought some shoes.

'He bought shoes for himself.'

(39c) Il a mangé un gâteau entier.

he has eaten a cake whole

'He ate a whole cake.'

(39d) Il s'est mangé un gâteau entier.

he MID-is eaten a cake whole

'He ate a whole cake (and enjoyed it).'

Middle marking may also be used to modify the perspectivization of an event without affecting the number of participants of their roles. In all cases, the participant selected by the middle form as $\mathrm{A}$ is less agentive that the $\mathrm{A}$ in the construction of the base verb. For example, in Greek, danéizomai 'borrow' is the middle form of danéizo 'lend'.

\subsubsection{Lexicalized middles}

Middle derivatives have a strong propensity to lexicalize. As a rule, the languages that have a middle voice also have verbs that show middle marking but cannot be analyzed as the middle form of another verb in a synchronic analysis, such as French s'avérer 'turn out to be', or s'évanouir 'faint'. Such verbs are traditionally called media / reflexiva tantum.

\footnotetext{
${ }^{24}$ Note that some languages have a dedicated auto-benefactive voice. This is the case of the so-called 'subjective version' of Georgian.
} 



\section{Lesson 3 \\ Valency-increasing voices and voice combinations}

\subsection{The causative voice}

\subsubsection{Definitions}

In their typical use, causative voices are morphologically coded valency alternations in which the argument structure of the morphologically more complex form differs that of the less complex one by the addition of causer showing the following two characteristics: formally, it is encoded as the A term of a transitive construction, and semantically, it exerts its control on a causee corresponding semantically to the A/U argument of the base verb. Ex. (1) illustrates the causativization of an intransitive verb (1a-b) and of a transitive verb (1c-d) in Nahuatl. Note that, in (1d), the slot dedicated to $P$ indexation in the causative verb form does not index the initial $\mathrm{P}$, but the causee.

(1) Classical Nahuatl (Launey 1980)

(1a) Ni-tzàtzi.

A.1SG-scream.PRS

'I am screaming.'

(1b) Ti-nēch-tzàtzītia.

A.2SG-P.1SG-scream.CAUS.PRS

'You are making me scream.'

(1c) Ti-c-cua in nacatl.

A.2SG-P.3SG-eat.PRS DEF meat

'You are eating the meat.'

(1d) Ni-mitz-cualtia in nacatl.

A.1SG-P.2SG-eat.CAUS.PRS DEF meat

'I am making you eat the meat.'

\subsubsection{Direct vs. indirect causation}

Some languages have two or more causative markers that express different semantic types of causation. Others have causative markers lending themselves to a wide range of interpretations.

Two main semantic types of causatives can be distinguished. With the first one, the causer actively participates in the caused event, acting on the causee in order to get the content of the base verb realized, which will imply some kind of coercion in case the causee is animate. This type of causative is often called the direct causative. In the indirect causative ('have someone do something'), the causer is conceived of as a mere instigator or distant cause of the realization of the verb content. Depending on the individual languages, direct and indirect causatives may be formally distinct. For example, in Wolof, toog 'sit' has two causative 
forms: toog-al, which implies that the causer is physically involved in the caused event (for example, by bringing a chair), and toog-loo, which does not imply more than an invitation to sit down.

In Tamil, the verb 'place' has been grammaticalized as a direct causative auxiliary, and the verb 'make' as an indirect causative auxiliary.

(2) Tamil (Fedson 1985)

\section{(2a) piLLaiyai tuunka vai-tt-een.}

child.ACC sleep.INF place-PRT-1SG

'I made the child sleep.'

\section{(2b) avaru jepam taan noNTiyai naTakka cey-t-atu.}

3.HON(GEN) prayer indeed cripple.ACC walk.INF make-PRT-3SG.N

'His (someone else's) prayer really made the cripple walk.'

It may also happen that the expression of direct causation involves lability, whereas indirect causation requires the use of a marked causative form, as in (3).

(3) Bambara (pers.doc.)

(3a) Sékù bé bòlí.

Sékou ICPL run

'Sékou is running.'

(3b) Sékù bé móbílí bòlí.

Sékou ICPL car.D run

'Sékou is driving the car.'

(3c) Sékù bé wùlû lá-bòlí.

Sékou ICPL dog.D CAUS-run

'Sékou is making the dog run.'

Direct causation typically applies to intransitive verbs, and indirect causation, to transitive verbs, but this is not a strict rule, just a tendency.

Often the indirect causative subsumes an assistive meaning ('help causee to V'), a permissive meaning ('let causee V'), or even a comitative meaning that can be viewed as a borderline case of assistive causation. For example, in Tswana, depending on the context, áxísá (causative of áxá 'build') can be interpreted as 'make build', 'let build', or 'help to build'. Ex. (4) provides further illustrations of the assistive-comitative use of the causative voice in Tswana. Note that, depending on the context, the causative verbs occurring in this example could also be found with the meanings 'make someone cry' or 'make someone speak', since Tswana is typically a language with a single causative marker lending itself to a wide range or interpretations.

\section{(4) Tswana (pers.doc.)}

\section{(4a) Bà-sádí $\quad{ }^{\dagger}$ bá-líd-ís-à mò-tthớláxâ:dì. \\ CL2-woman 2.CL2-cry-CAUS-FV CL1-widow}

'The women are crying with the widow.' 
(4b) Kì-tłàà-bú-ís-á

\author{
tàútơná kámò̀só.
}

A.1SG-FUT-speak-CAUS-FV (CL1)president tomorrow

'I'll talk with the president tomorrow.'

Another general particularity of indirect causatives is that they tend to imply some backgrounding of the causer. Interestingly, Wolof has two distinct suffixes for indirect causation, one of them compatible with the expression of the causer, the other blocking the expression of the causer, which must be interpreted as unspecified.

(5) Wolof (Nouguier-Voisin 2002)
(5a) Ñaw-loo naa ko roob.
sew-CAUS PRF.1SG 3SG dress
'I made him sew a dress.'
(5b) Naw-lu naa roob. sew-CAUS PRF.1SG dress
'I had a dress sewn.'

\title{
3.1.3. Restrictions on causative derivations, double causatives
}

A cross-linguistically common restriction on causative derivations is that, with few exceptions, morphological causatives can only be formed from intransitive verbs, and transitive verbs can only be causativized by means of more or less grammaticalized causative periphrases.

Interestingly, in the languages that have this kind of restriction, 'eat' and 'drink' are generally among the transitive verbs that exceptionally lend themselves to the same causative derivation as intransitive verbs.

The ban on morphological causativization of transitive verbs is however far from general in the languages of the word. Some of the languages that allow for the morphological causativization of transitive verbs even allow for double causativization, with a direct causative serving as the base for the formation of an indirect causative.

(6) Mandinka (pers.doc.)

(6a) Bòotôo fáa-tà.

bag.D get_full-CPL

'The bag is/got full.'

(6b) Kàmbàanôo yè bòotôo fá-ndì.

boy.D CPL bag.D be_full-CAUS

'The boy filled the bag.'

(6c) Mùsôo yè kàmbàanôo fá-ndí-ríndì bòotôo lá. woman.D CPL boy.D be_full-CAUS-CAUS bag.D POSTP

'The woman made the boy fill the bag.' 


\subsubsection{The causee in the construction of causative verb forms}

As a rule, as illustrated by several of the examples above, causatives derived from intransitives have a transitive construction with the causer in A role and the $\mathrm{U}$ argument of the base verb in $\mathrm{P}$ role.

Causatives derived from transitives show more variety in their possible constructions, and much more space than is available here would be necessary to give a detailed account of this question in the languages of the world.

In the languages in which trivalent verbs may have double-transitive constructions, a natural solution is to treat both the causee and the $\mathrm{P}$ argument of the base verb as P's in a double transitive construction. Among the languages illustrated in the previous sections, this is the case for Nahuatl, Wolof, and Tswana. Note however that, with respect to the mechanisms that do not treat the two P's in an equal way, it is the causee (rather than the $\mathrm{P}$ argument of the base verb) that tends to be fully assimilated to the $\mathrm{P}$ term of the basic transitive construction.

In the languages that do not have double-transitive constructions, the choice is essentially between maintaining the $\mathrm{P}$ argument of the base verb as the $\mathrm{P}$ term of the causative construction (the causee being encoded as an oblique), and demoting the $\mathrm{P}$ argument of the base verb (the causee taking the role of $\mathrm{P}$ in the causative construction). The rules accounting for the choice between these two solutions show considerable cross-linguistic variation. Sometimes they apply quite mechanically, but they may also be sensitive to semantic factors.

In Soninke, as illustrated by Ex. (7), the rule is that, if both the causee and the P argument of the base verb are expressed, the $\mathrm{P}$ argument of the base verb is maintained in $\mathrm{P}$ role, and the causee is expressed as an oblique; however, the $\mathrm{P}$ argument of the base verb may be left unexpressed, and then the $\mathrm{P}$ role in the causative construction is fulfilled by the causee.

(7) Soninke (pers.doc.)

(7a) Lémínè-n dà tíyè-n ñígá.

child-D TR meat-D eat

'The child ate meat.'

(7b) Hàatú dà tíyè-n ñígá-ndí lémínè-n yá.

Fatou TR meat-D eat-CAUS child-D POSTP

'Fatou made the child eat meat.'

(7c) Hàatú dà lémínè-n ñígá-ndí.

Fatou TR child-D eat-CAUS

'Fatou made the child eat.'

In other languages, as illustrated by Ex. (8), the choice is less mechanical, and seems to be sensitive to the degree of affectedness of the causee. In (8b), the causee is in the comitativeinstrumental case, and the initial $P$ in the accusative case, whereas in $(8 \mathrm{~d})$, the causee is in the accusative case, and the initial $\mathrm{P}$ in the comitative-instrumental case.

(8) Hungarian (pers.doc.)

$\begin{array}{lllll}\text { (8a) A } & \text { rendőrség } & \text { keres-i } & \text { a } & \text { gyerek-et. } \\ \text { DEF police } & \text { look_for-A.3SG.P.3DEF } & \text { DEF } & \text { child-ACC } \\ \text { 'The police is searching the child.' } & & \end{array}$




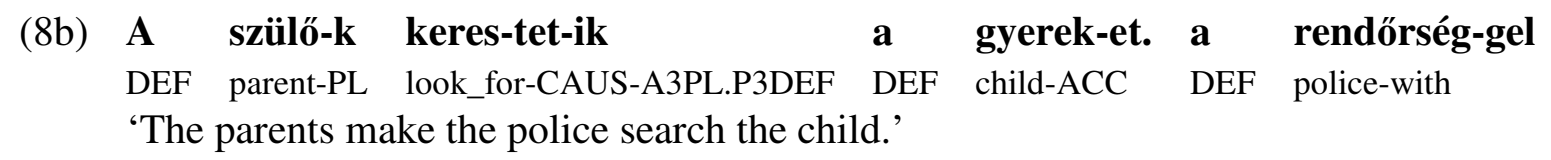

(8c) A gyerek tej-et isz-ik

DEF child milk-ACC drink-A3SG

'The child is drinking milk.'

(8d) Az anya tej-jel i-tat-ja a gyerek-et

DEF mother milk-with drink-A3SG.P.3DEF DEF child-ACC

'The mother is making the child drink milk.'

\subsubsection{Possible sources of causative voices}

\subsubsection{The grammaticalization path causation verb $>$ causative auxiliary $>$ causative derivational affix}

It seems reasonable to assume that all languages can encode the causation relationship between a causing event and a caused event by means of biclausal constructions, either of the 'main clause + subordinate clause' type, or of the serial type. Such constructions may evolve toward more tightly integrated clause combinations, and eventually give rise to complex predicates combining a causative auxiliary and a non-finite form of the verb encoding the caused event. The final stage of the evolution is the univerbation of the complex predicate, by which the former causative auxiliary is converted into a derivational affix. This explains why so many languages across the world have causative derivational affixes cognate with a verb 'do', or with another verb commonly used as a causative auxiliary in periphrastic causatives ('give', 'put', 'send', etc.)

There is a huge literature about the analysis of causative periphrases and the criteria according to which they can be analyzed as maintaining properties characteristic for the biclausal constructions from which they originate, or rather showing a behavior more typical for fully integrated constructions.

In this respect, it is for example easy to show that the English construction 'make V' behaves in many respects as a biclausal construction, whereas for most French speakers, 'faire V' has completely lost the properties that would justify a biclausal analysis, and can be viewed as an uncontroversial complex predicate. And in French, there is a clear-cut distinction in this respect between faire-causatives and other causative periphrases such as laisser-causatives (permissive causation) or aider-causatives (assistive causation), which still have many properties typical for biclausal constructions.

\subsubsection{Others}

Although the details of the diachronic scenario are not well-understood, it is worth mentioning here that several West Mande languages have causative prefixes (Bambara lá-, etc.) cognate with an instrumental postposition originating from a locational noun whose original meaning can be reconstructed as 'place, side, opening'. 


\subsubsection{Non-canonical causatives, lexicalized causatives}

\subsubsection{Causative voice and underspecified transitivization}

In the languages that have a causative voice, it may happen that formally causative verb forms encode events that cannot be dissociated into a caused event and the action of a causer. This is the domain of the non-productive / lexicalized causative, with causative forms expressing meanings that are not fully predictable from the meaning of their components.

For example, in the languages that have a causative voice:

- 'bring' may be expressed as the causative form of 'come',

- 'spend (some time)' may be expressed as the causative form of 'pass',

- 'miss' may be expressed as the causative form of 'run', etc.

In such cases, the causative derivation must be analyzed as creating transitive verbs that have some semantic relationship with the intransitive verb from which they derive, but cannot be analyzed in terms of manipulation exerted by a causer on a causee.

It is interesting at this point to mention that there are also languages, in particular in the Oceanic language family, whose underived verbs are usually intransitive, and in which consequently most transitive verbs (if not all) result from a transitivizing derivation. In Ex. (9), the suffixes -va and -a are allomorphs of a multipurpose transitivizing suffix used in Fijian to create transitive verbs regardless of the precise semantic relationship between the base verb and the derived verb. Note that the constituent order in the transitive construction of Fijian is VPA.

(9) Boumaa Fijian (Dixon)

(9a) E-la'o a gone.

3SG-go DEF child

'The child is going.'

(9b) E-la'o-va a suka a gone.

3SG-go-TR DEF sugar DEF child

'The child is going to get sugar.'

(9c) E-lo'i a kaukamea

3SG-get_twisted DEF iron

'The iron is twisted.'

(9d) E-lo'i-a a kaukamea a gone.

3SG-get_twisted-TR DEF iron DEF child

'The child is twisting the iron.'

\subsubsection{Causative voice and perspectivization}

Some languages attest uses of causative voices that are not related to a change in the number of participants or in their role in the event, but to the selection of one of the participants as the A term of a transitive construction. In such cases, the participant selected as the A term in the construction of the causative form is more agentive than that selected as $A$ or $U$ in the 
construction of the base verb. For example, many languages express 'frigten' as the causative form of 'fear' - Ex. (10), or 'sell' as the causative form of 'buy' - Ex. (11).

(10) Mandinka (pers.doc.)

(10a) Díndínò kà sílá wùlôo lá.

child.D ICPL be_afraid dog.D POSTP

'The child is afraid of the dog.'

(10b) Wùlôo kà díndínò sílá-ndì

child.D ICPL child.D be_afraid-CAUS

'The dog frightens the child.'

(11) Tswana (pers.doc.)

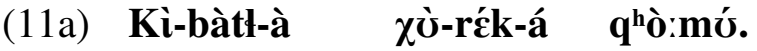

A.1SG-want-FV INF-buy-FV (CL9)cow

'I want to buy a cow.'

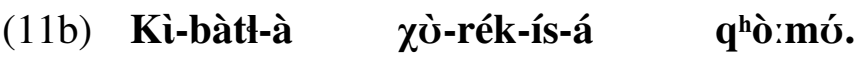

A.1SG-want-FV INF-buy-CAUS-FV (CL9)cow

'I want to sell a cow.'

\subsubsection{Causative voice encoding an increase in the agentivity of a participant}

Sometimes, a verb and its causative derivative lexify events that can be conceived as essentially identical, with the same number of participants, and differing only in the degree of agentivity of a participant, for example 'hear' and 'listen' - Ex. (12).

(12) Bambara (pers.doc.)

(12a) Sékù yé kìbàrô mén.

Sékou CPL news.D hear

'Sékou heard the news.'

(12b) Sékù yé cèkòròbâ lá-mén.

Sékou CPL oldman.D CAUS-hear

'Sékou listened to the oldman.'

Similarly, in East Uvean, -'i is a suffix typically used to add an argument to monovalent intransitive verbs, but in sio 'see' / sio-'i 'look at, observe', the base verb is semantically bivalent. In this case, the suffixation of -'i converts a verb with an extended intransitive construction into a transitive verb.

(13) East Uvean (Claire Moyse, pers.com.)

\section{(13a) Sio ia Paulo ki tona 'ohoaná. \\ see ABS Paulo OBL his wife \\ 'Paulo saw his wife.'}




$\begin{array}{llllll}\text { (13b) Sio-’i } & \text { e } & \text { Paulo ia } & \text { tona 'ohoaná. } \\ \text { see-TR } & \text { ERG } & \text { Paulo ABS } & \text { his } & \text { wife } \\ & \text { 'Paulo observed his wife.' } & & \end{array}$

\subsubsection{Syncretic causatives}

\subsubsection{The passive-causative syncretism}

In the languages in which morphological causatives from transitive verbs are possible, and in which the initial P (causee) may be demoted to oblique, there is an obvious similarity between the treatment of the initial $P$ in passive and causative construction - Ex. (14).

(14) French

(14a) Le directeur a fait écrire la lettre par la secrétaire. the manager has made write the letter by the secretary 'The manager had the letter written by the secretary.' (causative)

(14b) La lettre a été écrite par la secrétaire. the letter has been written by the secretary 'The letter was written by the secretary.' (passive)

In some languages, for example, Korean - Ex. (15), causative and passive constructions may coincide, not only in the treatment of the initial P, but also in their morphological marking.

(15) Korean (???)

(15a) Ai-ka pihayngki-lul po-ass-ta. child-SUBJ plane-ACC see- PAST-DECL

'The child saw the plane.'

(15b) Pihayngki-ka ai-eykey po-y-ess-ta.

plane-SUBJ child-by see-CAUS/PASS-PAST-DECL

'The plane was seen by the child.'

(15c) Emeni-ka ai-eykey pihayngki-lul po-y-ess-ta. mother-SUBJ child-by plane-ACC see-CAUS/PASS-PAST-DECL

'The mother made the child see the plane.'

A possible analysis is that the suffix $-\mathbf{y}$ - just encodes $\mathrm{A} / \mathrm{U}$ demotion, leaving open two possibilities: this demotion can be compensated, either by $\mathrm{P}$ promotion to $\mathrm{U}$ (passive), or by the introduction of a causer taking the A role.

The generally accepted diachronic explanation is that this syncretism results from an evolution of initially causative constructions lending themselves to morphologically unmarked reflexivization: a causative-from-transitive construction with a null $\mathrm{P}$ (something like 'Causer lets Causee V $\varnothing$ ') lended itself to a reflexive reading ('Causer ${ }_{i}$ lets Causee V Self ${ }^{\prime}$ '), which paved the way to the possibility of a plain passive reading.

This hypothesis is supported by the fact that, in French, the 'causative + reflexive' combination (se faire V) is not necessarily interpreted compositionally ('Causer ${ }_{i}$ makes 
Causee act on Self,'). For example, depending on the context, Il s'est fait tuer lit. 'He made himself kill' may have its literal interpretation 'He acted in such a way that he was killed', but most of the time, this construction is found in contexts in which it is clear that the intended meaning is simply 'He was killed'.

A causative-to-passive development involving the grammaticalization of a 'give' verb has been shown in a number of languages, among them Manchu-Tungusic (Nedjalkov 1993; Knott 1995) and Sinitic (e.g. Mandarin, Cantonese, Southern Min) (Hashimoto 1988; Cheng et al. 1999; Zhang 2000; Chin 2011; Yap \& Iwasaki 2003, 2007; Chappell \& Peyraube 2007).

\subsubsection{The antipassive-causative syncretism}

Soninke has an antipassive suffix -ndì ndí quasi-homonymous with the causative -ndí , and a similar homonymy (or quasi-homonymy) has been observed in other languages. A plausible explanation is that verbs 'do' have the potential to grammaticalize, not only as causative auxiliaries, but also as antipassive auxiliaries in antipassive periphrases, the subsequent univerbation of the periphrases in question resulting in an antipassive-causative syncretism.

Verbs with the meaning 'do, make' commonly occur in causative periphrases, and constitute a well-known source of causative markers. But such verbs are also very commonly involved in constructions that can be viewed as antipassive periphrases, although they are not commonly referred to as such, and the possibility that verbs with the meaning 'do, make' involved in such constructions grammaticalize as antipassive markers must be considered

For example, French has a causative construction in which faire 'do, make' combines with the infinitive of the verb expressing the caused event, as in Ex. (16a), but the use of faire with an event noun in $\mathrm{P}$ role is also a very common strategy to avoid specifying the $\mathrm{P}$ argument of transitive verbs with which the mere omission of the $\mathrm{P}$ phrase does not constitute the normal way to simply omit specifying $\mathrm{P}$, as in Ex. (16b).

(16) French

(16a) La femme a fait acheter le pain par son fils.

the woman has made buy the bread by her son

'The woman made her son buy the bread.'

(16b) La femme a fait des achats.

the woman has made some buying

'The woman did some shopping.'

In most Mande languages, the verbs expressing 'do, make' are reflexes of two Proto-Mande roots reconstructable as *ma and *ke , which quite obviously cannot be the source of the causative and antipassive suffixes of Soninke. But *ma and $* \mathbf{k} \boldsymbol{\varepsilon}$ are not the only roots reconstructable at least at Proto-West-Mande level with the meaning 'do, make'. In Mandinka, 'do' is commonly expressed as ké, but Mandinka also has a verb tîn tínnà túnnà 'cause', and this verb is probably cognate with Bozo Jenaama tîn (completive) tîná (incompletive) 'do'. Given the position of Mandinka and Bozo in the genealogical tree of Mande languages, a Proto-West-Mande root *tin 'do' can be reconstructed, and the hypothesis I propose is that the causative and antipassive suffixes of Soninke result from the grammaticalization of *tin 'do' in periphrases of the types illustrated in (16).

\subsubsection{The causative-applicative syncretism}

On the causative-applicative syncretism, see Section 3.2.7. 


\subsubsection{The causative-iterative syncretism}

Iterative is an aspectual notion that has no obvious link with valency-changing operations, but in Balant (Atlantic), the same morphological derivations are found with a causative function with some verbs, and with an iterative function with others. Moreover, in Kejom (Grassfields Bantu - Nguendjio 1989: 243), the Bantu causative suffix has become an iterative suffix, which suggests that the direction of change is from causative to iterative. The details of the scenario are however unclear.

\subsection{The applicative voice}

\subsubsection{Definition}

In the typological literature, the applicative is generally defined in terms of promotion of an oblique to P. However, a considerable proportion of the valency alternations designated as applicatives, in descriptions of individual languages as well as in the typological literature, do not meet this definition, which consequently must be revised.

The right definition of the applicative is as follows: applicative voices are morphologically coded valency alternations in which the argument structure of the morphologically more complex form differs from that of the less complex one by the addition of an applied argument encoded as the $\mathrm{P}$ term of a transitive construction, whereas the $\mathrm{A} / \mathrm{U}$ argument in the construction of the base verb is maintained as the A term of the applicative construction, . This definition leaves open the question of the treatment of the initial P, which shows crosslinguistic variation - see Section 3.2.4. It also leaves open the question of a possible alternative coding of the applied argument. In this respect, a distinction must be drawn between optional applicatives and obligatory applicatives.

\subsubsection{Optional applicatives}

In optional applicatives, the applied argument can be analyzed as a promoted oblique, since the participant it encodes also has the ability to be encoded as an oblique in the construction of the base verb - Ex. (17).

Wolof (Nouguier-Voisin 2002)

(17a) Mu séy ak doom-u nijaay-am.

3SG marry with child-CSTR uncle-3SG

'He married his uncle's daughter.'

(17b) Doom-u nijaay-am la séy-al.

child-CSTR uncle-3SG FOC.3SG marry-APPL

'He married HIS UNCLE'S DAUGHTER.'

This example illustrates a typical function of applicative voices: making participants normally encoded as obliques accessible to operations to which obliques do not have access. The point is that, in Wolof, comitative adjuncts cannot be focalized, whereas the core terms of the transitive construction can. Converting a comitative adjunct into the applied argument of an applicative construction is therefore a way around the problem. 
Some languages have mechanisms of adjunct promotion that suggest relaxing somewhat the definition of optional applicatives. Georgian and the other Kartvelian languages are a case in point. In Kartvelian languages, the so-called 'objective version' and 'locative version' are morphological modifications of the verb by which participants otherwise encoded as ordinary obliques are assigned dative coding. Crucially, Kartvelian languages are among the languages that have a syntactic function 'dative' whose properties are more similar to those of core arguments in the narrowest sense of this term than to those of ordinary obliques. A similar phenomenon can be observed in North West Caucasian languages (Circassian, Adyghe), and also in Kanuri (Saharan).

\subsubsection{Obligatory applicatives}

In obligatory applicatives, the participant encoded as the applied argument cannot feature in a monoclausal construction headed by the base verb. For example, in Tswana, the recipient of kwálá 'write' can only be encoded as the applied argument of the applicative derivative kwálélá; there is no possibility of encoding it as an oblique in the construction of the base verb.

(18a) Lơrátó ‘ó-tłáà-kwál-á lờ-kwâ:lò.

(CL1)Lorato A.CL1-FUT-write- FV CL11-letter

'Lorato will write a letter.'
Lòrátó
‘ú-tláà-kwál-ćl-á
${ }^{\downarrow}$ Kítsó
lò-kwâ:lj.
(CL1)Lorato A.CL1-FUT-write-APPL-FV
(CL1)Kitso
CL11-letter
'Lorato will write a letter to Kitso.'

Obligatory applicatives are particularly common among the languages of Subsaharan Africa (in particular, Bantu).

\subsubsection{The treatment of the initial $P$ in applicatives from transitives}

In languages in which trivalent verbs may have double-transitive constructions, the introduction of an applied argument in $\mathrm{P}$ role in the construction of applicatives derived from transitives does not necessitate the demotion of the initial P. This is illustrated by Ex. (18) above. Note however that the initial $\mathrm{P}$ and the applied argument, although equally encoded like the $\mathrm{P}$ term of the basis transitive construction, do not necessarily coincide in all the details of their behavior. In the particular case of Tswana, the crucial factor is their relative ranking in animacy hierarchy.

In languages that do not have double-transitive constructions, the introduction of the applied argument triggers the demotion of the initial P. In the applicative construction illustrated by Ex. (19b), the beneficiary is coded as the P term of a transitive construction, whereas the patient can only be expressed as an oblique in the Ablative case.

Yup'ik (Mithun 2000)
(19a)
Taqukaq tuqut-aa
bear kill-DECL.A.3SG.P.3SG
'The man is killing the bear.'
angute-m

\section{man-ERG}


(19b) Arnaq tuquy-ut-aa

angute-m taquka-mek.

woman kill-APPL-DECL.A.3SG.P.3SG man-ERG bear-ABL

'The man is killing the bear for the woman.'

\subsubsection{Semantically specialized vs. unspecified applicatives}

Applicative verb forms may specify the semantic role of the applied argument. For example, K'ichee' has applicative verb forms used exclusively to promote instrumental adjuncts - Ex. (20).

(20) K'ichee' (Campbell 2000)

(20a) X-Ø-u-paxiij ri b'o'j r-uuk' ab'aj ri ali. CPL-P.3SG-A.3SG-break DEF pot 3SG-with stone DEF girl 'The girl broke the pot with a stone.'

(20b)

$\begin{array}{lllllll}\text { Ab'aj } & \mathbf{x}-\varnothing-\mathbf{l}-\mathbf{p a x i b} \text { eej } & \text { r-eech } & \text { ri } & \text { b'o'j } & \text { ri } & \text { ali. } \\ \text { stone } & \text { CPL-P.3SG-A.3SG-break.APPL } & \text { 3SG-for } & \text { DEF } & \text { pot } & \text { DEF } & \text { girl } \\ \text { 'The girl broke the pot with a stone.' } & & & & & \end{array}$

Some languages may thus have a whole range of distinct applicative voices, each of them encoding the assignment of a particular semantic role to the applied argument - cf. Peterson (2007) on Hakka-Lai.

However, it may also happen that the only semantic indication provided by the use of an applicative verb form is that the construction includes a $\mathrm{P}$ term with a semantic role that cannot be assigned by the same verb in its non-applicative form. This means that the exact role of the applied argument must be inferred from contextual factors (either semantic or pragmatic). Such semantically unspecified applicatives are particularly common among Bantu languages. For example, Tswana has just one applicative marker, ${ }^{25}$ and Ex. (21) illustrates the variety of the semantic roles that can be fulfilled by the applied arguments it licenses.

(21) Tswana (pers.doc.)

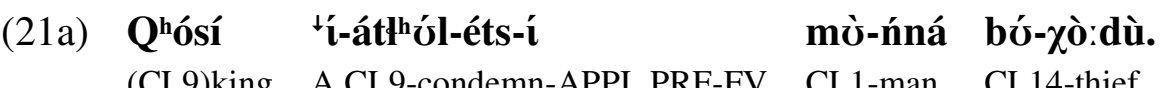

(CL9)king A.CL9-condemn-APPL.PRF-FV CL1-man CL14-thief

'The king condemned the man for theft.'

(21b) Q⿳ósí ' 'í-áth'ól-éts-í mò-ńná lò̀-sớ.

(CL9)king A.CL9-condemn-APPL.PRF-FV CL1-man CL11-death

'The king condemned the man to death.'

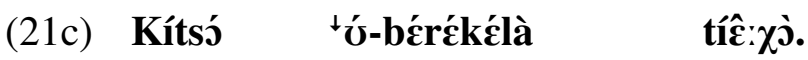

(CL1)Kitso A.CL16work-APPL-FV (CL9)delay

lit. 'Kitso is working for the delay.' ( $>$ in order to make up lost time)

\footnotetext{
${ }^{25}$ The suffix -ets- found in some of the sentences in Ex. (21) must be analyzed as the result of the fusion of the applicative suffix - $\mathbf{\varepsilon l -}$ with a 'palatal' feature encoding the TAM value 'perfect'.
} 


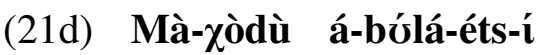

mò-ńná mà:-dí.

CL6-thief A.CL6-kill-APPL.PRF-FV CL1-man CL6-money

'The thieves killed the man for money.'

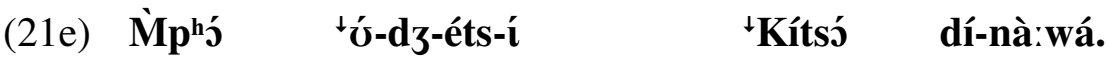

(CL1)Mpho A.CL1-eat-APPL.PRF-FV (CL1)Kitso CL10-bean

'Mpho ate the beans that were intended for Kitso.'

(21f) Kì-lèbò $\chi$-غ̀l-à Kìtsó mà:-dí.

A.1SG-thank-APPL-FV (CL1)Kisto CL6-money

'I am thanking Kitso for the money.'

(21g) Lò-síá 'ló-líl-ćl-à 林-â:jà.

CL11-baby A.CL11-cry-APPL-FV INF-suck

'The baby is crying [because he wants] to suck.'

(21h) Mờ-sádì jó ‘ú-ákélà rálìbíńttî:lì.

CL1-woman CL1.DEM A.CL1-tell_lies-APPL-FV (CL1)shopkeeper

'This woman is telling lies about the shopkeeper.'

(21i) Mà-bèlé ‘á-áláf-c̀l-w-à ts ${ }^{\text {h̀̀ }}$ pà.

CL6-sorghum A.CL6-treat-APPL-PASS-FV (CL9)tshupa

'The sorghum is treated against tshupa (a kind of worm).'

(21j) Mò-sádí ‘ú-bíl-éts-á b-àná dì-dzó.

CL1-woman A.CL1-call-APPL CL2-child CL8-food

'The woman is calling the children to eat.'

(21k) Mò-sádí ‘ú-bíl-éts-á b-àná Đâ:kà.

CL1-woman A.CL1-call-APPL CL2-child (CL9)doctor

'The woman is calling the doctor for the children.'

\section{(211) Kì-f-éts-í}

\section{jwánàké báisíkìlí mà:-dí.}

A.1SG-give-APPL.PRF-FV (CL1)child.1SG (CL9)bicycle CL6_money

'I gave money to my son for a bicycle.'

(21m) Kì-f-éts-í

$$
\text { màlớmé dí-qhòmó lì-tswâ:ì. }
$$

A.1SG-give-APPL.PRF-FV (CL1)uncle.1SG CL10-cow CL5-salt

'I gave salt to the cows for my uncle.'

(21n) Mò-sétsánà jó †ó-fós-éts-à bà-tsâ:dì.

CL1-girl CL1.DEM A.CL1-be_wrong-APPL-FV CL2-parent

'This girl behaves badly towards her parents.'

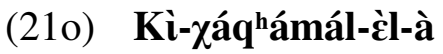
bò-pìứqhálì dzwá-nwàná:
jò.
A.1SG-be_impressed-APPL-FV CL14-courage CL14.GEN-CL1-child CL1.DEM
'I am impressed by the courage of this child.'

The following generalization can however be put forward: in the languages that have semantically specialized applicatives, benefactive applicatives (i.e. applicatives assigning the 
role of beneficiary to the applied argument) are particularly common; and in the languages that have semantically unspecified applicatives, the general rule seems to be that the role of beneficiary is the default choice in contexts that do not suggest another interpretation.

\subsubsection{Applicatives in diachrony}

\subsubsection{Adposition incorporation as a possible source of applicatives}

Adposition incorporation, illustrated by Ex. (22), seems to be a major source of applicatives. In (22a-b), the same argument is encoded either as an oblique in an intransitive construction, or as the P term of a transitive clause, and the verb in this transitive clause is a compound verb form incorporating the postposition used to mark the same argument when it is encoded as an oblique.

(22) Mandinka (pers.doc.)

\section{(22a) Bándíy-òo-lú bòyí-tà jùl-ôo-lú kây. bandit-D-PL fall-CPL merchant-D-PL on} 'The bandits attacked the merchants (lit. fell on the merchants).'

\section{(22b) Bándíy-òo-lú yè jùl-ôo-lú bòyì-n-káy. \\ bandit-D-PL CPL merchant-D-PL fall-EP-on \\ 'The bandits attacked the merchants.'}

In Mandinka, this phenomenon is sporadic, and similar things can also be observed sporadically in the languages of Europe (cf. French courir 'run (intr.)' / par-courir 'cover a distance (tr.)', where par- is cognate with the preposition par 'by, through'), but there is no difficulty in imagining that its systematization at some stage in the history of a language might lead to the emergence of a productive applicative voice.

\subsubsection{Applicative periphrases}

Applicative periphrases are biverbal constructions functionally comparable to monoverbal constructions headed by applicative verb forms. One of the verbs determines the type of event encoded by the applicative periphrasis, and the argument structure of the applicative periphrasis is the argument structure of the lexical verb augmented by an additional participant. The other verb acts as a valency operator whose contribution to the construction is limited to licensing the expression of an additional participant fulfilling a given semantic role in the event encoded by the lexical verb, without modifying the morphosyntactic treatment of the other participants.

Applicative periphrases licensing beneficiaries are particularly common, and 'give' is particularly common in the function of valency operator in such periphrases.

(23) Yoruba - Rowlands (1969:83), Abraham (1962:348)

\section{(23a) Rà á fún mi. buy 3SG give 1SG \\ 'Buy it for me.'}


(23b) Ó jíṣẹ fún mi.

3SG go_on_an_errand give 1SG

'He went on an errand for me.'

(24) Ecuadorian Highland Spanish - Haboud (1994)

(24a) Me dio cocinando.

DAT.1SG give.CPL.1SG cook.GER

'(S)he cooked for/instead of me.'

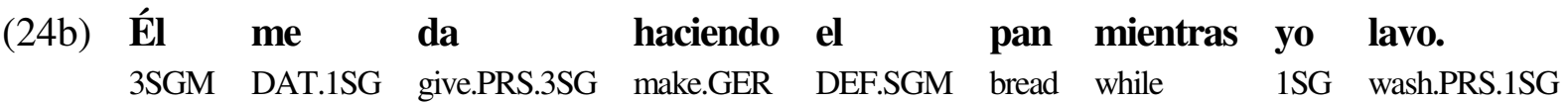
'He bakes the bread for/instead of me while I wash.'

(24c) Él me dio dando el cuchillo a la 3SGM DAT.1SG give.CPL.1SG give.GER DEF.SGM knife to DEF.SGF María 'He gave the knife to María instead of me.'

According to Peterson (2007), in Hakha Lai (Tibeto-Burman), the benefactive/malefactive applicative suffix -piak, seen in (25a), closely resembles the 'give' verb seen in (25b), "reflecting a grammaticalization path already well established for this verb".

(25) Hakha Lai - Peterson (2007:131-2)

\section{(25a) Tsewman=ni? door-?a? ?a-ka-kal-piak. \\ Tsewmang=ERG market-ALL/LOC A.3SG-P1SG-go-BEN \\ 'Tsewmang went to the market for me.'}

(25b) Tsewman=ni? Paar-saa Pa-ka-peek.

Tsewmang=ERG chicken-meat A.3SG-P.1SG-give

'Tsewmang gave me chicken meat.'

Interestingly, Old Nubian had "dative" periphrases involving the verbs den- 'give (to me/us)' and $\mathbf{t} \overline{\mathbf{r}}$ - 'give (to you/him/them). Not surprisingly, modern Nubian languages have benefactive applicative markers resulting from the grammaticalization of these verbs, for example -dèenand -tir- in Kunuz Nubian - Ex. (26).

(26) Kunuz Nubian - Abdel-Hafiz (1988:231)

Id ay-gi baab-ki alle-deen-s-u.

man 1SG-ACC door-ACC repair-BEN-PST-A.3SG

'The man repaired the door for me.'

Similar facts can be observed in many languages all around the world, which leads to the conclusion that the grammaticalization of verbs such as 'give' in applicative periphrases is a major source of applicative markers. 


\subsubsection{The causative-applicative syncretism}

Some languages have a single morphological operation yielding derived verbs that can be equally found in causative and applicative constructions.

A first possible explanation is that verbs 'give' are very commonly found in applicative periphrases, but can also be found in causative periphrases ('give someone something to do' > make someone do something'). Consequently, a syncretic causative-applicative marker may result from the grammaticalization of 'give' in both causative and applicative periphrases in the same language.

Another possible explanation of this syncretism is that some events may be ambiguous between the kind of conceptualization reflected in causative constructions, and that reflected in applicative constructions. For example, languages may have instrumental applicatives, in which the applied argument is assigned the role of instrument, but many Bantu languages do not use their semantically under-specified applicative voice to encode instruments as applied arguments, and encode instruments by means of causative verb forms. In the languages in question, the semantic role of instrument is assigned in constructions that, literally, are something like 'Agent makes Instrument act on Patient'. And even in a Bantu language like Tswana, in which instruments are standardly encoded as prepositional phrases, without any voice-marker added to the verb form, this kind of construction is marginally possible - Ex. (27).

(27) Tswana

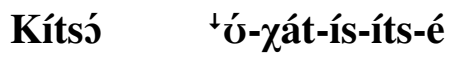
mó-thò m̀-mótớròkâ:rà.
(CL1)Kitso A.CL1-crush-CAUS-PRF-FV
CL1-person CL3-car
'Kitso drove over a person with his car.'
lit. 'Kitso let the car crush a person.'

Assistive causation can also be viewed as blurring the limit between causative and applicative - See Ex. (4) above.

Cf. also, in this connection, Section 3.1.7.1 on causativization and underspecified transitivization.

\subsubsection{Non-canonical applicatives: the case of Tswana}

Bantu languages in general provide many interesting data about non-canonical applicatives. As a rule, Bantu applicatives in their canonical use are obligatory and semantically underspecified applicatives - see Ex. (21) above.

\subsubsection{Applicative derivation and the promotion of instrumental adjuncts}

In Tswana, participants usually treated in the construction of the non-applicative form of a verb as instrumental adjuncts, i.e. represented by a prepositional phrase headed by the instrumental preposition ká, cannot be encoded as applied argumentss. By contrast, if no agent is mentioned, they can be encoded as the A term in the construction of an applicative verb form - Ex. (28). 


$\begin{array}{llll}\text { Ú-nè } & \text { à-àpàj-à } & \text { q }^{\text {háká }} & \text { á-fàbà } \\ \text { A.CL1-AUX } & \text { A.CL1.SEQ-cook-FV } & \text { (CL9)guinea-fowl } & \text { A.CL1.SEQ-flavour-fin }\end{array}$

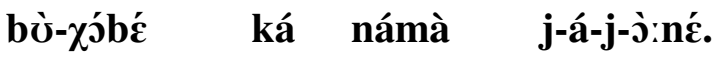

CL14-porridge with (CL9)flesh 9-GEN-9-CL9.PRO

'He cooked the guinea-fowl and flavoured the porridge with its flesh'

(28b)
Nàmà
í-Jáb-ćl-à
bò- $\chi \hat{\mathbf{s}}: \mathbf{b} \dot{\varepsilon}$.
(CL9)meat A.CL9-flavour-APPL-FV
CL14-porridge

'Meat is used to flavour the porridge.'

This use of applicative derivation is clearly non-canonical, since in (28b), the A argument of the base verb is left unexpressed (and interpreted as non-specific), and the instrumental adjunct is not promoted to the role of $\mathrm{P}$, but to that of $\mathrm{A}$. In other words, this particular use of the Tswana applicative meets the definition of an oblique voice (see Section 2.1.6) rather than that of an applicative voice.

\subsubsection{Applicative derivation and the semantic role of locative phrases: general remarks}

The use of Tswana applicative verb forms examined in this section has in common with their canonical use that it licenses the presence of a term with a particular semantic role in the construction of the verb. It however departs from the canonical use in that the term in question is not encoded as a $\mathrm{P}$, but as a locative phrase showing no evidence of a syntactic status different from that of ordinary obliques: it cannot be cross-referenced by a $\mathrm{P}$ index, or converted into the $\mathrm{U}$ term of a passive construction, and more generally, seems to have exactly the same syntactic behavior as locative phrases accompanying non-derived verbs.

In Tswana, locative phrases are not marked for the location vs. source vs. destination distinction, and their semantic role is regulated in the following way:

(a) any Tswana verb can combine with a locative phrase expressing the localization of the event, or of a participant in the event, as in Ex. (29a);

(b) in combination with some movement verbs, locative phrases are assigned the semantic role of source, as in Ex. (29b);

(c) with some other movement verbs, locative phrases are assigned the role of destination, as in Ex. (29c).

(29) Tswana (Bantu - pers.doc.)

(29a) Kítsó 'ớ-bérék-à kó Kà:jé.

(CL1)Kitso A.CL1-travailler-FV LOC (CL1)Kanye

'Kitso is working in Kanye.' 


$\begin{array}{llll}\text { Kítsó } & \text { 'ó-húdú } \chi \text {-íl-è } & \text { kó } & \text { Kà:jé. } \\ \text { (CL1)Kitso } & \text { A.CL1-move-PRF-FV } & \text { LOC } & \text { (CL1)Kanye } \\ \text { 'Kitso moved from Kanye.' } & & \end{array}$

Interestingly, applicative derivation may modify the semantic roles that verbs assign to locative phrases. Three cases must be distinguished.

\subsubsection{Verbs of movement that cannot assign the role of source or destination}

Tábóxá 'run' is semantically a verb of movement, but in its non-derived form, it has no semantic role to assign to a locative phrase, which means that the only available interpretation for a locative term in the construction of tábóxá in its non-derived form is the default interpretation of location of the event. By contrast, the applicative form tábóxźlà can assign the role of destination - Ex. (30). The same behaviour is observed with àkòfà 'hurry', fơfà 'fly', fità 'pass', etc.

(30) Tswana (Bantu - pers.doc.)

(30a) Kì-tłàà-tábó $\chi$-à kó tsìlê:-ỳ.

A.1SG-FUT-run-FV LOC (CL9)road-LOC

'I will run on the road.'

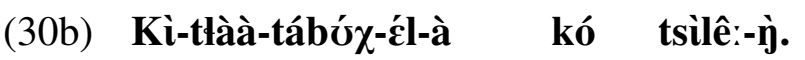

A.1SG-FUT-run-APPL-FV LOC (CL9)road-LOC

'I will run to the road.' ${ }^{26}$

In this particular case (but not in those examined in the following sections), a canonical applicative construction, with tsilà 'road' encoded as the $\mathrm{P}$ term of a transitive construction, would be possible with the same meaning:

\section{(30c) Kì-tłàà-tábó $\chi$-ćl-à tsì:là. \\ A.1SG-FUT-run-APPL-FV (CL9)road \\ 'I will run to the road.'}

There is an obvious relationship with the fact that, in Tswana, non-derived verbs of movement that assign the role of destination (such as yà 'go') have an alternative construction in which the destination is encoded as the $\mathrm{P}$ term of a transitive construction.

\subsubsection{Verbs of movement that can assign the role of source}

With verbs of movement whose non-derived form assigns the role of source to locative complements, the applicative form has the same formal valency as the non-derived form, but assigns to its locative complement the role of destination, as illustrated in Ex. (31) by húdúxá 'change one's residence'. Note that, in order to express 'move from A to B', Tswana must use successively the non-derived form of húdúxá introducing the source of movement, and the applicative form of the same verb introducing the destination - Ex. (31c). More generally, Tswana, like many languages of Subsaharan Africa, cannot specify the source and the destination of a movement within the frame of a monoverbal construction.

\footnotetext{
${ }^{26}$ See section 3.2.8.6 for another possible interpretation of this sentence.
} 
Tswana (Bantu - pers.doc.)

(31a) Kì-tłàà-húdúx-à kó Kà:jé.

A.1SG-FUT-move-FV LOC (CL1)Kanye

'I will move from Kanye.'

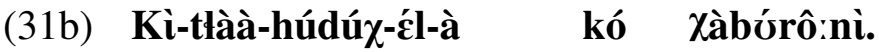

A.1SG-FUT-move-APPL-FV LOC (CL1)Gaborone

'I will move to Gaborone.'

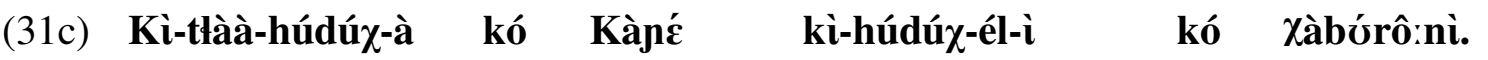

A.1SG-FUT-move-FV LOC (CL1)Kanye A.1SG-move-APPL-FV LOC (CL1)Gaborone

'I will move from Kanye to Gaborone.'

\subsubsection{Verbs that do not express movement}

Verbs that do not express movement freely combine with locatives expressing the location of the event or of a participant, as already illustrated by Ex. (30a) above, but the use of the applicative form is obligatory to license the presence of a locative whose semantic role departs more or less form the mere indication of a location. For example, Tswana syntax is sensitive to the difference in the semantic role of in the yard and in the big pot in She is cooking porridge in the yard / She is cooking porridge in the big pot. In the first sentence, in the yard expresses nothing more than the location of the event, whereas in the event represented by the second sentence, the pot contains the porridge, which justifies to code it as a locative, but it also plays the role of an instrument in the cooking event. In other words, the spatial relationship between the pot and the porridge is not accidental; it follows from the role they play in the cooking event. Consequently, in the Tswana equivalent of She is cooking porridge in the yard, the verb cook can remain in its non-derived form, whereas in the equivalent of She is cooking the porridge in the big pot, the verb cook must be in the same applicative form as when, for example, a noun phrase referring to a beneficiary is added to the construction of this verb, and the applicative derivation must be reiterated in order to make it possible to mention both the vessel used to cook the porridge and the beneficiary of the cooking event - Ex. (32).

(32) Tswana (Bantu - pers.doc.)

(32a) Lòrátó ‘ó-tláá-àpày-à mò-tò:xó.

(CL1)Lorato A.CL1-FUT-cook-FV CL3-porridge

'Lorato will cook the porridge.'
Lòrátó
‘ú-tłáá-àpè-èl-à
b-àná

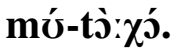
(CL1)Lorato A.CL1-FUT-cook-APPL-FV CL2-child
CL3-porridge
'Lorato will cook the porridge for the children.' 


$\begin{array}{lll}\text { Lòrátó } & \downarrow \text { 'ó-tłáá-àpè-c̀l-à } & \text { mò-tò̀ó } \\ \text { (CL1)Lorato } & \text { A.CL1-FUT-cook-APPL-FV } & \text { CL3-porridge }\end{array}$

mó pìtsé-ì é 'tỗ:nà.

LOC (CL9)pot-LOC (CL9)LK (CL9)big

'Lorato will cook the porridge in the big pot.'

(32d)
Lòrátó
‘ó-tłáá-àpè-èl-èl-à
b-àná
mớ-t’̀ $\chi \mathbf{j}^{\prime}$
(CL1)Lorato
A.CL1-FUT-cook-APPL-APPL-FV
CL2-child
CL3-porridge

$\begin{array}{llll}\text { mó } & \text { pìtsé-ỳ } & \text { é } & { }^{t} \text { tỗ:nà. } \\ \text { LOC } & \text { (CL9)pot-LOC } & \text { CL9.LK } & \text { (CL9)big }\end{array}$

'Lorato will cook the porridge for the children in the big pot.'

Ex. (33) provides additional illustrations of the obligatory use of applicative forms of verbs that do not express movement combined with a locative phrase referring to a participant whose role implies a spatial relationship with another participant, or more generally, a locative phrase whose semantic role is not limited to mere location.

(33) Tswana (Bantu - pers.doc.)

(33a) Dì-qhòmó 'dí́-nw-દ́l-à mó mò-kórô:-ìn.

CL8/10-cow A.CL8/10-drink-APPL-FV LOC CL3-mokoro-LOC

'Cows drink from a mokoro.' (a tree trunk carved in the shape of a canoe)

(33b) Rí-kwál-él-à mó pámpírî:-̀̀.

A.1PL-write-APPL-FV LOC (CL9)paper-LOC

'We write on paper.'

Instruments usually represented by locatives in this type of construction by virtue of the spatial relationship they necessarily have with another participant share with more typical instruments (encoded by means of the instrumental preposition ká) the possibility of being encoded also as the A term in the construction of applicative verb forms, as illustrated by Ex. (34), to be compared with Ex. (28) above.

(34) Tswana (Bantu - pers.doc.)
(34a)
$\begin{array}{ll}\text { Mò-sádí } & \text { ó-nè } \\ \text { CL1-woman } & \text { A.CL1-AUX }\end{array}$
à-tshò̀l-čl-à

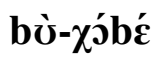
CL1-woman A.CL1-AUX A.CL1-dish_out-APPL-FV CL14-porridge

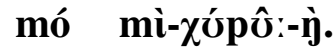

LOC CL4-wooden_bowl-LOC

'The woman dished out the porridge into the wooden bowls.'

(34b)

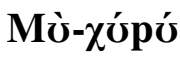

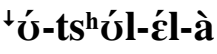
bò- $\chi \hat{\mathbf{s}}: \mathbf{b} \grave{\varepsilon}$.
CL3-wooden_bowl CL3-dish_out-APPL-FV CL14-porridge
'The wooden bowl is used to dish out porridge.'

Similarly, 'the mokoro used to water cows' is mòkórò ó ‘ónwélàń díq'òmó lit. 'the mokoro that drinks.APPL cows', 'coffee-cup' is kópì é 'ínwélàń ' 'kófî lit. 'the cup that drinks.APPL 
coffee', 'room used to do the cooking' is ǹtlò é t'iápéc̀làń lit. 'the room that cooks.APPL', etc.

\subsubsection{Applicative derivation and the focalization of locative phrases}

In constructions including a locative phrase that does not necessarily trigger the use of the applicative form of the verb, the applicative form of the verb can be used to focalize the locative phrase, without any change in the construction or in the semantic roles. Interestingly, this use of the applicative derivation is strictly limited to constructions including a locative phrase whose semantic role does not trigger the use of the applicative form of the verb. It constitutes an alternative to cleft constructions, which are in Tswana the standard way to express focalization.

For example, in Ex. (30) above, repeated here as (35), the second sentence is in fact ambiguous between an interpretation according to which the applicative suffix codes a change in the role-assigning properties of tábớxá ('I will run to the road (not on the road)'), and another interpretation according to which the applicative suffix codes the focalization of a locative phrase without modifying its semantic role of location.

Tswana (Bantu - pers.doc.)

(35a) Kì-tłàà-tábớ $\chi$-à kó tsìlê:-̀̀.

A.1SG-FUT-run-FV LOC (CL9)road-LOC

'I will run on the road.'

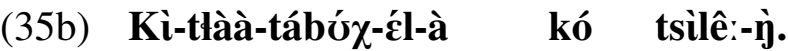

A.1SG-FUT-run-APPL-FV LOC (CL9)road-LOC

(a) 'I will run to the road.'

(b) 'I will run ON THE ROAD (and nowhere else).'

This ambiguity is general with verbs of movement that must be used in the applicative form in order to be able to assign the role of destination to locative phrases: the same applicative form can always be also used to focalize a locative phrase in the role of location. But with verbs whose applicative form cannot be used to assign the role of destination to a locative phrase that otherwise would be interpreted as expressing location, the focalization of a locative phrase is the only possible function of an applicative verb form used in a construction identical to that of the non-applicative form of the same verb. Ex. (36) illustrates applicative forms whose only possible interpretation is that they focalize a locative phrase expressing location. In Tswana, contrary to what could suggest the use of the applicative derivation with verbs such as tábóxá, a directional interpretation of the applicative form of verbs that do not express movement is not possible.

(36) Tswana (Bantu - pers.doc.)

(36a) Lòrátó ‘ú-ápé-c̀l-à mó dzáràtê:-ì.

(CL1)Lorato A.CL1-cook-APPL-FV LOC (CL9)yard-LOC

'Lorato does the cooking IN THE YARD.'

(36b) Mò-ńnà w-á-mí ‘ó-sw-éts-ì kó mò-ráfô:-ì.

CL1-man CL1-GEN-1SG A.CL1-die-APPL.PRF-FV LOC CL3-mine-LOC

'My husband died IN THE MINE.' 
(36c) Kì-tsál-étsw-ì

kó Kà:jé.

A.1SG-give_birth-APPL.PRF.PASS-FV LOC Kanye

'I was born IN KANYE.'

(36d)

$\begin{array}{llll}\text { B-àná } & \text { b-á-tlàdí } & \text { 'bá-án-ćl-á } & \text { ló-ràtlê:-ì. } \\ \text { CL2-child } & \text { CL2.GEN-(CL9)thunder } & \text { A.CL1-suck-APPL-FV } & \text { CL11-noise-LOC } \\ \text { 'The sons of the thunder suck IN THE NOISE.' (proverb) }\end{array}$

\subsubsection{Discussion}

In Tswana (and presumably in many other Bantu languages, although the relevant information is available for some Bantu languages only), the same applicative marker occurs both in contexts in which it fulfills valency-changing functions without any particular discursive implication, and in contexts in which it has a purely discursive function, without triggering any change in valency. In the present state of Tswana, it seems difficult to propose a unified definition of the syntactic and pragmatic uses of this marker. It is particularly puzzling that the focalizing function of the applicative marker is strictly limited to locative phrases. There is however a possible connection between this duality in the uses of the applicative verb forms of Tswana and several other syntactic phenomena.

In Tswana, $\mathrm{P}$ phrases precede obliques, and in double-transitive constructions, $\mathrm{P}$ phrases relatively higher on Animacy Hierarchy obligatorily precede those that stand lower. In general, violations of these constraints result in ungrammaticality, with however an interesting exception: $\mathrm{P}$ phrases and oblique phrases can be questioned in situ, but alternatively, interrogative pronouns and adverbs can also be placed immediately after the verb, even if this contradicts the principles that govern the linear order of $\mathrm{P}$ phrases and oblique phrases in the corresponding declarative clauses - Ex. (37).

Tswana (Bantu - pers.doc.)
Kì-bón-í
mờ-ńnà j-ó
máàbâ:nì.
A.1SG-see.PRF-FV
CL1-man
CL1-DEM yesterday
'I saw this man yesterday.'

(37b) * Kì-bón-í máàbání mò-ńnà: j-ó.

ó-bón-ì líń mò-ńnà: j-ó?
A.2SG-see.PRF-FV when CL1-man CL1-DEM
'When did you see this man?'

This variation in the constituent order in clauses including interrogative words has no semantic correlate, but it is reasonable to think that, given the inherent focality of interrogative words, it reveals a dual status of the immediate postverbal position. This position is quite obviously the position normally assigned to NP's syntactically assimilated to the patient of prototypical transitive verbs, but its behavior in interrogative sentences suggests to recognize it also as (the vestige of) an immediate-after-verb focus position: in limited conditions, a constraint assigning the immediate postverbal position to a focalized constituent overrides the constraint assigning it to a $\mathrm{P}$ phrase standing relatively high on animacy hierarchy. 
This possibility of using the immediate-after-verb position for particular discursive purposes rather than assigning it automatically to a particular argument is confirmed by the existence of the inversion construction illustrated in (38). ${ }^{27}$ Interestingly, interrogative words cannot occupy the canonical $U$ position, even if they fulfill a semantic role normally assigned in this position, but can occur as inverted U's - Ex. (38c-d).

(38) Tswana (Bantu - pers.doc.)

(38a) Bà-símàní ' 'bá-tláà-bî:n-à.

CL2-boy A.CL2-FUT-dance-FV

'The boys will dance.'

(38b) Xú-tláà-bín-á bà-símà:ní.

A.CL17-FUT-dance-FV CL2-boy

'There will be a dance performed by (the) boys.' (lit. 'There will dance boys.')

(38c) Xó́-tláà-bín-á

'bó-mâ:ỳ̀?

A.CL17-FUT-dance-FV CL2-who

'Which persons will dance?' (lit. 'There will dance which persons?')

(38d) *Bó-máń ' ‘bá-tláà-bî:n-à?

CL2-who A.CL2-FUT-dance-FV

The function of this inversion construction with an expletive class 17 index in the verb form is $\mathrm{U}$ detopicalization. This is a so-called 'presentational' construction encoding that the argument which otherwise would be encoded as a preverbal U refers to new information. In Tswana, interrogative words cannot function as canonical U's, because of a general ban on non-topical A's or U's, but the inversion construction can be used to get round this constraint.

In this connection, it is also interesting to observe that a handful of Tswana verb are attested with another inversion construction, clearly residual in Tswana (but productive in other Bantu languages - see Section 4.8), whereby the $U$ term of the non-inverted construction moves to immediate-after-verb position, and a phrase referring to a participant encoded as a locative oblique in the non-inverted construction is encoded as the A term of a transitive construction.

(39) Tswana (Bantu - pers.doc.)

(39a) Mà-dí á-tsw-à mó ǹt $\mathbf{n}^{\mathrm{h}} \hat{\mathbf{o}}_{\text {:-ỳj}}$.

CL6-blood A.CL6-come from-FV in (CL9)wound-LOC

'The blood is flowing out from the wound.'

(39b)

$\begin{array}{lll}\text { Ǹth }^{\text {b́ }} & \text { 'í-tsw-á } & \text { mà:-dí. } \\ \text { (CL9)wound } & \text { A.CL9-come_from-FV } & \text { CL6-blood }\end{array}$

'The wound is bleeding.' lit. 'The wound flows out blood.'

\footnotetext{
${ }^{27}$ For a detailed analysis of this construction, see Creissels (2011).
} 
Tswana (Bantu - pers.doc.)

(40a)

$\begin{array}{lll}\text { Dàkà } & \text { j-á-sì-tswáná } & \text { 'í-á } \chi \text {-íl-è } \\ \text { (CL9)doctor } & \text { CL9-GEN-CL7-Tswana } & \text { A.CL9-settle-PRF-FV }\end{array}$

mó mó-tsì-ì lí-bâ:-thò.

in CL3-village-LOC with-CL2-person

'The traditional doctor lives in the village with the people.'

$(40 \mathrm{~b})$

$\begin{array}{llll}\text { Lì-fátshì } & \text { l-é } & { }^{\dagger} \text { lí-á } \boldsymbol{\chi} \text {-íl-é } & \text { Bà-sâ:rwà. } \\ \text { CL5-territory } & \text { CL5-dem } & \text { A.CL5-settle-PRF-FV } & \text { CL2-San }\end{array}$

'This territory is inhabited by San.' lit. 'This territory settles San.'

Here again, as reflected in the translations, $\mathrm{U}$ demotion involving movement to immediateafter-verb position is motivated by a change in information structure.

To conclude, applicative derivation and placement of constituents in immediate-after-verb position in constructions that trigger no morphological marking on the verb share an important particularity: both are crucially involved in the particular way the general notion of $\mathrm{P}$ is codified in Tswana morphosyntax, but both have uses that cannot be described adequately with reference to argument structure only, and necessitate taking into account information structure. A clue to this puzzle must probably be sought in an ancient state of Bantu syntax in which constituent order was less grammaticalized, more flexible and more sensitive to variations in information structure than in modern Bantu languages. Very general principles governing the most basic aspects of the syntactic organization of languages seem to be at play here:

(a) as a core term of transitive clauses, $\mathrm{P}$ shares with $\mathrm{A}$ the property of representing a participant in the event that has intrinsically a certain degree of salience;

(b) as opposed to A, which typically represents the initiator of the event, and consequently tends to be taken as the initial term from the point of view of communicative dynamism too, $\mathrm{P}$ is characterized by a lesser degree of topicality. (cf. Dalrymple \& Nikolaeva 2011)

However, before trying to evaluate the possible diachronic scenarios (the one according to which the use of applicative derivation as a focalizing device would be an innovation of some Bantu languages, as suggested by current Bantu reconstructions, and the one according to which a suffix originally involved in the expression of information structure got syntacticized to a considerable extent), it would be crucial to gather more data on the focalizing use of applicative derivation across Bantu language family, and possibly also in other language families having applicatives.

\subsection{Some rare types of valency increasing derivations}

\subsubsection{The possessive voice of Wolof}

Wolof (Atlantic) has a particularly rich and original system of valency-changing derivations, described in detail by Nouguier-Voisin $(2002,2011)$. This system includes a suffix -le encoding the following type of valency change: intransitive verbs become transitive, their $U$ argument is demoted to $\mathrm{P}$, and the A term in the construction of the derived verb represents a possessor. To put it somewhat differently, an additional argument with the semantic role of 
possessor is introduced in A position, whereas the $\mathrm{P}$ term in the construction of the derived possessive verb cumulates the role of possessee and the semantic role assigned to the $U$ argument of the base verb. The resulting construction can be viewed as a particular variety of morphologically marked external possession construction.

(41) Wolof (Atlantic - Voisin-Nouguier 2002: 383)

(41a) Woto bi gaaw na.

car CLb-D be_fast PRF.3SG

'The car is fast.'

(41b) Sàmba gaaw-le na woto.

Samba be_fast-POSS PRF.3SG car

'Samba has a fast car.'

To summarize, the derived possessive verbs of Wolof occur in a transitive construction A Vle $\mathrm{P}$ that can be glossed as ' $\mathrm{A}$ is the possessor of a $\mathrm{P}$ that has the property expressed by $\mathrm{V}$ '.

This derivation has a valency-increasing effect, which however differs from that induced by causative or applicative markers.

The productivity of the possessive suffix -le is limited to a class of intransitive verbs assigning non-agentive roles to their $U$ argument, such as dee 'die' or réer 'get lost'. It is particularly common with verbs expressing meanings that, cross-linguistically, tend to be encoded by adjectives, such as rafet 'be beautiful', baax 'be good'.

(42) Wolof (Atlantic - Voisin-Nouguier 2010: 384)

(42a) Baax-le na ay téeré.

be_good-POSS PRF.3SG INDEF.PL book

'He has good books.'

(42b) Góor g-ii, moo dee-le jabar.

man CLg-DEM SFOC.3SG die-POSS wife

'This man's wife is dead.'

(French: 'Cet homme a sa femme qui est morte')

(42c) Maa réer-le xar.

SFOC.1SG be_lost-POSS sheep

'My sheep got lost.'

(French: 'J'ai un mouton de perdu')

Typologically, it is worth noting that other languages have semantically comparable derivations: the 'adversative passive' in Japanese - Ex. (43), and the combination of applicative and passive derivation in Bantu languages - Ex. (44). What is however particular in the case of Wolof is the use of a specific suffix that does not lend itself to any decomposition within the frame of a synchronic analysis. ${ }^{28}$

\footnotetext{
${ }^{28}$ See Nouguier (2002) for the discussion of a possible diachronic analysis of possessive -le.
} 
(43) Japanese (Martin, 1956:400-401)

Watakushi-wa hon-o tor-are-ta.

1SG-TOP book-ACC take-PASS-PST

'I had my book taken.' (lit. 'I was taken a book.')

(44) Tswana (Bantu - pers.doc.)

Ba-tho ba-š-el-w-a ke ma-ntlo.

CL2-person A.CL2-burn-APPL-PASS-FV by CL6-house

'People's houses are burning.' (lit. 'People are burnt-for by houses.')

\subsubsection{Others}

Some rare types of valency-increasing mechanisms resulting probably from the univerbation of various types of complex predicates are attested in Eskimo languages. In Ex. (45), the suffix -yuk- (glossed 'believe', although it is not attested independently as a verb) encodes the addition of a phrase representing a 'believer' in A role. If the base verb is intransitive, its $\mathrm{U}$ argument is encoded as $\mathrm{P}$ in the construction of the derived verb. If it is transitive, its $\mathrm{A}$ argument is demoted to oblique (marked by the Allative case).

(45) Yup'ik (Mithun 2000)

(45a) Angun ayag-tuq.

man go-DECL.U.3SG

'The man went away.'

(45b) Nuk'a-m angun ayag-yuk-aa.

Nuk'aq-ERG man go-believe-DECL.A.3SG.P.3SG

'Nuk'aq believes that the man went away.'

(45c) Angute-m kiput-aa

kelipaq.

man-ERG buy-DECL.A.3SG.P.3SG bread

'The man bought the bread.'

(45d) Nuk'am angut-mun kipu-cuk-aa kelipaq.

Nuk'aq-ERG man-ALL buy-believe-DECL.A.3SG.P.3SG bread

'Nuk'aq believes that the man bought the bread.'

\subsection{Voice combinations}

\subsubsection{Combinations of voices with a compositional meaning}

Ex. (46) shows that Tswana verb forms already including voice markers may take further voice markers with a fully compositional meaning. 
(46) Tswana (pers.doc.)

(46a) Kì-tłàà-kwál-á lò-kwâ:lj̀

A.1SG-FUT-write-FV CL11-letter

'I will write a letter.'

(46b) Lò-kwáló 'lớ-tłáà-kwâ:l-w-à.

CL11-letter A.CL11-FUT-write-PASS-FV

'The letter will be written.'

(46c) Kì-tlàà-kwál-ćl-á 产phó lò-kwâ:lò.

A.1SG-FUT-write-APPL-FV (CL1)Mpho CL11-letter

'I will write a letter to Mpho.'

(46d) Kítsó ‘ó-tláá-ì-kwád-ís-á lò-kwâ:lò.

(CL1)kitso A.CL1-FUT-P.1SG-write-CAUS-FV CL11-letter

'Kitso will make me write a letter.'

(46e) Kítsó ‘ó-tláà-kwád-ís-éts-à $\quad$ Mppó lơ-kwâ:lj̀.

(CL1)kitso A.CL1-FUT-write-CAUS-APPL-FV (CL1)Mpho CL11-letter

'Kitso will make someone write a letter to Mpho.'

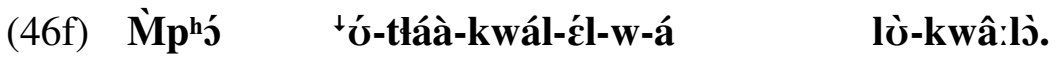

(CL1)Mpho A.CL1-FUT-write-APPL-PASS-FV CL11-letter

'A letter will be written to Mpho.'

(46g) Kì-tłàà-kwád-íS-íw-à 吕-kwâ:lò.

A.1SG-FUT-write-CAUS-PASS-FV CL11-letter

'Someone will make me write a letter.'

$\begin{array}{llll}\text { (46h) } & \text { M̀ph́ } & { }^{\mathrm{h}} \mathbf{o} \text {-tláà-kwád-ís-éd-ìw-à } & \text { lò-kwâ:lj. } \\ & \text { (CL1)Mpho } & \text { A.CL1-FUT-write-CAUS-APPL-PASS-FV } & \text { CL11-letter }\end{array}$

'Someone will make someone else write a letter to Mpho.'

This phenomenon is not general, and many languages have arbitrary restrictions on the stacking of voice markers. For example, French and Italian have very similar passive and causative constructions, but passivization of causative constructions is ungrammatical in French, whereas it is acceptable in Italian (as in Fummo fatti scendere, lit. 'We were made go down').

In this connection, it is interesting to observe that, when working with consultants, one often gets the impression that speakers may feel uncomfortable processing verb forms including two or more voice markers. And even if they have no problem with the verb form itself, they may have problems with constructions in which all the participants it implies are overtly expressed.

\subsubsection{Combinations of voices with non-compositional interpretations}

Another interesting phenomenon is that, depending on the individual languages, some combinations of voices may lend themselves to non-compositional interpretations. Here are some examples: 
- In French, 'reflexive + causative' (compositional meaning: Causer ${ }_{i}$ makes unspecified Causee act on Self $\mathrm{f}_{\mathrm{i}}$ ) can be interpreted as synonymous with passive;

- In Tswana, Mandinka, Jóola, etc. 'reflexive + causative' can express a simulative meaning ('pretend to $\mathrm{V}$ ');

- In Tswana, 'reflexive + applicative' can express 'enjoy V-ing';

- In Tswana, the stacking of two applicative suffixes may be used with its compositional meaning (as in kwálá 'write' > kwál-él-él-à 'write to someone on behalf of someone else', but it may also encode intensity of action without any change in the valency.

The honorific use of voice in Classical Nahuatl is particularly interesting. The general rule is that the combination 'reflexive + causative' is used as the honorific form of intransitive verbs, whereas the combination 'reflexive + applicative' is used as the honorific form of transitive verbs.

(47) Classical Nahuatl (Launey 1981)

(47a) Ti-mo-cochī-tia.

A.2SG-MID-sleep-CAUS

lit. 'You are making yourself sleep.' > 'You are sleeping.' (hon.)

(47b) Ø-Qui-mo-chīhu-ilia.

A.3SG-P.3SG-MID-do-APPL

lit. 'He is doing it for himself.' > 'He is doing it.' (hon.) 


\section{Lesson 4 \\ Morphologically unoriented valency alternations}

This lesson deals with two types of valency alternations: valency alternations bound to some morphological coding, but in which morphology does not provide clear evidence for distinguishing a base verb and a derived verb, and valency alternations devoid of any specific morphological coding.

N.B. Systems of multiple transitive coding (or symmetrical voices), already presented in Lesson 1, are not resumed here. They constitute a particular type of morphologically undirected valency alternation, which differs from most of those dealt with in the remainder of this lesson by the fact that they manipulate the mapping of argument structure on syntactic roles without affecting the transitivity of the constructions involved in the alternation.

\subsection{Equipollent derivation in valency alternations}

In this type of alternation, the two verb forms involved in a valency alternation affecting transitivity are equally complex. Either their relationship involves non-concatenative morphology in such a way that there is no evidence supporting the selection of one of them as the base form, or they share a common stem, but each of them includes a derivational affix in addition to this stem.

It may happen that the stem shared by the two verbs has no existence by itself. For example, in Jóola Fooñi búk-én 'injure' / búk-ó 'get injured', it is possible to identify the causative suffix -én (cf. gím 'get lost' > gím-én 'lose') and the anticausative suffix -ó (cf. kámbúl 'open (tr.) > kámbúl-ó 'open (intr.)), but the stem búk- is not attested independently.

It may also happen that the stem shared by two verbs in a valency alternation involving equipollent derivation is attested, but with a meaning that excludes considering it as the base form in a synchronic analysis. For example, Jóola Fooñi gor-en 'move (tr.)' and gor-oor 'move (intr.)' are probably cognate with gor 'touch', but the meaning of these three verbs has evolved in such a way that, synchronically, no regular semantic relationship can be recognized between gor and gor-en / gor-oor.

Another possibility is that the stem shared by two verbs in an equipollent valency alternation is attested with a meaning that allows viewing it as the source of a regular derivation, but not as a verb. For example, in Hungarian, jav-ul 'improve (intr.)' and jav-ít 'improve (tr.)' derive from the adjective jó 'good', and there is no reason for orienting the relationship between the two verbs as javul (base form) > javít (causative) or javít (base form) $>$ javul (anticausative).

(1) Hungarian (pers.doc.)
(1a) Jav-ul-t- $\varnothing$
a helyzet.
good-ADJ>V.INTR-PST-A.3SG DEF situation
'The situation improved.'
(1b) Hibákat
jav-ít-ott- $\varnothing$
a tanár.
mistake.PL.ACC good-ADJ>V.TR-PST-A.3SG
DEF professor
'The professor corrected some mistakes.'




\subsection{Inflectional classes of verbs and valency (inflectional voices)}

The valency alternations described in Lessons 2 and 3 can be characterized as 'derivational voices', but the valency operations they express may also be encoded, at least to some extent, through verb inflection.

In the languages in which verbs divide morphologically into two or more inflectional classes, it may happen that verbs with similar valency properties tend to group into the same inflectional class, and that a given verb stem changes its valency depending on the inflectional class in which it is conjugated. In such cases, there is generally a default (or unmarked) voice, in which verbs with all possible kinds of valency patterns can be found, and one or two marked voices characterized by a clear predominance of verbs with a given type of valency pattern. Traditionally, the unmarked voice in such systems is designated as the 'active' voice, and labels such as 'passive' or 'middle' are used for the other one(s).

Ancient Greek had three inflectional voices (active / middle / passive), and this system has been reduced to a binary system (active / mediopassive) in Modern Greek. Latin had a binary system in which the marked voice is traditionally designated as 'passive', although 'mediopassive' would certainly be more appropriate, since this voice is widely attested in typically middle functions - Ex. (2).

(2) Latin (Ernout \& Thomas 1953)

(2a) Magister pueros laud-at.

teacher boy.PL.ACC congratulate-PRS.3SG

'The teacher is congratulating the boys.'

(2b) Pueri a magistro laud-antur.

boy.PL by teacher.ABL congratulate-PRS.3PL.MDPASS

'The boys are congratulated by the teacher.'

(2c) Pueri exerc-ebantur.

boy.PL practice-IPRF.3PL.MDPASS

'The boys were practicing.'

(2d) Copul-antur dexteras.

join-PRS.3PL.MDPASS right_hand.PL.ACC

'They are shaking hands.'

(2e) Laet-antur.

rejoice-PRS.3PL.MDPASS

'They are rejoicing.'

A system of inflectional voice very similar functionally to the Ancient Greek system is found in Fulfulde - Ex. (3).

(3) Fulfulde (pers.doc.)

(3a) O moobt-ii be.

A.CLo gather-CPL P.CLbe

'He gathered them.' 
(3b) Be moobt-aama.

A.CLo gather-PASS.CPL

'They were gathered.'

\section{(3c) Be moobt-iima.}

A.CLo gather-MID.CPL

'They gathered.'

Balant Ganja also has a ternary system of inflectional voice, in which however the two marked voices must rather be characterized as 'mediopassive' and 'causative' (Creissels and Biaye 2016).

Diachronically, a possible source of inflectional voice is the fusion of inflectional affixes of the type commonly found in verb inflection with derivational affixes encoding valency alternations. Another possible source is the univerbation of analytic verb forms in systems characterized by a relationship between auxiliary selection and valency (cf. Section 4.3).

\subsection{Auxiliary selection and valency}

In Basque, with the exception of a limited number of verbs that have synthetic finite forms, all finite verb forms are analytical (auxiliary + non-finite form), and two distinct auxiliaries are used: 'be' with the verbs whose coding frame includes no Ergative-marked argument, and 'have' with the verbs that have an Ergative-marked argument in their coding frame. A high proportion of verbs can combine with both auxiliaries without changing their form. With the verbs in question, auxiliary selection expresses the same type of valency alternation as anticausative derivation in other languages.

(4) Basque (pers.doc.)

(4a) Haurrek ispilua puskatu dute.

child.PL.ERG mirror.SG break.CPL have.A.3SG.P.3PL

'The children broke the mirror.'

(4b) Ispilua puskatu da.

mirror.SG break.CPL be.P.3SG

'The mirror broke.'

\subsection{A note on unexpressed arguments}

Before discussing lability and ambitransitivity, some precisions are in order about the question of unexpressed arguments, since languages greatly differ in the way they regulate the possibility of leaving core arguments unexpressed, either with an anaphoric or unspecified reading. Moreover, in this respect, the definitions found in most elementary handbooks, according to which an essential property of arguments is their 'obligatoriness', are quite misleading.

It is true that, in some languages (for example, in most Mande languages), there is a total ban on unexpressed core arguments, but in the languages of the world, this situation is rather exceptional, and some languages (for example, Japanese) are extremely liberal about the possibility of leaving core arguments unexpressed, either with an anaphoric or unspecified reading. 
The cross-linguistic variation in the regulation of unexpressed arguments can be illustrated by the contrast between most European languages and Turkish as regards the interpretation of unexpressed P's. In European languages, the mere omission of the P term of a transitive clause is a common strategy for leaving the $\mathrm{P}$ argument unspecified. By contrast, in Turkish, null P's have an anaphoric rather than arbitrary reading, and the cognate-P strategy is widely used to encode unspecific P's. Ex. (5) illustrates the anaphoric reading of null P's. The cognate-P strategy can be illustrated by örgü örmek lit. 'knit the knitting' > 'knit (an unspecified thing)', dikiş dikmek lit. 'sew the sewing' > 'sew (an unspecified thing)'.

(5) Turkish (Göksel \& Kerslake 2005:140-1, 537-8)

\begin{tabular}{|c|c|c|c|c|c|}
\hline $\begin{array}{c}-\mathbf{B u} \\
\text { DEM }\end{array}$ & $\begin{array}{l}\text { ev-i } \\
\text { house-ACC }\end{array}$ & $\begin{array}{ll}\text { bir gün } & \text { gone } \\
\text { onay }\end{array}$ & $\begin{array}{l}\text { mutlaka } \\
\text { certainly }\end{array}$ & $\begin{array}{l}\text { el-de } \\
\text { hand-LOC }\end{array}$ & $\begin{array}{l}\text { ed-eceğ-im } \\
\text { do-FUT-1SG }\end{array}$ \\
\hline
\end{tabular}

\section{-Ne-den bu kadar çok ist-iyor-sun? what-ABL DEM like much want-PRS-2SG -Why do you want [it] so much?'}

(5b) Ayşe'yi gör-dü-m ve çok sev-di-m. Ayşe-ACC see-CPL-1SG and much like-CPL-1SG 'I saw Ayşe and liked [her] very much.'

Similarly, in Mandarin Chinese, a null P in the construction of 'eat' can only be interpreted as anaphoric, and lit. 'eat rice' is the usual way of referring to an eating event without specifying the $\mathrm{P}$ argument.

As illustrated by Ex. (6), in Basque, some transitive verbs at least equally allow for an anaphoric or unspecific reading of an unexpressed P. In Basque, the use of third person indexes with no corresponding noun phrase constitutes the usual strategy to encode that the argument in question must be identified anaphorically, but in the case of arguments in the Zero case (including P's), constructions with a third person singular index and no corresponding noun phrase may be ambiguous between an anaphoric and a non-specific reading.

(6) Basque (pers.doc.)

(6a) Bilbon ikasi dut.

Bilbao.LOC learn.CPL PRS.A.1SG.P.3SG

'I learnt it in Bilbao.' OR 'I studied in Bilbao.'

(6b) Jonek erretzen du.

Jon.ERG burn.ICPL PRS.A.3SG.P.3SG

'Jon burns/smokes it.' OR 'Jon smokes (= is a smoker).'

\subsection{Ambitransitivity}

\subsubsection{A terminological clarification}

'Labile' can be found in the literature with broader or narrower definitions. In this course, I use 'labile' in the broadest sense: a verb is designated as labile if it can be involved in a 
valency alternation without any formal change, whatever the precise nature of the valency alternation in question.

Note however that, in the case of polysemous verbs, the property of being labile or not must be evaluated separately for each possible meaning. For example, the fact that the French verb prendre 'take' is used intransitively in (7) does not justify considering it as labile. Rather, prendre 'take' is transitive in some of its possible meanings, intransitive in some others.

(7) French

Le feu a pris.

'The fire started.'

According to the definition of lability retained here, ambitransitivity, defined as the ability for verbs to be used transitively or intransitively without any formal change, is a particular case of lability. Several types of ambitransitivity can be distinguished, according to the relationship between the semantic roles assigned by the ambitransitive verb in its transitive and in its intransitive use.

\subsubsection{Major types of ambitransitivity}

Dixon (1994) introduced a distinction between P-lability (or patient-preserving lability - Ex. (8)) and A-lability (or agent-preserving lability - Ex. (9)), which unquestionably constitute the two major types of ambitransitivity.

(8) English

(8a) I broke the stick.

(8b) The stick broke.

(9) English

(9a) John is drinking tea.

(9b) John is drinking.

\subsubsection{A typology of ambitransitivity}

\subsubsection{Introductory remarks}

The typology of ambitransitivity I propose is based on three logically independent parameters:

- a first distinction between A-lability, P-lability, reflexive lability, and reciprocal lability,

- a second (semantic) distinction between argument structure preserving and argument structure modifying ambitransitivity,

- a third (formal) distinction between weak and strong ambitransitivity. 
Note that some of the theoretically possible combinations of values of these three parameters may be unattested, but I will not try to be more precise on this point.

\subsubsection{A-lability, P-lability, reflexive lability, and reciprocal lability}

This distinction takes into account the relationship between the semantic role of $U$ in the intransitive use of an ambitransitive verb and the semantic roles assigned to A and $\mathrm{P}$ in the transitive use of the same verb: the semantic role of $U$ in the intransitive use of the ambitransitive verb may coincide with that of A (A-lability, cf. Ex. (9) above) or with that of P (P-lability, cf. Ex. (8) above), but it may combine both roles, with two possibilities: either the ambitransitive verb in its intransitive use represents an event conceived as reflexive, as in (10) (reflexive lability), or an event conceived as reciprocal, as in (11) (reciprocal lability).

(10) English

(10a) The mother washed the child.

(10b) The child washed.

(11) English

(11a) John kissed Mary.

(11b) John and Mary kissed.

\subsubsection{Argument structure preserving vs. argument structure modifying ambitransitivity}

The semantic distinction between argument structure preserving and argument structure modifying ambitransitivity is defined as follows:

- in argument structure preserving ambitransitivity, the verb in its intransitive use implies the same participants with the same roles as in its transitive use, but in the intransitive use, one of the participants is demoted to oblique or left unexpressed;

- in argument structure modifying ambitransitivity, the intransitive use of the ambitransitive verb implies a single participant whose role may be related in various ways to the roles the ambitransitive verb assigns to two distinct participants in its transitive use.

In other words, argument structure preserving ambitransitivity is semantically similar to the valency-decreasing derivations that do not affect the argument structure of transitive verbs (passive and antipassive), whereas argument structure modifying ambitransitivity is semantically similar to the valency-decreasing derivations that modify the argument structure of transitive verbs.

For example, contrary to John is drinking tea / John is drinking, which illustrates argument structure preserving ambitransitivity, The child broke the vase / The vase broke is undoubtedly an instance of argument structure modifying ambitransitivity, since the intransitive construction does not imply the involvement of an agent (in other words, The vase broke is not synonymous with The vase has been broken). 


\subsubsection{Weak vs. strong ambitransitivity}

The formal distinction between weak and strong ambitransitivity is defined as follows:

- in weak ambitransitivity, the only core argument of the intransitive construction is encoded exactly like the argument with a similar or identical role in the transitive construction, and superficially, the two constructions show no other formal distinction than the presence $v s$. absence of a noun phrase (as in English John is drinking tea / John is drinking);

- in strong ambitransitivity, the two constructions differ formally in other respects than the mere presence vs. absence of a nominal term, either because the only core argument of the intransitive construction is encoded differently form the argument with a similar or identical role in the transitive construction (as the vase in English The vase broke / The child broke the vase), or for other reasons, for example transitivity marking, as in Example (12).

(12) Mandinka

(12a) Mòôlú yè bâa těe.

people.D.PL CPL.TR river.D cross

'The people crossed the river.'

(12b) Mòôlú těe-tà.

people.D.PL CPL.INTR

'The people crossed.'

In (12a) and (12b), mòôlú 'the people' shows the same coding properties, but Mandinka has two partially distinct sets of TAM-polarity markers in transitive and intransitive constructions, and consequently 'completive positive' is marked by yè in the transitive use of těe 'cross' and -tà in its intransitive use.

Note that the examples given above show the independence of the two parameters argument structure preserving vs. modifying and weak vs. strong: the English example John drinks (tea) and the Mandinka example Mòốlú těe-tà / Mòôlú yè bâa těe are two instances of argument structure preserving ambitransitivity, but John drinks (tea) is a case of weak ambitransitivity, whereas Mòôlú těe-tà / Mòôlú yè bâa těe illustrates strong ambitransitivity.

In fact, the distinction between weak and strong lability is conditioned by the alignment property of the language and the existence of transitivity marking. In languages like Mandinka, in which the distinction between transitive and intransitive predication is overtly marked (for example, by the choice between two distinct sets of TAM markers), weak ambitransitivity cannot exist. By contrast, in the absence of overt transitivity marking, obligatory A coding ('accusative') languages (like English) can only have weak A-lability and strong P-lability, whereas obligatory P coding ('ergative') languages can only have strong Alability and weak P-lability.

Ex. (13) shows that, in an obligatory $P$ coding language such as East Uvean, the intransitive use of A-labile verbs triggers a change in the flagging of A converted into the $U$ term of an intransitive predication. 
(13) East Uvean (Claire Moyse, pers.com.)

$\begin{array}{llllllll}\text { (13a) } & \text { 'E } & \text { huo } & \text { e } & \text { Soane } & \text { tana } & \text { gāue'aga } & \text { 'ufi. } \\ \text { NPST } & \text { weed } & \text { ERG } & \text { Soane } & \text { his } & \text { field } & \text { yam }\end{array}$

'Soane is weeding his yam field.'

(13b) 'E huo ia Soane

NPST weed ABS Soane

'Soane is weeding.'

Dargi languages are an interesting example of obligatory $\mathrm{P}$ coding languages with a phenomenon of A-lability (misleadingly described by most authors as an instance of antipassivization) whose analysis is made difficult by the polyfunctionality of the Ergative case used in Dargi languages to flag agents. The point is that the same morphological case is also used to flag some types of obliques (in particular, instrumental adjuncts), and in the intransitive construction of A-labile verbs, the oblique term corresponding to the $\mathrm{P}$ term of the transitive construction is Ergative-marked, which may give the impression that the core terms of the transitive construction exchange their roles - Ex. (14).

(14) T'ant'i Dargi (Sumbatova \& Lander 2014: 270)

\section{(14a) Murad-li T'ant'i-d qul-re d-irq'-u-le=sa-j.}

Murad-ERG T'ant'i-NPL(LOC) house-PL NPL-make.IPF-PRS-CONV=COP-M

'Murad is building houses in T'ant'i.' (basic transitive construction)

(14b) Murad T'ant'i-w qul-ra-li w-irq'-u-le=sa-j.

Murad T'ant'i-M(LOC) house-PL-ERG M-make.IPF-PRS-CONV=COP-M

'Murad is building houses in T'ant'i.' (intransitive variant of (a))

What is decisive for a correct analysis of A-lability in Dargi languages is the observation of agreement. As illustrated by Ex. (14a), in the basic transitive construction, both A and P act as agreement controllers: in the glosses, $\mathrm{M}$ (masculine) indicates agreement with the agent Murad, whereas NPL (non-human plural) indicates agreement with the patient qul-re 'houses'. By contrast, Ergative-marked obliques do not intervene in agreement mechanisms, and in intransitive predication, all agreement mechanisms are controlled by the unique core argument. Consequently, the fact that all the agreement marks in (14b) are masculine must be analyzed as evidence that the patient has been demoted to Ergative-marked oblique, and that the Zero-marked NP representing the agent is the U term of an intransitive predication.

\subsubsection{Two semantic types of P-lability}

P-labile verbs are verbs that can be used in their underived form either transitively, or intransitively with a $U$ term undergoing the same process as the $\mathrm{P}$ term of the transitive construction. However, this definition encompasses two semantic varieties of P-lability:

- (anti)causative lability, if the $\mathrm{U}$ term of the intransitive construction represents a participant undergoing the same process as the $\mathrm{P}$ argument of the transitive construction, but not necessarily as the result of the action of an agent,

- active / passive lability, if the intransitive construction implies the participation of an unexpressed agent. 
Cross-linguistically, (anti)causative lability, illustrated by English break, is extremely common, and its existence has long been widely acknowledged in typological investigations of valency changes, whereas until not long ago, the very possibility of active / passive lability was either ignored or even explicitly denied by typologists working on valency-decreasing derivations (Haspelmath 1990). Arka \& Kosmas (2005) on Manggarai (Autronesian) and Lüpke (2005) on Jalonke (Mande) are to the best of my knowledge the first published works that have explicitly argued the case for the recognition of zero-coded passives (aka barepassives), but this recognition was implicit in many previously published descriptions of languages belonging to various families, both within and outside Africa (for a review, see Cobbinah and Lüpke (2009)).

The Mande language family shows a particular concentration of languages with more or less productive zero-coded passives, or active/passive lability (Lüpke (2007), Cobbinah and Lüpke (2009)). Manding languages illustrate the extreme case of languages which have no strictly transitive verb, and a very restricted class of A-labile verbs, but in which all the verbs that have a transitive use can also be used intransitively in their underived form with a passive reading.

In language description, the analysis of ambitransitivity is conditioned not only by the alignment properties of the languages, but also by the existence of a more or less clear-cut distinction between transitive and intransitive predications - Creissels (2014). In Mandinka and other Mande languages, the analysis of ambitransitivity is facilitated by the rigidity of the A/U P V X constituent order and the total ban on null core arguments: in Mande languages, a single NP in preverbal position in assertive or interrogative clauses can only the $U$ term of an intransitive construction. Morever, some TAM-polarity markers may have variants conditioned by the transitive vs. intransitive nature of the predicative construction.

For example, in (15b), the absence of any specific passive marking might suggest positing a null $\mathrm{A}$ with an arbitrary reading. However, if kúlúyò were the $\mathrm{P}$ term of a transitive construction with a null $\mathrm{A}$, the TAM-polarity marker would be yè preceding kúlúnò rather that -tá suffixed to the verb, as in the ungrammatical sequence $(15 \mathrm{c})$.

(15) Mandinka (pers. doc.)

(15a) Kèwôo yè kúlúyò dádáa.

man.D CPL.TR boat.D repair

'The man repaired the boat.'

(15b) Kúlúyò dádàa-tá.

boat.D repair-CPL.INTR

'The boat will not be repaired.'

$\begin{array}{llll}* \emptyset & \text { yè } & \text { kúlúyò dádáa. } \\ \text { CPL.TR } & \text { boat.D } & \text { repair }\end{array}$

Consequently, (15b) is not a transitive construction with a null $\mathrm{A}$, but an intransitive construction expressing the same argument structure, in which the U term (kúlúyò) has the same semantic role as the $\mathrm{P}$ term of the transitive construction (15a), whereas the participant expressed as $\mathrm{A}$ in the transitive construction is understood as non-specified - in other words, a zero-coded passive.

A decisive proof of the passive nature of the intransitive constructions involved in this active / passive alternation is their ability to include agent-oriented adverbs, such as 
fèerèetòo- 'cleverly' in Ex. (16b), since agent-oriented adverbs are impossible in anticausative constructions with inanimate U's.

(16) Mandinka (pers. doc.)

(16a) Kàmbàanôo yè násòo fèerèetòo-bón kòlóyò kónò. boy.D CPL.TR magic_water.D cleverly-pour well.D inside 'The boy cleverly poured the magic water into the well.'

(16b) Násòo fèerèetòo-bón-tà kòlóyò kónò. magic_water.D cleverly-pour-CPL.INTR well.D inside 'The magic water was cleverly poured into the well.'

In spite of the absence of any specific passive morphology, the construction illustrated by sentences $(15 b) \&(16 b)$ is passive in the sense that the patient is the $U$ term of an intransitive construction in which the agent is syntactically demoted without however being deleted from argument structure.

In Manding languages, the passive reading of such intransitive clauses is not bound to any particular condition on aspect, mood, or referentiality. Manding speakers use them in the same conditions, with the same freedom, and with the same semantic implications, as agentless passive clauses in languages that have a canonical and fully productive passive voice.

There is however an interesting difference between Mandinka and most other Manding languages in the syntactic properties of the zero-coded passive construction. In most Manding languages, intransitive clauses constituting the passive counterpart of a transitive clause may include an oblique representing the agent, as in Ex. (17).

(17) Bambara (pers. doc.)

(17a) Wùlû má sògô dún.

dog.D CPL.NEG meat.D eat

'The dog did not eat the meat.'

(17b) Sògô má dún (wùlú fè).

meat.D CPL.NEG eat dog.D beside

'The meat was not eaten (by the dog).'

This possibility does not exist in Mandinka. Interestingly, the passive clauses of Mandinka may include obliques marked by the same postpositions as those used to encode the demoted agent in the other Manding languages (i.e. postpositions whose basic meaning is reference to the personal sphere of an individual), but in the passive clauses of Mandinka, such obliques are interpreted as referring to a person who has some link with the event but does not play an active role in it, or to an involuntary agent, as in Ex. (18).

(18) Mandinka (pers. doc.)

$\begin{array}{llll}\text { Kódòo } & \text { dómò-tá } & \text { ý } & \text { fèe. } \\ \text { money.D } & \text { spend-CPL.TR } & 1 \mathrm{SG} & \text { beside }\end{array}$

'The money was spent without my knowing.'

OR 'I spent the money, but I did not do it on purpose.' 
Interestingly, (anti)causative lability, which is cross-linguistically a much more widespread type of P-lability, is also found in Mandinka and other Manding languages. However, in Manding languages, contrary to active / passive lability, which is a property shared by all potentially transitive verbs, (anti)causative lability is a lexical property of individual verbs. As illustrated by Ex. (19), with the verbs that have this property, the intransitive construction is potentially ambiguous between an anticausative-like and a passive-like reading: sentence (19b) can be equally found in contexts unambiguously triggering an anticausative interpretation, and in others suggesting a passive interpretation.

(19) Mandinka (pers. doc.)

(19a) Kèwôo yè sàajíyòo făa.

man.D CPL.TR sheep.D kill/die

'The man killed the sheep.'

\section{(19b) Sàajíyòo făa-tà.}

sheep.D kill/die-CPL.INTR

'The sheep died.' OR 'The sheep was killed.'

Note that, irrespective of its precise interpretation, the Mandinka sentence (18b) is an instance of strong ambitransitivity, since TAM and polarity marking unambiguously designates sàajíyòo 'the sheep' as the U term of an intransitive construction.

\subsubsection{Two semantic types of A-lability}

The distinction between argument structure preserving and argument structure modifying lability is less obvious in the domain of A-lability, since most of the A-labile verbs one may come across are equally bivalent in their transitive and intransitive uses. Argument structure modifying A-lability can however be illustrated by A-labile verbs that are clearly monovalent in their intransitive use, such as French pleurer 'cry', used transitively with the meaning 'lament someone's death'. Mandinka jélè 'laugh', used transitively with the meaning 'make fun of someone', is another good example.

(20) Mandinka (pers. doc.)

(20a) Díndínò jélè-tá.

child.D laugh-CPL.INTR

'The child laughed.'

(20b) Díndínò yè ý jélè.

child.D CPL.TR 1SG laugh

'The child made fun of me.'

\subsubsection{Underspecified ambitransitivity}

By underspecified ambitransitivity, I mean the case of verbs that can be used in three different ways without any specific morphological marking: transitively, intransitively with the U term corresponding to the A term of the transitive construction, or intransitively with the $U$ term corresponding to the $\mathrm{P}$ term of the transitive construction. 
(21) Soninke (pers.doc.)

(21a) Lémínèn yá qátìn mìnní bà?

child.D ICPL milk.D drink.GER Q

'Is the child drinking the milk?'

(21b) Lémínèn yá mìnní bà?

child.D ICPL drink.GER Q

'Is the child drinking?'

(21c) Jí ké wá mìnní bà?

water DEM ICPL drink.GER Q

'Is this water safe to drink?' lit. 'Does this water drink?'

(22) Samoan (Mosel \& Hovdhaugen 1992: 718, 108)

(22a) Sā 'ai e le teine le i'a.

PST eat ERG DEF girl DEF fish

'The girl ate the fish.'

(22b) Sā 'ai le i’a.

PST eat DEF fish

'The fish ate.' OR 'The fish was eaten.'

\subsection{A-P reversal}

Given the terminological system used in this course, A-P reversal is a convenient label for a type of valency alternation that has been described in several Bantu languages under the name of 'subject-object reversal'. As illustrated by Ex. (23), in A-P reversal, like in P-lability, one of the two alternative constructions clearly has all the properties of a canonical transitive construction, and the other construction can be described in terms of $\mathrm{P}$ promotion and $\mathrm{A}$ demotion. $\mathrm{P}$ promotion is evidenced by the change in verb agreement. The difference with $\mathrm{P}$ lability is that the A argument is obligatorily expressed, and there is nothing suggesting that it has been demoted to oblique. Consequently, at least superficially, the construction looks like a transitive construction with the demoted A argument in the P slot, hence the term 'reversal'.

(23) Tswana (pers.doc.)
(23a) Mètsí ‘á-tléts-í
(CL6)water A.CL6-fill.PRF-FV
'The water filled the dam.'
lì-tâ:mò.

\section{CL5-dam}
(23b)
Lì-támó `lí-tłéts-í
mè:tsí.
CL5-dam A.CL5-fill.PRF-FV
(CL6)water
'The dam is full of water.'

Functionally, this alternation expresses the same reversal of the $\mathrm{A}>\mathrm{P}$ topicality hierarchy as passive constructions (either morphologically marked or unmarked). 
In Tswana, this kind of valency alternation is extremely marginal, but in some Central Bantu languages (Lomongo, etc.), it is much more productive, although it is always limited to transitive constructions in which the semantic nature of the protagonists is such that the semantic roles can be retrieved regardless of syntactic structure.

\subsection{A X lability}

By A X lability, I mean morphologically uncoded valency alternations in which both alternative constructions are transitive, and a participant encoded as an oblique in one of them is encoded as A in the other. Ex. (24) illustrates this kind of alternation with an instrumental adjunct. Note that, in this particular case, the participant encoded as A in (24a) is still semantically present in $(24 \mathrm{~b})$, but cannot be expressed.

(24) English

(24a) I opened the front door with this key.

(24b) This key opens the front door.

\subsection{Locative lability}

By locative lability, I mean morphologically uncoded valency alternations in which one of the alternative constructions is clearly intransitive, and a participant encoded as a locative adjunct in this construction is encoded as A or $\mathrm{U}$ in the other - Ex. (25). Note that, in this particular case, the demoted $\mathrm{U}$ is obligatorily present in a position superficially similar to that of $\mathrm{P}$ in a transitive construction, although it does not have the properties of a canonical P. This alternation is relatively marginal in Tswana, it is more productive in other Bantu languages.

(25) Tswana (Bantu - pers.doc.)

(25a) Mà-dí á-tsw-à mó ìnthồ:-̀̀.

CL6-blood A.CL6-come from-FV in (CL9)wound-LOC

'The blood is flowing out from the wound.'

(25b) ̀̀thó ' 'í-tsw-á mà:-dí.

(CL9)wound A.CL9-come_from-FV CL6-blood

'The wound is bleeding.' lit. 'The wound flows out blood.'

A remarkable property of many Bantu languages (not found however in Tswana and other Southern Bantu languages) is that, due to the way the expression of localization is integrated in their noun class system, they also have alternations of this type in which locative adjuncts moving to preverbal position maintain their locative marking, and at the same time govern verb agreement in the same way as canonical A's or U's.

(26) Chichewa (Bresnan and Kanerva 1989: 2)

$\begin{array}{llll}\text { (26a) } & \text { A-lendô-wo } & \text { a-na-bwérá } & \text { ku-mu-dzi. } \\ \text { CL2-visitor-CL2.DEM } & \text { A.CL2-RECPST-come } & \text { CL17-CL3-village }\end{array}$

'Those visitors came to the village.' 


$\begin{array}{lll}\text { Ku-mu-dzi } & \text { ku-na-bwérá } & \text { a-lendô-wo. } \\ \text { CL17-CL3-village } & \text { A.CL17-RECPST-come } & \text { CL2-visitor-CL2.DEM }\end{array}$

'To the village came those visitors.'

\subsection{Impersonal lability}

\subsubsection{Unmarked impersonalization of transitive constructions with demotion of $A$ to oblique}

Ex. (27) illustrates the possibility of morphologically unmarked impersonalization of the Russian verb trjasti 'shake' with demotion of A to oblique. Sentences (a) and (b) illustrate the use of this verb in the basic transitive construction. However, when shaking is not caused by a human agent, but by the physical state of the person affected, or by some inanimate force (and only in such cases), an impersonal construction is possible in which the cause is encoded as a prepositional phrase, whereas the coding of the person affected is not modified, and the verb form does not change, apart from the fact that, in the impersonal construction, it can only express default agreement (3rd person singular in the present, neuter singular in the past).

Russian (pers.knowl.)

(27a) Ja trjasu kovër.

1SG shake.PRS.1SG carpet.ACC

'I am shaking the carpet.'

(27b) Menja trjasët lixoradka.

1SG.ACC shake.PRS.3SG fever

lit. 'Fever is shaking me.'

(27c) Menja trjasët ot lixoradki.

1SG.ACC shake.PRS.3SG from fever-GEN

lit. 'It's shaking me from fever.' > 'I am shaking with fever.'

(27d) V poezde trjasët

in train.LOC shake.PRS.3SG

lit. 'It shakes in the train.' > 'One gets shaken in the train.'

Similarly, ex. (28) illustrates the possibility that, if the A argument of razbit' 'destroy' is an inanimate force (and not a human agent), the A argument can be demoted to oblique without any other change in the construction, and without any change in the verb form, apart from the fact that, in the absence of an $\mathrm{A} / \mathrm{U}$ argument, it can only express default neuter singular agreement.

(28) Russian (pers.knowl.)

Stenu razbilo $\quad$ molniej.
wall.ACC destroy.PST.SGN thunderbolt.INSTR
lit. 'I destroyed the wall by a thunderbolt.'
> 'The wall was destroyed by a thunderbolt.'




\subsubsection{Impersonal lability in presentational constructions}

In the languages whose basic constituent order in verbal predication can be schematized as A/U V P X ('SVO languages' in the tradition initiated by Greenberg's account of word order typology), there is often a discursively marked construction of intransitive verbs whose function is to de-topicalize the $\mathrm{U}$ argument, and whose general characteristic is the postverbal position of the $U$ argument, contrasting with its canonical pre-verbal position. There is variation as regards the possible restriction of this construction to a sub-class of so-called 'unaccusative' intransitive verbs (i.e., intransitive verbs assigning a patient-like role to U), or its possible extension to transitive verbs, but this point will not be discussed here. There is also variation as regards the syntactic demotion of the $U$ argument, and the possible promotion of a locative adjunct.

Presentational inversion has been particularly studied for Romance and Bantu languages. In some cases at least, the presentational inversion construction is a clear instance of impersonal lability, in the sense that the initial $U$ moving to post-verbal position loses properties such as the control of verb agreement, and no other argument shows evidence of being promoted. This situation is illustrated by Ex. (29) for French, and Ex. (30) for Tswana.

(29) French

(29a) Deux femmes viendront.

two $\quad$ woman(F).PL come.FUT.3PL

'Two women will come.'

(29b) Il viendra deux femmes.

A.3SGM come.FUT.3SG two woman(F).PL

'Two women will come.'

(30) Tswana (pers.doc.)

(30a) Bà-símàní ' 'bá-tláà-bî:n-à.

CL2-boy A.CL2-FUT-dance-FV

'The boys will dance.'

(30b) Xó-tláà-bín-á bà-símà:ní.

A.CL17-FUT-dance-FV CL2-boy

lit. 'There will dance boys.' > 'The/some boys will dance.'

However, not all presentational inversion constructions can be straightforwardly analyzed as instances of impersonal lability. The point is that, in some languages (French and Tswana among others), the $U$ argument moving to postverbal position loses the control of verb agreement, which can be viewed as evidence for demotion. However, this is not always the case, and in this respect there is huge variation, across both Bantu and Romance languages.

Finnish has a semantically similar inversion construction with the $U$ argument of an intransitive verb in the partitive case and the verb invariably in the 3rd person singular - ex. (31). Interestingly, in Finnish, case marking provides additional evidence in favor of the analysis according to which this construction is an instance of impersonalization. The point is that Partitive case marking is possible for $\mathrm{P}$, but not for $\mathrm{A}$, and consequently, the construction illustrated by (31b) violates the constraint of obligatory A coding. 
(31) Finnish (Sands \& Campbell 2001)

(31a) Lapset leikkivät ulkona.

child.PL play.PST.3PL outside

'The children played outside.'

\section{(31b) Ulkona leikki lapsia}

outside play.PST.3SG child.PL.PART

'There were children playing outside.'

Mandarin Chinese has neither case marking of core arguments nor indexation, and the notion of impersonal construction is not traditional in Chinese linguistics, but the transitive construction of Mandarin has the basic A V P order, without any possibility to move A to postverbal position, whereas the $U$ argument of intransitive verbs occurs in postverbal position (and can therefore be analyzed as overtly aligned with $\mathrm{P}$ ) in 'presentative sentences' - ex. (32).

(32) Mandarin Chinese (Li \& Thompson 1981:509-519)

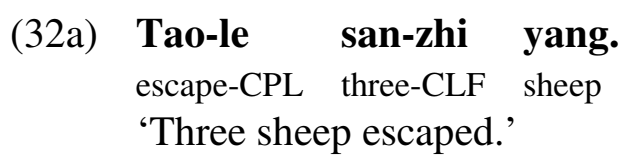

\section{(32b) Women-de wanhui zhi lai-le Zhangsan gen Lisi. 1PL-GEN party only come-CPL Zhangsan and Lisi \\ 'Only Zhangsan and Lisi came to our party.'}

Functionally, the impersonal constructions examined in this section belong to a family of constructions (including in particular so-called 'locative inversion' - Bresnan 1994) in which a presentational reading is triggered by the postverbal position of the $U$ argument of intransitive verbs in languages that have the basic AVP order in the prototypical transitive construction. Presentational constructions, which have figured prominently in discussions about unaccusativity (see a.o. Levin \& Rappaport Hovav 1995: 215-77), show variation with respect to case marking and indexation of $U$ arguments in postverbal position, but in the perspective of valency grammar, some of them at least are clear instances of the type of valency alternation designated in this course as impersonal lability.

\subsubsection{Other instances of impersonal lability}

In Russian, an impersonal construction with the $U$ argument of an intransitive verb in the Genitive case, and default 3rd person singular or neuter verb agreement, is possible under certain conditions with intransitive verbs combined with negation - ex. (33). The identification of this construction as an instance of unmarked impersonalization (or impersonal lability) follows from the fact that agents never appear in the 'genitive of negation'. 
(33a) Otvet ne prišel. answer(M) NEG come.PST.SGM

'The answer did not come.'

(33b) Otveta ne prišlo.

answer(M).GEN NEG come.PST.SGN

lit. 'It didn't come of-answer.' > 'No answer came.'

\subsection{G-lability}

In the term of 'G-lability' as I propose to use it, $\mathrm{G}$ must be understood as referring to the role of goal (or destination, recipient, etc.) in the argument structure of trivalent verbs. In this kind of morphologically unmarked valency alternation, the expression of the most agent-like participant in the argument structure of the trivalent verb is not affected, but the other two participants can be encoded in two different ways: in one of the possible coding frames, the goal/destination/recipient is encoded as an oblique, whereas in the alternative coding frame, it has the same coding properties as the $\mathrm{P}$ term of the basic transitive construction.

The alternation known as 'dative-shift' in English grammar - ex. (34) - clearly meets this definition. In this particular case, the alternation is between an extended transitive construction showing indirective alignment and a double-transitive construction.

(34) English

(34a) John gave the book to Mary.

(34b) John gave Mary the book.

The so-called 'locative alternation' illustrated by Ex. (35) is another variety of G-lability.

(35) English

(35a) John smeared paint on the wall.

(35b) John smeared the wall with paint.

This kind of morphologically unmarked valency alternation is quite widespread crosslinguistically. Ex. (36) \& (37) provide some Mandinka illustrations. Interestingly, in Mandinka, when the recipient or goal is encoded as P, the theme encoded as an oblique is invariably flagged by the instrumental postposition lá, but when the recipient or goal is encoded as an oblique, the postposition varies according to its precise semantic role.

(36) Mandinka (pers.doc.)

(36a) Kèwôo yè bàtáayòo sáfée à díjò yé. man.D CPL letter.D write 3SG son.D to 'The man wrote a letter to his son.' 
(36b) Kèwôo yè à díyò sáfée bàtáayòo lá. man.D CPL 3SG son.D write letter.D with

'The man wrote a letter to his son. (lit. wrote his son with a letter)'

(37) Mandinka (pers.doc.)

(37a) Kèwôo yè tìyôo sóolì bòotôo kónò. man.D CPL peanut.D stuff bag.D in 'The man stuffed the peanuts into the bag.'

(37b) Kèwôo yè bòotôo sóolì tìyôo lá. man.D CPL bag.D stuff peanut.D with 'The man stuffed the bag with peanuts.'

\subsection{Alternations between terms of predicative constructions and adnominal possessors}

\subsubsection{External possession}

External possession constructions are constructions in which the semantic relationship between a nominal term $\mathrm{N} 1$ of a predicative construction and a noun $\mathrm{N} 2$ found elsewhere in the sentence could justify coding N1 as an adnominal possessor of N2.

Such constructions are commonly in competition with a construction in which the participant in question is coded as an adnominal possessor - Ex. (38), and a general characteristic of external possession constructions, insofar as they are in competition with an adnominal possession construction, is that they highlight the affectedness of the possessor. However, depending on the individual languages, external possession constructions may be marked constructions, not very frequent in spontaneous discourse, whereas in some other languages, they are extremely frequent, sometimes virtually obligatory. Romanian is remarkable in this respect.

(38) French

(38a) J'ai la jambe cassée.

I-have the leg broken

'My leg is broken.'

(38b) Ma jambe est cassée.

my leg is broken

'My leg is broken.'

Not all such alternations qualify as valency alternations, since they may involve constructions whose analysis as mono- or biclausal is debatable. This is in particular the case in (38a). Uncontroversial cases of external possession constructions analyzable as instances of valency alternation are given in (39) and (40). Ex. (41) illustrates the kind of ambiguity that may follow from the use of an external possession construction. 
(39) French

(39a) Il nous a réparé la voiture.

he to.us has fixed the car

'He fixed our car.'

(39b) Il a réparé notre voiture.

he has fixed our car

'He fixed our car.'

(40) Basque (pers.doc.)

(40a) Edurne-ri ama hil zaio.

Edurne-DAT mother die.CPL be.A.3SG.DAT.3SG

'Edurne's mother died.' lit. 'To Edurne the mother is.to.her dead.'

(40b) Edurne-ren ama hil da.

Edurne-GEN mother die.CPL be.3SG

'Edurne's mother died.'

(41) Basque (pers.doc.)

\section{Eskutitz-a iritsi zait}

letter-SG arrive.CPL be.A.3SG.DAT.1SG

lit. 'The letter is.to.me arrived.'

can be interpreted as, either 'The letter [sent by another person] came to me.', or 'My letter (i.e. the letter I sent) has reached its destination.'

Interestingly, Bantu languages have both morphologically marked and morphologically unmarked valency alternations of this type. In Tswana, the rule is that external possession constructions involving body-part nouns do not require morphological marking, as in (42b), whereas external possession constructions involving alienable possession require applicative marking, as in (42a). In both cases, the external possessor is syntactically the primary $\mathrm{P}$ in a double-transitive construction.

(42) Tswana (doc.pers.)

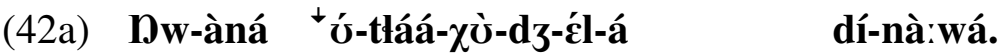

CL1-child A.CL1-FUT-P.2SG-eat-APPL-FV CL.10-beans

lit. 'The child is going to eat.APPL you the beans.'

$>$ 'The child is going to eat your beans.'

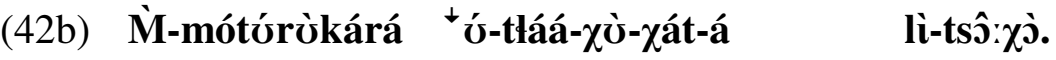

CL3-car A.CL3-FUT-P.2SG-crush-FV CL.5-hand

lit. 'The car is going to crush you the hand.'

$>$ 'The car is going to crush your hand.'

\subsection{1. 'Indirect object lowering'}


The alternation known in the literature as 'indirect object lowering' is formally similar to the alternation between an external possession construction and a construction in which the possessor is encoded as a noun modifier. It differs semantically in that the participant whose coding alternates between adnominal possessor and term of a predicative construction cannot be characterized as a possessor affected by an event in which an element of its personal sphere is directly involved, but rather as a recipient or beneficiary that will end up possessing the item encoded as P. As noted by Croft (1985: 43), this kind of alternation is marginally possible in English, when sentences such as (43a) are uttered in a particular type of context. In most languages (including English), sentences like (43a) and (43b) are not synonymous, since (43a) implies the possibility of viewing the relationship between the two terms of the genitival construction as already established in some way or another, whereas (43b) carries no such implication. However, this constraint may be sporadically violated by speakers, resulting in the use of sentences like (43a) in situations in which they normally do not occur.

(43) English (Croft 1985: 43)

\section{(43a) Let's go get your beret.}

\section{(43b) Let's go get a beret for you.}

What occurs in the languages in which 'indirect object lowering' is regular is that, in the languages in question, the construction illustrated by (43a) is not bound to the conditions that limit its use in most languages, and regularly occurs whenever a recipient or beneficiary can also be characterized as a future possessor. Creissels (1979) mentions two Mayan languages, Q'eqchi' and K'ichee' - Ex. (44) and (45), and indicates that such constructions are common in Guatemalan Spanish (i.e. in a Spanish variety influenced by a Mayan substrate).

(44) Q’eqchi' (Creissels 1979: 572)

$\begin{array}{lll}\text { Tixloq' } & \text { li } & \text { r-ixim. } \\ \text { FUT.A.3SGP.3SG } & \text { DEF } & \text { 3SG-maize } \\ \text { lit. 'He will buy his maize.'> 'He will buy maize for himself.' }\end{array}$

(45) K'ichee' (Creissels 1979: 573)

$\begin{array}{lll}\text { Kutzukuj } & \text { jun } & \text { u-kamixa'. } \\ \text { ICPL.A.3SG.P.3SG.look_for } & \text { INDEF } & \text { 3SG-shirt }\end{array}$

lit. 'He is looking for a shirt of his.'> 'He is looking for a shirt for himself.'

Croft (1985) also mentions Tlapanec, Hixkaryana, Kobon, Buin, and Mokilese. Similar constructions are analyzed by Lehman (1999) for Yucatec Maya, and by Sonnenschein (2015) for San Bartolomé Zoogocho Zapotec. 


\section{Lesson 5 \\ Incorporation and transitivity}

\subsection{Incorporation as a morphological operation}

The definition of incorporation retained in this course is that according to which incorporation is a morphological operation creating verbal lexemes by compounding a verbal lexeme and a lexeme belonging to another category (noun, adjective, adverb, ideophone, or adposition). Adposition incorporation has been mentioned in lesson 3 as a possible source of applicatives. However, since the central topic of this course is transitivity, in this lesson, we will be mainly concerned by noun incorporation.

The notion of incorporation is sometimes broadened so as to include 'verb + noun' combinations that do not show evidence of morphological compounding, but in which the noun behaves, at least to some extent, like an incorporated noun (reduced mobility, incompatibility with determiners) and not like the head of a full-fledged noun phrase. I propose to characterize this phenomenon as quasi-incorporation.

Ex. (1) illustrates quasi-incorporation in Futunan. Sentence (1a) illustrates the basic transitive construction, with the VAP constituent order, and A flagged by the ergative preposition e. In sentence ( $1 \mathrm{~b}$ ), there is no morphological evidence of compounding, but the noun 'car' has moved to immediate post-verbal position, and the agentive argument is not flagged, which suggests that $\mathrm{P}$ has been demoted, and $\mathrm{A}$ has been converted into the U term of an intransitive construction. Given the position of the noun 'car' and the lack of any evidence of oblique status, the notion of quasi-incorporation seems to be the right way of summarizing the observations on this construction.

(1) Futunan (Moyse-Faurie 1997)

(1a) $\mathbf{E}$ taki e le fafine le motokā kula. ICPL drive ERG DEF woman DEF car red 'The woman is driving the red car.'

(1b) $\mathbf{E}$ taki motokā le fafine

ICPL drive car DEF woman

'The woman is driving.'

Given the topic of this course, it is not necessary to discuss this point in more detail, and it will be sufficient to illustrate the relationship between incorporation and transitivity by examples from languages that have an uncontroversial and productive mechanism of morphological incorporation.

\subsection{Argument incorporation}

In this type of incorporation, the incorporated noun 'absorbs' the semantic role assigned by the verb to one of its arguments. The meaning of the verb is restricted to events involving potential referents of the incorporated noun in the role in question, but this role cannot be assigned to an NP. Since argument incorporation is most of the time restricted to the $\mathrm{P}$ argument of transitive verbs, this results in a detransitivizing mechanism comparable to the antipassive: P-incorporation converts transitive verbs into intransitive verbs assigning to $U$ the 
role assigned by the base verb to A, reinforcing thus the topicality of the A argument converted into the $\mathrm{U}$ term of an intransitive construction.

In Ex. (2), the valency decrease is made obvious by the fact that both $\mathrm{A}$ and $\mathrm{P}$ are obligatorily indexed in the basic transitive construction, and the compound verb naca-cua 'eat meat' has just one morphological slot for argument indexation. Note that the analysis of naca-cua as a morphological compound follows from the use of a form of the noun 'meat' that cannot be used by itself as a word.

(2) Classical Nahuatl (Launey 1980)

\section{(2a) Ni-c-cua in nacatl. \\ A.1SG-P.3-eat DEF meat \\ 'I am eating the meat.'}

\section{(2b) Ni-c-cua nacatl.}

A.1SG-P.3-eat meat

'I am eating meat.'

\section{(2c) Ni-naca-cua.}

\section{A.1SG-meat-eat}

lit. 'I am meat-eating.'

Formally, in this Nahuatl example, the distinction between P-incorporation and the use of an indefinite noun in $\mathrm{P}$ role is quite clear-cut. Semantically, the distinction is less obvious, and in some other languages (for example, Soninke), it is dubious whether there is any semantic distinction at all, although the formal distinction is equally clear-cut. In Nahuatl (and the same has been observed in many other languages), it seems that P-incorporation is particularly common in reference to activities that can be characterized as socially salient, stereotyped, or ritualized. For example, naca-cua does not just refer to meat eating, but for example to meat eating as ritually performed within the framework of some celebration.

\subsection{Possessive incorporation}

Possessive incorporation can be viewed as a particular variety of external possession constructions. As illustrated by Ex. (3), in possessive incorporation, there is a part-whole relationship between the incorporated noun and another noun in $\mathrm{P}$ or $\mathrm{U}$ role, and the incorporated noun is assigned the semantic role normally assigned to the syntactic position occupied by its possessor. The presence of two argument indexes in (3b) shows that this kind of incorporation affects the assignment of semantic roles, but does not affect the transitivity of the construction.

(3) Classical Nahuatl (Launey 1980)

(3a) Ni-c-pāca in pilli.

A.1SG-P.3-wash DEF child

'I am washing the child.'

(3b) Ni-c-tzom-pāca in pilli.

A.1SG-P.3-hair-wash DEF child

lit. 'I am hair-washing the child.' > 'I am washing the child's hair.' 
This type of incorporation is quite widespread cross-linguistically. In particular, as a rule, in the languages of Europe, incorporation is sporadic at best. The only exception is the relative productivity of possessive incorporation in Catalan and other closely related Romance varieties.

(4) Catalan (Gràcia \& Fullana 1991)

$$
\begin{array}{lll}
\text { cama-trencar } & \text { leg-break } & >\text { break someone's leg } \\
\text { cor-trencar } & \text { heart-break } & >\text { break someone's heart } \\
\text { ull-ferir } & \text { eye-injure } & >\text { impress someone }
\end{array}
$$

The case of ull-ferir 'eye-injure > impress' illustrates the propensity for compound verbs resulting from this type of incorporation to develop lexicalized meanings. Similar cases of lexicalized possessive incorporation abound, for example, in Manding languages and in Soninke.

\subsection{Modifying incorporation}

In modifying incorporation, the incorporated noun restricts the meaning of the verb in the same way as NP's in adjunct function, and does not trigger any change in its valency. An important difference between modifying incorporation and NP adjunction is that, as a rule, the flagging of adjunct NP's provides some information about their semantic role, whereas in modifying incorporation, there is no overt indication about the semantic nature of the relationship between the incorporated noun and the verb.

Modifying incorporation affects neither the transitivity of the construction, nor the assignment of semantic roles.

Ex. (5) illustrates the incorporation of a cause adjunct, and Ex. (6) illustrates similative incorporation, a cross-linguistically widespread variety of modifying incorporation.

(5) Classical Nahuatl (Launey 1980)

(5a) Ø-Huāqui in xōchitl.

A.3-fade DEF flower

'The flower is fading.'

(5b) Ø-Tle-huāqui in xōchitl.

A.3-fire-fade DEF flower

lit. 'The flower is fire-fading.' > 'The flower is fading under the influence of fire.'

(6) Classical Nahuatl (Launey 1980)

(6a) Ø-Cuepōni in xōchitl.

A.3-bloom DEF flower

'The flower is blooming.'

(6b) Ø-Xōchi-cuepōni in no-cuīc.

A.3-flower-bloom DEF 1SG-song

lit. 'My song is flower-blooming.' > 'My song is blooming like a flower.' 
In Manding languages, several semantic types of incorporation are attested, but similative incorporation, illustrated by Ex. (7), is the only fully productive type of incorporation.

(7) Mandinka (pers.doc.)

(7a) Kàmbàanôo sólí-sáwùn-tá.

boy.D leopard-jump-CPL.INTR

'The boy jumped like a leopard.'

(7b) Mòôlú yè sùy-ôo wùlù-fáa.

person.D.PL CPL.TR thief-D dog-kill

'The people killed the thief like a dog.'

In (7a), the similarity relationship is between JUMP(the boy) and JUMP(leopards), whereas in (7b), it is between KILL(the people, the thief) and $\operatorname{KILL}(x, \operatorname{dogs})$ ('The people killed the thief as if he were a dog'). Crucially, this construction is not available to express similarity between KILL(the people, the thief) and KILL(dogs, y) ('The people killed the thief as if they were dogs'). In other words, in terms of semantic roles, the incorporated noun can be identified to $\mathrm{U}$ in intransitive predication or to $\mathrm{P}$ in the transitive construction, but not to $\mathrm{A}$. This constitutes an instance of P-alignement (or 'ergative' alignement) in a language in which A-alignment (or 'accusative' alignement) is predominant.

\subsection{Classificatory incorporation}

In classificatory incorporation, the incorporated noun is a hypernym of another noun in $\mathrm{P}$ or $\mathrm{U}$ role, or more generally a classifier expressing the categorization of the noun in $\mathrm{P}$ or U role. In Ex. (8), -'ič'ah- 'eye' acts as a classifier for small round objects, and is incorporated to the verb (with some morphophonological changes) in the presence of nouns such as 'bead' or 'plum' in U or P role.

(8) Caddo (Mithun 1986)

(8a) Kassi' háh-'ič’á-sswí'-sa'.

bead TAM-eye-string-TAM

'I am stringing beads.'

(8b) Ka'ás háh-'ič'ah-'i’-sa'.

plum TAM-eye-grow-TAM

'Plums are growing.'

Semantically, this type of incorporation is in some respects not very different from argument incorporation. The difference is however that, in classificatory incorporation, the incorporated noun does not absorb the semantic role of the corresponding argument, which makes it possible for a semantically more specific NP to occupy the syntactic position in which it is assigned this role.

\subsection{Incorporation in diachrony}

As regards the historical origin of incorporation, the first explanation that comes to mind is the univerbation of 'noun + verb' or 'verb + noun' sequences in which the noun is the head of 
a noun phrase in argument or adjunct function. This hypothesis is however difficult to reconcile with the observation that, in many languages, the relative order of the verb and the incorporated noun is different from the relative order of the verb and a noun phrase fulfilling the same semantic role.

A plausible explanation is that verbal compounds may also develop from the conversion (or 're-verbalization') of compound event nouns (such as English truck-driving). This explanation is supported by the fact that, cross-linguistically, nominal compounds are much more common than verbal compounds, and the order of the formatives in nominal compounds headed by a nominalized verb is often different from the order of the corresponding constituents in a predicative construction.

\subsection{Incorporation and transitivity marking: the case of Soninke}

\subsubsection{Introductory remarks}

In the previous sections, incorporation has been illustrated mainly by Nahuatl examples. Interestingly, Soninke is in many respects quite different typologically from Nahuatl (in particular the constituent order in verbal predication is A/U P V X, as opposed to the V A/U P $\mathrm{X}$ constituent order found in Nahuatl) but it has incorporation mechanisms strikingly similar to those found in Nahuatl.

In Soninke, as in Nahuatl, incorporation as a morphological operation creates compound verbal lexemes by attaching the non-autonomous form of a nominal lexeme to the left of a verbal lexeme. The distinction between incorporated nouns and nouns occupying a syntactic position immediately to the left of the verb is ensured by the following two particularities of nominal and verbal morphology in Soninke:

(a) most nouns have a non-autonomous form distinct from their free form, and this nonautonomous form is used whenever nouns occur as non-final formatives within compound or derived lexemes. For example, the non-autonomous form of séllìnjé 'chicken' (plural séllìnłú) is séllín-;

(b) in some conditions (for example, in combination with some negative markers) the inherent tonal melody of the verb is replaced by an entirely low melody, and this tonal change affects incorporated nouns as part of a compound verb stem, but not nouns occupying a syntactic position immediately to the left of the verb - Ex. (9).

(9) Soninke (pers.doc.)

(9a) Ì wá séllìnłû-n gáagà-ná.

3PL ICPL chicken.PL-D sell-GER

'They are selling the chickens.'

(9b) Ì ntá séllìnjú-n gàagà-nà.

3PL ICPL.NEG chicken.PL-D sell-GER ${ }^{\mathrm{L}}$

'They are not selling the chickens.'

(9c) Ì wá séllín-gáagè-né.

3PL ICPL chicken-sell.DETR-GER

'They sell chickens.' 


\section{(9d) ì ntá sèllìn-gàagè-nè. \\ 3PL ICPL.NEG chicken-sell.DETR-GER ${ }^{\mathrm{L}}$ \\ 'They don't sell chickens.'}

\subsubsection{Functional subtypes of incorporation in Soninke}

Three functional subtypes of incorporation can be distinguished in Soninke: possessive incorporation, $\mathrm{P}$ incorporation, and oblique incorporation:

- in possessive incorporation, the construction with an incorporated noun can be paraphrased by a construction in which this noun is the head of a noun phrase in U role, with a genitival modifier corresponding to $\mathrm{U}$ in the construction of the compound verb Ex. (10);

- in P incorporation, the construction with an incorporated noun can be paraphrased by a construction in which this noun is the head of a noun phrase in P role - Ex. (11);

- in oblique incorporation, the construction with an incorporated noun can be paraphrased by a construction in which this noun is the head of a noun phrase in oblique role - Ex. (12).

(10) Soninke (pers.doc.)

(10a) Múusá bùttê-n bí.

Moussa liver-D burn

Moussa got furious.' lit. 'Moussa's liver burnt.'

(10b) Múusá búttí-n-bí.

Moussa liver-EP-burn

'Moussa got furious.' lit. 'Moussa liver-burnt.'

(11) Soninke (pers.doc.)

(11a) Yàxàrú-n dà kónpè-n céllà.

woman.PL-D TR room-D sweep

'The women swept the room.'

(11b) Yàxàrû-n kónpó-séllè.

woman.PL-D room-sweep.DETR

'The women did room sweeping.' lit. 'The women room-swept.'

(12) Soninke (pers.doc.)

(12a) À yàxí qóò qùsô.

3SG get_married like girl.D

'He got married like a girl (i.e. very early).'

(12b) ì qùsù-n-ñàxí.

3SG girl-EP-get_married

'He got married like a girl (i.e. very early).' lit. 'He got girl-married.'

As illustrated by these examples, this functional distinction has two morphological correlates: 
- in possessive incorporation and oblique incorporation (but not in $\mathrm{P}$ incorporation) a linking (or epenthetic) -n- (glossed EP) occurs between the two formatives of the compound verb;

- in $\mathrm{P}$ incorporation (but not in possessive incorporation or oblique incorporation), the verbal lexeme that constitutes the second formative of the compound verb is marked as detransitivized.

The presence of the linking -n- can only be detected if the non-autonomous form of the incorporated noun does not end with a nasal. The linking -n- also occurs in some types of nominal compounds, but as discussed by Diagana (1995), its occurrence cannot be predicted by a general rule. It must be emphasized that it is probably not cognate with the determination marker -n suffixed to nouns, since the determination marker includes a floating low tone, whereas the linking -n- is tonally inert.

Interestingly, the presence vs. absence of the linking -n- may be the only clue to the distinction between $\mathrm{P}$ incorporation, as in (13b), and the incorporation of an adjunct to the detransitivized form of the same verb, as in (14b).

(13) Soninke (pers.doc.)

(13a) Múusá dà hàrû-n kátú.

Moussa TR donkey.PL-D beat

'Moussa beat the donkeys.'

(13b) Múusá hàrì-kátí.

Moussa donkey-beat.DETR

'Moussa did donkey beating.'

(14) Soninke (pers.doc.)

(14a) Múusá kátí qóò hàrê.

Moussa beat.DETR like donkey-D

'Moussa was beaten like a donkey.'

(14b) Múusá hàrì-n-kátí.

Moussa donkey-EP-beat.DETR

'Moussa was beaten like a donkey.' lit. 'Moussa was donkey-beaten.'

\subsubsection{Possessive incorporation}

In Soninke, possessive incorporation seems to be possible with intransitive verbs only, and the incorporated noun is always a body part noun. There seems to be no semantic distinction between possessive incorporation constructions and their paraphrases (in particular, they show the same tendency toward lexicalization). Possessive incorporation does not affect the transitivity of the construction either.

Morphologically, as can be seen from Ex. (15), the syntactic rearrangement that characterizes possessive incorporation is particularly apparent if a third person pronoun is involved, since in Soninke, third person pronouns have a $\mathrm{L}$ tone in core argument function $(\mathrm{A} / \mathrm{U}$ or $\mathrm{P})$, and a $\mathrm{H}$ tone in genitive function. In this example, it is also possible to observe a change in the tone of the noun 'liver', due to the fact that, in Soninke, nouns heading a 
genitival construction take a grammatical LH pattern analyzable as the mark of a construct form of nouns.

(15) Soninke (pers.doc.)

(15a) Á bùttê-n bí. $3 \mathrm{SG}^{\mathrm{H}}$ liver- $\mathrm{D}^{\mathrm{LH}}$ burn

'(S)he got furious.' lit. 'His/her liver burnt.'

(15b) À búttí-n-bí.

3SG liver-EP-burn

'(S)he got furious.' lit. 'He/she liver-burnt.'

\subsection{4. $P$ incorporation}

Semantically, $\mathrm{P}$ incorporation implies a generic reading of the incorporated noun. Syntactically, all the mechanisms sensitive to transitivity unambiguously show that $\mathrm{P}$ incorporation yields intransitive compound verbs, and this is consistent with the detransitivization marking observed in $\mathrm{P}$ incorporation.

However, although P incorporation can be analyzed functionally as a variety of antipassive (since it converts the $\mathrm{A}$ argument of a transitive verb into the $\mathrm{U}$ term of an intransitive predication), detransitivization marking in $\mathrm{P}$ incorporation is not identical to antipassive marking. In the antipassive, the general rule is the use of the dedicated antipassive marker -ndì -ndí, with the exception of a limited number of transitive verbs that have an antipassive form in -i. In $\mathrm{P}$ incorporation, the detransitivization marker -i can be used with all verbs ending with $\mathbf{a}, \mathbf{o}$, or $\mathbf{u}$; with verbs ending with $\mathbf{i}$ or $\mathbf{e}$, the antipassive marker -ndì $\sim$-ndí is sometimes found, but its use is optional, and not very frequent. Ex. (16) illustrates the case of a transitive verb whose detransitivization is marked differently in antipassive derivation and in $\mathrm{P}$ incorporation.

(16) Soninke (pers.doc.)

(16a) ì wá yìràamû-n gáagà-ná.

3SG ICPL cloth.PL-D sell-GEN

'(S)he sells (the) clothes.'

(16b) ̀̀ wá yìràn-gáagè-né.

3SG ICPL cloth-sell.DETR-GER

'(S)he does cloth selling.'

(16c) ì wá gáagá-ndì-ní.

3SG ICPL sell.ANTIPASS-GER

'She does selling.'

\subsubsection{Oblique incorporation}

In Soninke, oblique incorporation is productive with similative adjuncts, temporal adjuncts, and reduplicated numerals used adverbially with a distributive meaning. It operates on transitive and intransitive verbs without affecting their valency properties. 


\subsubsection{Similative incorporation}

As illustrated by Ex. (17) with an intransitive verb, in this kind of incorporation, the incorporated noun is semantically equivalent to a similative adjunct introduced by the preposition qóò 'like'. There seems to be no semantic difference between the two constructions, except from the fact that incorporation excludes a specific reading of the incorporated noun.

(17) Soninke (pers.doc.)

(17a) À wùrú qóò yàxàrê.

3SG run like woman.D

'He ran like a woman.'

(17b) ì yàxàrì-n-yùrú.

3SG woman-EP-run

'He ran like a woman.' lit. 'He woman-ran.'

Ex. (18) illustrates the same mechanism with a transitive verb, showing that similative incorporation has no incidence on transitivity. Note that, semantically, as already observed above about a Mandinka example, the incorporated noun describes the way the referent of $\mathrm{P}$ participates in the event: the meaning of sentence (18b) is '... like one kills dogs', not '... like dogs kill'.

(18) Soninke (pers.doc.)

(18a) À wá sòró-n kàrì-ní qóò wùllû.

3SG ICPL person.PL-D kill-GER like dog.PL.D

'He kills the people like dogs.'

(18b) À wá sòró-n jùllì-n-kàrì-ní.

3SG ICPL person.PL-D dog-EP-kill-GER

'He kills the people like dogs.' lit. 'He dog-kills the people.'

Ex. (19) shows that similative incorporation (19b) has no incidence on the behavior of transitive verbs with respect to antipassive (19c) and passive (19d) derivations.

(19) Soninke (pers.doc.)

(19a) Ì dà Múusá kátú qóò hàrê.

3PL TR Moussa beat like donkey.D

'They beat Moussa like a donkey.'

(19b) ì dà Múusá hàrì-n-kátú.

3PL TR Moussa donkey-EP-beat

'They beat Moussa like a donkey.' lit. 'They donkey-beat Moussa.'

(19c) Ì hàrì-n-kátú-ndì.

3PL donkey-EP-beat-ANTIPASS

'They beat people like donkeys.' 
(19d) Múusá hàrì-n-kátí.

Moussa donkey-EP-beat.DETR

'Moussa was beaten like a donkey.' lit. 'Moussa was donkey-beaten.'

\subsubsection{Incorporation of temporal adjuncts}

As illustrated by Ex. (20) with an intransitive verb, in this kind of incorporation, the incorporated noun is interpreted in the same way as when it occurs in post-verbal position as a as an adjunct expressing temporal location. There seems to be no semantic difference between the two constructions.

(20) Soninke (pers.doc.)

(20a) À dàgá sùxúbà.

3SG leave morning

'(S)he left in the morning.'

(20b) ì sùxùbà-n-dàgá.

3SG morning-EP-leave

'(S)he left in the morning.' lit. '(S)he morning-left.'

Ex. (21) illustrates the same mechanism with a transitive verb, and Ex. (21c-d) show that similative incorporation has no incidence on the behavior of transitive verbs with respect to antipassive and passive derivations.

(21) Soninke (pers.doc.)

(21a) À dà kónpè-n céllà sùxúbà.

3SG TR room-D sweep morning

'(S)he swept the room in the morning.'

(21b) ì dà kónpè-n cùxùbà-n-céllà.

3SG TR room-D morning-EP-sweep

'(S)he swept the room in the morning.' lit. '(S)he morning-swept the room.'

(21c) ì sùxùbà-n-céllá-ndì.

3SG morning-EP-sweep-ANTIPASS

'(S)he did the sweeping in the morning.'

(21d) Kónpè-n cùxùbà-n-céllè.

room-D morning-EP-sweep.DETR

'The room was swept in the morning.' 


\section{Bibliography \\ on transitivity, valency, voice, and related topics}

Abeillé, Anne, Danièle Godard \& Philip Miller. 1997. Les causatives en français: un cas de compétition syntaxique. Langue Française 115. 62-74.

Agel, Vilmos (ed.). 2006. Dependenz und Valenz: ein internationales Handbuch der zeitgenossischen Forschung. Berlin: Mouton.

Aikhenvald, Alexandra, Robert Dixon \& Masayuki Onishi (eds.). 2001. Non-canonical marking of subjects and objects. Amsterdam / Philadelphia: John Benjamins.

Aissen, Judith L. 1987. On the syntax of obviation. Language 73(4). 705-750.

Aissen, Judith L. 2000. YI and BI: proximate and obviative in Navajo. In Andrew Carnie, Eloise Jelinek \& Mary Ann Willie (eds.), Papers in honor of Ken Hale. MIT Working Papers on Endangered and Less Familiar Languages.

Aissen, Judith L. 2003. Differential object marking: iconicity vs. economy. Natural Language and Linguistic Theory 21. 435-83.

Aldai, Gontzal. 2008. From ergative case marking to semantic case marking: the case of historical Basque. In Mark Donohue and Søren Wichmann (eds.) The typology of semantic alignment. Oxford: Oxford University Press. 197-218.

Alexiadou, Artemis. 2010. On the morphosyntax of (anti)causative verbs. In Malka Rappaport Hovav, Edith Doron \& Ivy Sichel (eds.), Lexical semantics, syntax, and event structure. Oxford University Press. 177-203.

Alexiadou, Artemis, E. Anagnostopoulou \& M. Everaert (eds.). The unaccusativity puzzle. Oxford University Press.

Alexiadou, Artemis \& Florian Schäfer (eds.). 2010. Non-canonical passives. John Benjamins. Allerton, David John 1982. Valency and the English verb. Londres: Academic Press.

Alsina, Alex. 1991. On the argument structure of causatives. Linguistic Inquiry 23. 517-555.

Alsina, Alex. 1996. The role of argument structure in grammar, evidence from Romance. Stanford: CSLI Publications.

Alsina, Alex. \& Sam A. Mchombo. 1993. Object asymmetries and the Chichewa applicative construction. In Mchombo, Sam A. (ed.), Theoretical aspects of Bantu grammar. Stanford: CSLI Publications. 17-45

Amberber, Mengistu. 2000. Valency-changing and valency-encoding devices in Amharic. In Robert Dixon \& Aikhenvald, Alexandra (eds.), Changing valency. Cambridge University Press.

Amberber, Mengistu. 2002. Verb classes and transitivity in Amharic. Munich: Lincom.

Andersen, Torben. 1988. Ergativity in Päri, a Nilotic OVS language. Lingua 75. 289-324.

Andersen, Torben. 2002. Case inflection and nominal head marking in Dinka. Journal of African Languages and Linguistics 23(1). 1-30.

Anderson, John M. 1999. Case. In Keith Brown \& Jim Miller (eds.), Concise encyclopedia of grammatical categories. Oxford: Elsevier. 58-65

Anderson, Gregory D. S. 1995. 'Ditransitives, possessor raising, copying-to-OBJ: Animacy in morphosyntax'. Chicago Linguistic Society 31. 1-17.

Anderson, Stephen R. 1976. On the notion of subject in ergative languages. In Charles N. Li, ed. Subject and topic. New York: Academic Press, 1-23.

Anderson, Stephen R. 1977. On mechanisms by which languages become ergative. In Charles N. Li, ed. Mechanisms of syntactic change. Austin: University of Texas Press, 317-363. 
Andrews, Avery D. 2001. Non-canonical A/S marking in Icelandic. In Aikhenvald, Alexandra, Robert Dixon and Masayuki Onishi (eds.), Non-Canonical Marking of Subjects and Objects. Amsterdam: J. Benjamins. 85-111.

Aranovich, R. (ed.). 2007. Split auxiliary systems. Amsterdam / Philadelphia: John Benjamins.

Arcaini, Enrico \& Pia Galetto. 1990. Diatesi media / diatesi riflessiva, esame comparato in aree linguistiche diverse. Studi Italiani di Linguistica Teorica ed Applicata 19-2. 229-311.

Arka, I Wayan \& Malcolm Ross (eds.). 2005. The many faces of Austonesian voice systems : Some new empirical studies. Canberra: Pacific Linguistics.

Arkad'ev, Petr M.. 2006. Tipologija dvuxpadežnyx sistem. PhD thesis, Russian Academy of Sciences, Moscow.

Arkadiev, Peter M. 2009. Poor (two-term) case systems: Limits of neutralization. In Andrej Malchukov \& Andrew Spencer (eds.), Handbook of Case. Oxford: Oxford University Press. 686-699

Arkadiev, Peter M. 2015. The Berber «state » distinction: Dependent marking after all? A commentary on Mettouchi and Frajzyngier (2013). Linguistic Typology 19(1). 87-100.

Arms, David G. 1974. Transitivity in Standard Fijian. PhD dissertation. University of Michigan.

Austin, Peter K. 1982. Transitivity and cognate objects in Australian languages. In Paul J. Hopper \& Sandra A. Thompson (eds.), Studies in transitivity. New York: Academic Press. 37-47.

Austin, Peter K. 1997. Causative and applicatives in Australian aboriginal languages. In Kazuaki Matsamura \& Tomoyuki Hayashi (eds.), The dative and related phenomena. Tokyo: Hituzi Syobo. 165-225.

Authier, Gilles and Katharina Haude (eds.). 2012. Ergativity, valency and voice. De Gruyter.

Babby, Leonard. 2001. The genitive of negation: a unified analysis. In Franks S., T. King \& M. Yadroff (eds.), Formal approaches to Slavic linguistics, The Bloomington meeting 2000. Ann Arbor: Michigan Slavic Publications. 39-55.

Baker, Mark C. 1988a. Theta theory and the syntax of applicatives in Chichewa. Natural Language and Linguistic Theory 6. 353-380.

Baker, Mark C. 1988. Incorporation: a theory of grammatical function changing. Chicago: University of Chicago Press.

Barbosa, Pilar, Maria Eugènia L. Duarte \& Mary A. Kato. 2003. Sujeitos indeterminados em PE e PB. Boletim da Associação Brasileira de Linguística 26. 405-9.

Benveniste, Emile. 1952. La construction passive du parfait transitif. Bulletin de la Société de Linguistique de Paris 48. 52-62.

Bhaskararao, Peri. \& Karumuri Venkata Subbarao (eds.). 2004. Non-nominative subjects. Amsterdam / Philadelphia: John Benjamins. 169-193.

Bhatt, Rajesh \& Roumyana Pancheva. 2004. Implicit arguments. Ms. University of Texas, Austin, and University of Southern California.

Bickel, Balthasar. 2011. Grammatical relations typology. In Jae Jung Song, ed. The Oxford handbook of linguistic typology. Oxford: Oxford University Press.

Bickel, Balthasar, Taras Zakharko, Lennart Bierkandt \& Alena Witzlack-Makarevich. 2014. Semantic role clustering: an empirical assessment of semantic role types in non-default case assignment. Studies in Language 38(3). 485-511.

Bisang, Walter. 2006. Widening the perspective: Argumenthood and syntax in Chinese, Japanese and Tagalog. In Daniel Hole, Andre Meinunger \& Abraham Werner (eds.), Datives and Other Cases. Between Argument Structure and Event Structure. Amsterdam: Benjamins. 331-381. 
Biktimir, Tuvana. 1986. Impersonal passives and the -ArAk construction inTurkish. In Dan I. Slobin \& Karl Zimmer (eds.), Studies in Turkish linguistics. Amsterdam / Philadelphia: John Benjamins. 53-75.

Blake, Barry J. 1994. Case. Cambridge: Cambridge University Press.

Blevins, J. 2003. Passives and impersonals. Journal of Linguistics 39. 473-520.

Blume, Kerstin. 1998. A contrastive analysis of interaction verbs with dative complements. Linguistics 36(2). 253-280.

Boas, Hans C. 2006. A frame-semantic approach to identifying syntactically relevant elements of meaning. In Petra Steiner, Hans C. Boas \& Stefan Schierholz (eds.), Contrastive Studies and Valency: Studies in Honor of Hans Ulrich Boas. Frankfurt: Peter Lang. 119-149.

Bobaljik, Jonathan David. 1993. On ergativity and ergative unergatives. MIT Working Papers in Linguistics 19. 45-88.

Bossong, Georg. 1985. Differentielle Objektmarkierung in den Neuiranischen Sprachen. Tübingen: Gunter Narr Verlag.

Bossong, Georg. 1998. Le marquage differentiel de l'objet dans les langues d'Europe. In Jack Feuillet (ed.), Actance et valence. Berlin: Mouton de Gruyter. 259-294.

Bossong, Georg. 1998. Le marquage de l'experient dans les langues d'Europe. In Jacques Feuillet (ed.), Actance et valence dans les langues de l'Europe. Berlin: Mouton de Gruyter. 259-294.

Butt, Miriam. 2006. Theories of Case. Cambridge: Cambridge University Press.

Bostoen, Koen, Sebastian Dom, and Guillaume Segerer 2015. The antipassive in Bantu. Linguistics 53(4). 731-772.

Brahim, Ahmed. 1996. L'occultif: hypothèse pour un traitement trans-linguistique du 'passif' et des structures apparentées. Le Bardo (Tunisie): Association Tunisienne de Linguistique.

Brandner, E. \& Heike Zinsmeister (eds.). 2003. New perspectives on case theory. Stanford: CSLI Publications.

Brandt, Patrick \& Marco García García. 2010. Transitivity: form, meaning, acquisition, and processing. John Benjamins.

Bresnan, Joan. 1994. Locative inversion and the architecture of Universal Grammar. Language 70. 72-131.

Bresnan, Joan \& Lioba Moshi. 1990. Object asymmetries in comparative Bantu syntax. Linguistic Inquiry 21. 147-185. (retaken in Mchombo, Sam A. (ed.), Theoretical aspects of Bantu grammar. Stanford: CSLI Publications. 47-91).

Bresnan, Joan \& Jonni Kanerva. 1989. Locative inversion in Chichewa. Linguistic Inquiry 20. $1-50$.

Bril, Isabelle. 2005. Semantic and functional diversification of reciprocal and middle prefixes in New Caledonian and other Austronesian languages. Linguistic Typology 9(1). 25-75.

Bril, Isabelle. 2007. Reciprocal constructions in Nêlêmwa (New Caledonia). In Vladimir P. Nedjalkov (ed.), Reciprocal Constructions. Amsterdam: John Benjamins. 1439-1509.

Broadwell, George \& Lachlan Duncan. 2002. A new passive in Kaqchikel. Linguistic Discovery 1/2. 26-43.

Brown, Lea, 2003. Nias: an exception to universals of argument-marking. Paper delivered at the ALT 5 Conference, Cagliari.

Bruening, Benjamin \& Thuan Tran. 2015. The nature of the passive, with an analysis of Vietnamese. Lingua 165: 133-172.

Buth, Randall. 1981. Ergative word order - Luwo is OVS. Occasional Papers in the Study of Sudanese Languages 1. 74-90. 
Butt Miriam 2001. A reexamination of the accusative to ergative shift in Indo-Aryan. In Miriam Butt \& Tracy Holloway King (eds.), Time over matter: diachronic perspectives on morphosyntax. Stanford: CSLI Publications. 105-141.

Bynon, Theodora. 2005. Evidential, raised possessor, and the historical source of the ergative construction in Indo-Iranian. Transactions of the Philological Society 103:1. 1-72.

Cabredo Hofherr, Patricia. 2014. Les pronoms impersonnels humains : syntaxe, sémantique, morphologie. Mémoire de synthèse en vue d'une HDR. Paris: Université Paris 8.

Campbell, Lyle. 1996. 2000. Valency-changing derivations in K'iche'. In Dixon, Robert \& Alexandra Aikhenvald (eds.), Changing valency. Cambridge University Press. 236-281.

Cardinaletti, Anna. 1990. Impersonal constructions and sentential arguments in German. Padova: Unipress.

Cardona, George. 1970. The Indo-Iranian construction mana (mama) krtam. Language 46. 112.

Carrier Julien. 2012. L'expression de la transitivité en Itivimiut. MA thesis. Université du Québec à Montréal.

Chierchia, Gennaro. 1995. 'The variability of impersonal subjects'. In Emmon Bach, Eloise Jelinek, Angelika Kratzer, \& Barbara H. Partee (eds.), Quantification in natural languages. Dordrecht: Kluwer. 107-143.

Cinque, Guglielmo. 1988. 'On si constructions and the theory of arb.' Linguistic Inquiry 19. 521-582.

Clark, Ross. 1973. Transitivity and case in Eastern Oceanic languages. Oceanic Linguistics 12. $559-606$.

Cobbinah, Alexander and Friederike Lüpke. 2009. 'Not cut to fit - zero coded passives in African languages'. In M. Brenzinger and A.-M. Fehn (eds.). Proceedings of the 6th World Congress of African Linguistics. Cologne: Köppe. 153-165.

Cole, Peter. 1983. The grammatical role of the causee in universal grammar. International Journal of American Linguistics 49. 115-133.

Cole, Peter. \& Jerrold M. Sadock (eds.), Grammatical relations. New York: Academic Press.

Comrie, Bernard. 1973. The ergative: Variations on a theme. Lingua 32: 239-253.

Comrie, Bernard. 1977. In defense of spontaneous demotion: the impersonal passive. In Peter Cole, \& Jerrold M. Sadock (eds.), Grammatical relations. New York: Academic Press. 4758.

Comrie Bernard. 1978. Ergativity. In Winfred P. Lehmann (ed.), Syntactic typology, Austin, University of Texas Press, p. 329-394.

Comrie, Bernard. 2008. What is a passive? In Zarina Estrada-Fernandez, Soren Wichmann, Claudine Chamoreau \& Albert Alvarez Gonzalez (eds.), Studies in Voice and Transitivity. Munich: Lincom Europa. 1-18.

Comrie, Bernard \& Maria Polinsky (eds.). 1993. Causatives and transitivity. Amsterdam / Philadelphia: John Benjamins.

Comrie, Bernard \& Helma van den Berg. 2006. Experiencer constructions in Daghestanian languages. In Ina Bornkessel, Matthias Schlesewsky, Bernard Comrie \& Angela D. Friederici (eds.), Semantic Role Universals and Argument Linking: Theoretical, Typological, and Psycholinguistic Perspectives. Berlin: Mouton de Gruyter. 127-154.

Condoravdi, Cleo 1989. 'Indefinite and generic pronouns'. In E. Jane Fee \& Kathryn Hunt (eds.), Proceedings of the Eight West Coast Conference on Formal Linguistics. Stanford: CSLI. 71-81.

Cooreman, Ann. 1988. The antipassive in Chamorro: variations on the theme of transitivity. In Shibatani, Masayoshi. (ed.). Passive and voice. Amsterdam / Philadelphia: John Benjamins. 561-593. 
Cooreman, Ann. 1994. A functional typology of antipassive. In Fox, B. \& P. Hopper (eds.), Voice: form and function. Amsterdam / Philadelphia: John Benjamins. 49-88.

Creissels, Denis. 1979. Les constructions dites "possessives", étude de linguistique générale et de typologie linguistique. Habilitation thesis. University of Paris IV.

Creissels, Denis. 1991. La voix en soninké. Mandenkan 23. 1-24.

Creissels, Denis. 2000. L'emploi résultatif de 'être + participe passé' en français. Cahiers Chronos 6 (Passé et parfait). Amsterdam / Atlanta: Rodopi. 133-142.

Creissels, Denis. 2002. Valence verbale et voix en tswana. Bulletin de la Société de Linguistique de Paris 97(1). 371-426.

Creissels, Denis. 2005. S-O-V-X constituent order and constituent order alternations in West African languages. In Rebecca T. Cover \& Yuni Kim (eds.), Proceedings of the 31st Annual Meeting of the Berkeley Linguistics Society: Special Session on Languages of West Africa. Berkeley: Berkeley Linguistics Society. 37-52.

Creissels, Denis. 2006. A typology of subject and object markers in African languages. In F. K. Erhard Voeltz (ed.) Studies in African linguistic typology. Amsterdam \& Philadelphia: John Benjamins, 43-70.

Creissels, Denis. 2007a. Contraintes sur l'accession au rôle de sujet et stratégies de contournement : le cas du tswana. Cahiers de l'INALCO 6. 107-127.

Creissels, Denis. 2007b. Réflexivisation, transitivité et agent affecté. In André Rousseau, Didier Bottineau \& Daniel Roulland (eds.), L'énoncé réfléchi. Rennes: Presses Universitaires de Rennes. 83-106.

Creissels, Denis. 2008a. Direct and indirect explanations of typological regularities: the case of alignment variations. Folia Linguistica 42(1). 1-38.

Creissels, Denis. 2008b. Impersonal and anti-impersonal constructions: a typological approach. Text of a series of conferences delivered at the University of Tartu (Estonia, June 2008). http:// deniscreissels.fr/public/Creissels-impers.constr.pdf

Creissels, Denis. 2008a. Remarks on split intransitivity and fluid intransitivity. In Olivier Bonami \& Patricia Cabredo Hofherr (eds.), Empirical Issues in Syntax and Semantics 7. 139-168.

Creissels, Denis. 2009. Uncommon patterns of core term marking and case terminology. Lingua 119. 445-459.

Creissels, Denis. 2010. Fluid intransitivity in Romance languages: a typological approach. Archivio Glottologico Italiano 2010(2). 117-151.

Creissels, Denis. 2011. Tswana locatives and their status in the inversion construction. Africana Linguistica 17. 33-52.

Creissels, Denis. 2013. Aparición y evolución de esquemas de valencia no canónicos y ergatividad. Dans Gómez, Ricardo, Joaquín Gorrochategui, Joseba A. Lakarra \& Céline Mounole (eds.), Koldo Mitxelena Katedraren III. Biltzarra. Vitoria-Gasteiz: UPV/EHU. 141-162.

Creissels, Denis. 2014a. P-lability and radical P-alignment. Linguistics 52(4). 911-944.

Creissels, Denis. 2014b. Cross-linguistic variations in the treatment of beneficiaries and the argument vs. adjunct distinction. Linguistic Discovery 12(2). 41-55.

Creissels, Denis. 2015a. Univerbation of light verb compounds and the Obligatory Coding Principle. In Léa Nash and Pollet Samvélian (eds.), Approaches to complex predicates. Brill. 46-69.

Creissels, Denis. 2015b. Valency properties of Mandinka verbs. In Andrej Malchukov and Bernard Comrie (eds.), Valency classes in the world's languages, volume 1. De Gruyter Mouton. 221-260. 
Creissels, Denis. Forthcoming. The Obligatory Coding Principle in diachronic perspective. In Sonia Cristofaro and Fernando Zúñiga (eds.), Typological hierarchies in diachrony. Amsterdam: John Benjamins.

Creissels, Denis and Alain-Christian Bassène. 2013. Valency patterns for bivalent verbs in two West African languages: Mandinka (Mande) and Jóola Banjal (Atlantic). Afrikanistik Online.

Creissels, Denis and Céline Mounole. Forthcoming. Non-canonical valency patterns in Basque, variation and evolution.

Creissels, Denis and Anna Marie Diagne. 2013. Transitivity in Bakel Soninke. Mandenkan 50. 5-38.

Creissels, Denis and Djibril Dramé. Forthcoming 2016. Transitivity and incorporation in Soninke. Frankfurter Afrikanistische Blätter 26.

Creissels, Denis Sokhna Bao Diop, Alain-Christian Bassène, Mame Thierno Cissé, Alexander Cobbinah, El Hadji Dieye, Dame Ndao, Sylvie Nouguier-Voisin, Nicolas Quint, Marie Renaudier, Adjaratou Sall, \& Guillaume Segerer. 2015. L'impersonnalité dans les langues de la région sénégambienne. Africana Linguistica 21. 29-86.

Creissels, Denis \& Sylvie Nouguier-Voisin. 2008. Valency-changing operations in Wolof and the notion of co-participation. In Ekkehard König \& Volker Gast (eds.) Reciprocal and Reflexives, Theoretical and typological explanations. Mouton de Gruyter. 289-305.

Creissels, Denis \& Jérémie Kouadio. 2010. Ditransitive constructions in Baule. In Malchukov Andrej, Martin Haspelmath, and Bernard Comrie, Studies in ditransitive constructions: a comparative handbook. De Gruyter Mouton.

Croft, William. 1985. Indirect object 'lowering'. In Mary Niepokuj, Mary Van Clay, Vassiliki Nikiforidou \& Deborah Feder (eds.), The proceedings of the Eleventh Annual Meeting of the Berkeley Linguistic Society. Berkeley CA: Berkeley Linguistic Society. 39-51.

Cummins, Sarah. 2000. The Unaccusative Hypothesis and the Impersonal Construction of French. Canadian Journal of Linguistics / Revue canadienne de linguistique 45 (3/4). $225-$ 51.

Dahl, Eystein \& Krzysztof Stroński.2016. Indo-Aryan ergativity in typological and diachronic perspective. John Benjamins.

D’Alessandro, Roberta. 2007. Impersonal si-constructions. Berlin: Mouton De Gruyter.

D'Alessandro, Roberta \& Aartemis Alexiadou. 2003. 'Nome: a subject clitic in a southern Italian dialect'. In Martine Coene \& Y. D'Hulst (eds.), Current Studies in Comparative Romance Linguistics. Antwerp: Antwerp Papers in Linguistics. 189-218.

D'Alessandro, Roberta \& Artemis Alexiadou. 2006. 'The syntax of the indefinite pronoun nome'. Probus 18(2). 189-218.

Dalrymple, Mary, Makoto Kanazawa, Yookyung Kim, Sam Mchombo \& Stanley Peters. 1998. Reciprocal expressions and the concept of reciprocity. Linguistics and Philosophy 21. 159-210.

Dalrymple, Mary and Irina Nikolaeva. Objects and information structure. Cambridge University Press.

Danziger, Eva. 1996. Split intransitivity and active-inactive patterning in Mopan Maya. International Journal of American Linguistics, 62 (4). 379-414.

Dayley, Jon P. 1983. Voice and ergativity in Mayan languages. In A. Schlachter, Wallace L. Chafe, and Leanne L. Hinton (eds.) Studies in Meso-American linguistics. University of California, Berkeley. 5-119

de Hoop, Helen \& Peter de Swart (eds). 2008. Differential subject marking. Springer, New York.

DeLancey, Scott. 1981. An interpretation of split ergativity and related patterns. Language 57 (3): 626-657. 
DeLancey, Scott. 2004. The blue bird of ergativity. In Queixalós, Francesc (ed.), Ergativity in Amazonia III. Paris: Celia.

de Reuse, Willem J. 1994. Noun incorporation in Lakota (Siouan). International Journal of American Linguistics. 60(3). 199-260.

de Reuse, Willem J. 1999. Noun incorporation. In Keith Brown \& Jim Miller (eds.), Concise encyclopedia of grammatical categories. Oxford: Elsevier. 252-258.

de Swart, Peter, Monique Lamers \& Saunder Lestrade. 2008. Animacy, argument structure, and argument encoding. Lingua 118. 131-140.

Dimmendaal, Gerrit. 2003. Locatives as core constituents. In Shay, E. \& U. Siebert (eds.), Motion, direction, and location in languages. Amsterdam / Philadelphia: JohnBenjamins. 91-109.

Dixon, Robert. 1979. Ergativity. Language 55. 59-138.

Dixon, Robert. 1994. Ergativity. Cambridge: Cambridge University Press.

Dixon, Robert 2000. A typology of causatives: form, syntax, and meaning. In Robert Dixon \& Alexandra Aikhenvald (eds.). Changing Valency: Case Studies in Transitivity. 312-332. Cambridge University Press.

Dixon, Robert \& Alexandra Aikhenvald Aikhenvald (eds.). 2000. Changing Valency: Case Studies in Transitivity. Cambridge University Press.

Dixon, Robert \& Alexandra Aikhenvald. 2000. Introduction. In Robert Dixon \& Alexandra Aikhenvald (eds.). Changing Valency: Case Studies in Transitivity. Cambridge University Press.1-28.

Dobrovie-Sorin, Carmen. 1998. Impersonal SE constructions in Romance. Linguistic Inquiry 29. 399-437.

Dom, Sebastian, Guillaume Segerer \& Koen Bostoen. 2015. Antipassive/associative polysemy in Cilubà (Bantu L31a): A plurality of relations analysis. Studies in Language 39(2). 354-485.

Donohue, Mark and Søren Wichmann. 2008. The typology of semantic alignment. Oxford: Oxford University Press.

Dorleijn, M. 1996. The decay of ergativity in Kurmanci, language internal or contact induced? Amersfoort: Tilburg University Press.

Doron, Edit. 2003. Agency and voice: the semantics of the Semitic templates. Natural Language Semantics 11(1). 1-67.

Dowty: David. 1991. Thematic proto-roles and argument selection. Language 67. 547-619.

Dryer, Matthew. S. 1986. Primary objects, secondary objects, and antidative. Language 62. 808-45.

Dryer, Matthew \& Edward Keenan. 2007. 'Passive in the world's languages'. In Shopen, T. (ed.), Syntactic typology and linguistic description, 2nd edition. Volume I: Clause structure. Cambridge: Cambridge University Press. 325-361.

Dubinsky, Stan. 1994. Predicate union and the syntax of Japanese causatives. Journal of Linguistics 30. 43-79.

Dubinsky, Stansley, Maria-Rose Lloret \& Paul Newman. 1988. Lexical and syntactic causatives in Oromo. Language 64. 485-500.

Egerland, V. 2003. 'Impersonal pronouns in Scandinavian and Romance'. Working papers in Scandinavian syntax 71. Lund University. 75-102.

Egerland, V. 2006. 'On the syntax of uomo in Old Italian'. Paper presented at the Cambridge Italian Dialect Syntax Meeting. Cambridge.

Embick, David. 1998. Voice systems and the syntax/morphology interface. MIT Working Papers in Linguistics 32. 41-72.

England, Nora. 1983. Ergativity in Mamean (Mayan) languages. International Journal of American Linguistics 49. 1-19. 
Erteschik-Shir, Nomi \& Tova Rappaport. 2007. Projecting argument structure: the grammar of hitting and breaking revisited. In Eric Reuland, Tanmoy Bhattacharya \& Giorgos Spathas (eds.), Argument structure. John Benjamins. 37-48.

Escalante, Fernando. 1990. Voice and argument structure in Yaqui. $\mathrm{PhD}$ dissertation. University of Arizona.

Essegbey, James. 1999. Inherent complement verbs revisited: Towards an account of argument structure in Ewe. Nijmegen: University of Nijmegen doctoral dissertation.

Estival, Dominique \& John Myhill. 1988. Formal and functional aspects of the development from passive to ergative systems. In Masayoshi Shibatani (ed.), Passive and voice. Amsterdam \& Philadelphia: John Benjamins, 441ff.

Evans, Nicholas. 2004. Experiencer objects in Iwaidjan languages (Australia). In Peri Bhaskararao \& Karumuri Venkata Subbarao (eds.), Non-nominative subjects. Vol. 1. Amsterdam \& Philadelphia: John Benjamins. 169-192.

Etxepare, Ricardo. 2003. Valency and argument structure in the Basque verb. In José Ignacio Hualde and Jon Ortiz de Urbina (eds.) 2003. 363-426.

Evans, Bethwyn.2003. A study of valency-changing devices in Proto-Oceanic. Canberra: Pacific Linguistics.

Evans, Nicholas. 2004. Experiencer object in Iwaidjan languages. In Bhaskararao, P. and K.V. Subbarao (eds.), Non-nominative subjects. vol. 1. Amsterdam and Philadelphia: John Benjamins. 169-193.

Farkas, D. F. \& H. de Swart. 2003. The semantics of incorporation: from argument structure to discourse transparency. Stanford: CSLI Publications.

Fauconnier, Stefanie and Jean-Christophe Verstraete. 2014. A and O as each other's mirror image? Problems with markedness reversal. Linguistic typology 18(1). 3-49.

Faulhaber, Susen. 2011. Verb Valency Patterns: A Challenge for Semantics-based Accounts. Berlin: Mouton De Gruyter.

Fehrmann, Dorothee, Uwe Junghanns \& Denisa Lenertová. 2010. Two reflexive markers in Slavic. Russian Linguistics 34(3). 203-238.

Fernández, Beatriz and Milan Rezac. 2012. A Basque approach to differential object marking. Syntax of the World's Languages V. Dubrovnik, 1/4-10-2012.

Fernández, Zarina Estrada, Søren Wichmann \& Claudine Chamoreau. 2007. Studies in voice and transitivity. Munich: Lincom.

Fernández Soriano, O. 1999a. Two types of impersonal sentences in Spanish: locative and dative subjects. Syntax 2(2). 101-40.

Fernández Soriano, O. 1999b. Dative constructions with unaccusative se. Catalan Working Papers in Linguistics 7. 889-105.

Feuillet, Jack. (ed.). 1991. Actance et valence In les langues d'Europe. Berlin: Mouton de Gruyter.

Fillmore, Charles. 1968. The case for case. In Emmon Bach \& R. Harms (eds.), Universals in Linguistic Theory. New York: Holt, Rinehart and Winston. 1-88.

Fillmore, Charles. 1970. The grammar of hitting and breaking. In R.A. Jacobs \& P. S. Rosenbaum (eds.) Readings in English transformational grammar. Waltham MA: Gin and Company. 120-133.

Fleck, David W. 2006. Antipassive in Matses. Studies in Language 30(3). 541-573.

Foong Ha Yap \& Soichi Iwasaki. 2003. From causatives to passives: A passage in East and Southeast Asian languages. In Eugene Casad \& Gary Palmer (eds.), Cognitive linguistics and non-Indo-European languages. Berlin: Mouton de Gruyter. 419-445.

Foong Ha Yap \& Soichi Iwasaki. 2007. The emergence of GIVE passives in East and Southeast Asian languages. SEALSVIII: Papers from the 8th meeting of the Southeast Asian Linguistics Society (1998). Canberra, Pacific Linguistics. 
Forker, Diana. 2012. The bi-absolutive construction in Nakh-Daghestanian. Folia Linguistica 46(1). 75-108.

Fortescue, Michael. 1996. West Greenlandic half-transitive affixes in a diachronic perspective. In Brigitte Jacobsen \& Claus Andreasen (eds.), Cultural and social research in Greenland 95/96: Essays in honour of Robert Petersen. Nuuk: Iisimatusarfik / Atuakkiorfik.

Fortis, Jean-Michel. 2003. Voix et relations spatiales en tagalog. Bulletin de la Société de Linguistique de Paris 98. 455-484.

Fox, B. \& P. J. Hopper (eds.). 1994. Voice: form and function. Amsterdam / Philadelphia: John Benjamins.

Frajzyngier, Zygmund \& T. Curl (eds.). 2000a. Reflexives: forms and functions. Amsterdam / Philadelphia: John Benjamins.

Frajzyngier, Zygmund \& T. Curl (eds.). 2000b. Reciprocals: forms and functions. Amsterdam / Philadelphia: John Benjamins.

Frigeni, C. 2004. 'How do you miss your external argument?' Non-active voice alternations in Italian'. Toronto Working Papers in Linguistics 23(1). 47-94.

Fukui, Naoki, Shigeru Miyagawa \& Carol Tenny. 1985. Verb classes in English and Japanese: a case study in the interaction of morphology, syntax and semantics. Lexicon Working Papers, 3. Center for Cognitive Science, MIT.

Gaatone, David. 1998. Le passif en français. Paris / Bruxelles: Duculot.

Galkina-Fedoruk, E. M. 1958. Bezličnye predloženija v sovremennom russkom jazyke. Moscow.

Garrett, Andrew. 1990. The origin of NP split ergativity. Language 66: 261-296.

Geisler, Hans \& Jacob Daniel (eds.). 1998. Transitivität und Diathese in Romanischen Sprachen. Tübingen: Niemeyer.

Geniušienè, Emma. 1987. The typology of reflexives. Berlin: Mouton de Gruyter.

Gensler, Orin. 2003. Object ordering in verbs marking two pronominal objects: nonexplanation and explanation. Linguistic Typology 7(2). 187-231.

Gerdts, Donna \& Kaoru Kiyosawa. 2005. Halkomolem psych applicatives. Studies in Language 29(2). 329-362.

Giacalone, Anna \& Andrea Sansò. 2007a. 'The spread and decline of indefinite manconstructions in European languages: An areal perspective'. In P. Ramat \& E. Roma (eds.), Europe and the Mediterranean as linguistic areas: convergencies from a historical and typological perspective. Amsterdam / Philadelphia: John Benjamins. 95-131.

Giacalone, Anna \& Andrea Sansò. 2007b. 'The indefinite usage of uomo ('man') in early Italo-Romance. Grammaticalization an areality'. Archivio Glottologico Italiano XCII(I). 65-111.

Gildea, Spike. 1997. Evolution of grammatical relations in Cariban: How functional motivation precedes syntactic change. In T. Givón (ed.), Grammatical relations: $a$ functionalist perspective. Amsterdam and Philadelphia: John Benjamins. 155-198.

Gildea, Spike \& Francesc Queixalós (eds.). 2010. Ergativity in Amazonia. John Benjamins.

Givón, Talmy 1994. 'The pragmatics of de-transitive voice: functional and typological aspects of inversion'. In Givón (ed.), Voice and inversion. Amsterdam: Benjamins. 3-44.

Givón, Talmy (ed.). 1994. Voice and inversion. Amsterdam: Benjamins.

Givón, Talmy (ed.). 1997. Grammatical Relations: a Functionalist Perspective. Amsterdam / Philadelphia: John Benjamins.

Goldberg, Adele. 1992. The inherent semantics of argument structure: the case of the English ditransitive construction. Cognitive Linguistics 3(1). 37-74.

Goldberg, Adele. 1995. Constructions: A construction grammar approach to argument structure. Chicago: The University of Chicago Press. 
Goldberg, Adele. 2001. Patient arguments of causative verbs can be omitted: the role of information structure in argument distribution. Language Sciences 23. 503-524.

Goldberg, Adele. 2010. Verbs, constructions, and semantic frames. In Malka Rappaport Hovav, Edith Doron \& Ivy Sichel (eds.), Lexical semantics, syntax, and event structure. Oxford University Press. 39-58.

Gràcia, Lluïsa \& O. Fullana. 1991. On Catalan Verbal Compounds. Probus 11(2). 239-261.

Greenberg, Joseph. 1959. The origin of the Masai passive. Africa 29. 171-176.

Grimshaw, Jane. 1990. Argument structure. Cambridge, MA: MIT Press.

Grimshaw, Jane \& Sten Vikner. 1993. Obligatory adjuncts and the structure of events. In Eric Reuland \& Werner Abraham (eds.), Knowledge of language II: Lexical and conceptual structure. Dordrecht: Kluwer. 143-155.

Gropen, Jess, Steven Pinker, Michelle Holander \& Richard Goldberg. 1991. Affectedness and direct objects: the role of lexical semantics in the acquisition of verb argument structure. Cognition 41. 153-195.

Guiraud-Weber, Margueritte. 1984. Propositions sans nominatif en russe moderne. Paris: Institut d'études slaves.

Gutiérrez-Bravo, R. 2006. A reinterpretation of quirky subjects and related phenomena in Spanish. In Montreuil, J.P. \& C. Nishida (eds.), New perspectives on Romance linguistics. Amsterdam / Philadelphia: John Benjamins. 127-142.

Hagège, Claude. 2010. Adpositions. Oxford University Press.

Hale, Kenneth \& Samuel Jay Keyser. 2002. On the double object construction. Prolegomenon to a theory of argument structure. Cambridge MA: MIT Press. 159-188.

Hamlaoui, Fatima. 2014. A note on bare-passives in (selected) Bantu and western Nilotic languages. ZAS Papers in Linguistics 57. 123-135.

Harford, C. 1993. The applicative in Chishona and Lexical Mapping Theory. In Mchombo, S. A. (ed.), Theoretical aspects of Bantu grammar. Stanford: CSLI Publications. 93-111.

Harris, Alice C. 1990. Georgian: A language with active case marking. A reply to B. G. Hewitt. Lingua 80: 35-53.

Harris, Alice. 1997. Review of Ergativity by Robert Dixon. Language 73(2). 359-374.

Hartmann, Iren, Martin Haspelmath \& Michael Cysouw. 2014. Identifying semantic role clusters and alignment types via microrole coexpression tendencies. Studies in Language 38(3). 463-484.

Haspelmath, Martin. 1990. The grammaticization of passive morphology. Studies in Language 14. 25-72.

Haspelmath Martin, 1991, On the question of deep ergativity: The evidence from Lezgian. Papiere zur Linguistik 44/45, 1/2, 5-27.

Haspelmath, Martin. 1993. More on typology of inchoative/causative alternations. In Comrie Bernard and Maria Polinsky (eds), Causatives and transitivity. Amsterdam: John Benjamins.

Haspelmath, Martin. 2001. Non-canonical marking of core arguments in European languages. In Alexandra Y. Aikhenvald, Robert M. W. Dixon \& Masayuki Onishi (eds.), NonCanonical Marking of Subjects and Objects. Amsterdam: Benjamins. 53-83.

Haspelmath, Martin. 2005a. Ditransitive constructions: the verb 'give'. In Haspelmath, Martin, Matthew Dryer, David Gil \& Bernard Comrie (eds.), The World Atlas of Language Structures. Oxford: Oxford University Press. 426-429.

Haspelmath, Martin. 2005b. Argument marking in ditransitive alignment types. Linguistic Discovery 3.

Haspelmath, Martin. 2011. On S, A, P, T, and R as comparative concepts for alignment typology. Linguistic Typology 15(3). 535-567. 
Haspelmath, Martin. 2013. Argument indexing: a conceptual framework for the syntax of bound person forms. In Dik Bakker \& Martin Haspelmath (eds.), Languages Across Boundaries: Studies in Memory of Anna Siewierska, 197-226. Berlin: De Gruyter Mouton.

Haspelmath, Martin. 2014. Arguments and adjuncts as language-particular syntactic categories and as comparative concepts. Linguistic Discovery 12(2). 3-11.

Haspelmath, Martin. 2015. Transitivity prominence. In Andrej Malchukov and Bernard Comrie (eds.), Valency Classes in the World's Languages, Vol. 1. Berlin: De Gruyter Mouton. 131-147.

Haspelmath, Martin \& Iren Hartmann. 2015. 'Comparing verbal valency across languages'. In Andrej L. Malchukov \& Bernard Comrie (eds.), Valency classes in the world's languages: A comparative handbook, vol. 1. Berlin: De Gruyter Mouton. 41-71.

Haspelmath, Martin \& Thomas Müller-Bardey. Valency change. In Booij, Geert \& Lehmann, Christian \& Mugdan, Joachim (eds.), Morphology: A Handbook on Inflection and Word Formation. Vol. 2. (Handbücher zur Sprach- und Kommunikationswissenschaft) Berlin: de Gruyter. 1130-1145.

Haude, Katharina. 2009. Hierarchical alignment in Movima. International Journal of American Linguistics 75(4). 513-532.

Haude, Katharina. 2010. The intransitive basis of Movima clause structure. In Spike Gildea \& Francesc Queixalós (eds.), Ergativity in Amazonia. John Benjamins. 285-315.

Haude, Katharina and Fernando Zúñiga. 2016. Inverse systems and symmetrical voice: a unified view on languages with two transitive constructions. Linguistics 54(3). 443-481.

Heim, I., H. Lasnik \& R. May. 1991. Reciprocity and plurality. Linguistic Inquiry 22. 63-101.

Herbst, Thomas \& Katrin Gotz-Votteler (eds.). 2007. Valency: Theoretical, Descriptive and Cognitive Issues. Berlin/New York: de Gruyter.

Hériau, M. 1980. Le verbe impersonnel en français moderne. Lille: Atelier de reproduction de thèses, Université de Lille III.

Hermon, G. 2001. Non-canonically marked A/S in Imbabura Quechua. In alexandra Aikhenvald, Robert Dixon \& Masayuki Onishi (eds.), Non-canonical marking of subjects and objects. Amsterdam / Philadelphia: John Benjamins. 149-176.

Herslund, Michael. 2007. L'antipassif réfléchi en français et en danois. In André Rousseau, Didier Bottineau \& Daniel Roulland (eds.), L'énoncé réfléchi. Rennes: Presses Universitaires de Rennes. 175-186.

Hewitt, B. G. 1981. Antipassive and labile constructions in North Caucasian. General Linguistics 22. 158-171.

Holton, Gary. 2008. The emergence of stative-active systems in North Halmahera, Indonesia. In Donohue, Mark and Søren Wichmann (eds.), The typology of semantic alignment. Oxford: Oxford University Press.

Hewitt, Steve. 2002. The impersonal in Breton. Journal of Celtic Languages 7. 1-39.

Hohepa, P. W. 1969. The accusative-to-ergative drift in Polynesian languages. Journal of Polynesian Society 78. 297-329.

Holmberg, A. Forthcoming. The null generic subject pronoun in Finnish. In Kaiser E., S. Manninen, K. Hiietam \& V. Vihman (eds.), Passives and impersonals in European languages. Oxford: Oxford University Press.

Hook, Peter E. 1991. The compound verb in Munda: An areal and typological overview. Language Sciences 13/2. 181-195.

Hopper Paul J. \& Sandra A. Thompson, 1980, Transitivity in grammar and discourse. Language 56(2). 251-299.

Hopper, Paul J. \& Sandra A. Thompson (eds.). 1982. Studies in transitivity. New York: Academic Press. 
Horrocks, Geoffrey \& Melita Stavrou. 2010. Morphological aspect and the function and distribution of cognate objects across languages. In Malka Rappaport Hovav, Edith Doron \& Ivy Sichel (eds.), Lexical semantics, syntax, and event structure. Oxford University Press. 284-308.

Horváth, Julia \& Tal Siloni. 2010. Lexicon versus syntax: Evidence from morphological causatives. In Malka Rappaport Hovav, Edith Doron \& Ivy Sichel (eds.), Lexical semantics, syntax, and event structure. Oxford University Press. 153-176.

Hudson, R. A. 1992. So-called 'double objects' and grammatical relations. Language 68. 251276.

Humphreys, R. L. 1999. Valency changing alternations. In Keith Brown \& Jim Miller (eds.), Concise encyclopedia of grammatical categories. Oxford: Elsevier. 391-400.

Iemmolo, Giorgio. 2010. Topicality and differential object marking: Evidence from Romance and beyond. Studies in Language 34. 239-272.

Iemmolo, Giorgio. 2011. Towards a typological study of differential object marking and differential object indexation. Doctoral dissertation. Pavia: Università degli studi di Pavia.

Iemmolo, Giorgio \& Gerson Klump (eds.). 2014. Special thematic issue on Differential Object Marking. Linguistics 52(2).

Iwasaki, Shoichi \& Foong-Ha Yap. 2000. Give constructions in Thai and beyond: A cognitive and grammaticalization perspective. Proceedings of the International Conference on Tai Studies, July 29-31, 1998. Bangkok: Institute of Language and Culture for Rural Development, Mahidol University. 371-382.

Jacques, Guillaume. 2014. Denominal affixes as sources of antipassive markers in Japhug Rgyalrong. Lingua 138. 1-22.

Jacques, Guillaume \& Anton Antonov. 2014. 'Direct/inverse systems'. Language and Linguistics Compass 8/7, 301-318.

Janic, Katarzyna. 2013. L'antipassif dans les langues accusatives. $\mathrm{PhD}$ thesis. University of Lyon.

Janko-Trinitskaja, N. A. 1962. Vozvratnye glagoly v sovremennom russkom jazyke. Moscow: AN SSSR.

Johns, Alana, Diane Massam \& Juvénal Ndariyagije (eds.). 2006. Ergativity: Emerging issues. Dordrecht: Springer.

Jones, Douglas (ed.). 1994. Working Papers and Projects on Verb Class Alternations in Bangla, German, English, and Korean. MIT AI Memo 1517.

Jónsson, J. 1992. 'The pronoun maður in Icelandic'. Ms. Amherst: University of Massachusetts.

Joppen-Hellwig, Sandra. 2001. Verbklassen und Argumentlinking. Tubingen: Niemeyer.

Kageyama, Taro \& Wesley M. Jacobsen (eds.). Forthcoming. Transitivity and Valency Alternations: Studies on Japanese and Beyond. Berlin: De Gruyter Mouton.

Kaiser, E. \& V. Vihman. 2006. 'Invisible arguments: Effects of demotion in Estonian and Finnish'. In B. Lyngfelt \& T. Solstad (eds.), Demoting the agent. Amsterdam / Philadelphia: John Benjamins. 111-140.

Kalmár, I. 1979. The antipassive and grammatical relations in Eskimo. In Plank, F. (ed.), Ergativity: towards a theory of grammatical relations. Londres / New York: Academic Press. 117-44.

Károly, Sándor. 1982. Intransitive-transitive derivational suffixes in Hungarian. In Ferenc Kiefer (ed.), Hungarian Linguistics. John Benjamins. 185-244.

Kaufmann, Ingrid. 1995. O- and D-predicates: a semantic approach to the unaccusativeunergative distinction. Journal of Semantics 12. 377-427.

Kawasha, B. 2007. Passivization in Lunda. Journal of African Languages and Linguistics 28/1. 37-56. 
Kazenin, Konstantin I. 1994a. Split syntactic ergativity: toward an implicational hierarchy. Sprachtypologie und Universalienforschung 47. 78-98.

Kazenin, Konstantin I. 1994b. On the lexical distribution of agent-preserving and objectpreserving transitivity alternations. Nordic Journal of Linguistics 17. 141-154.

Keenan, Edward L. 1976. Towards a universal definition of 'subject'. In Li, C. (ed.), Subject and topic. New York: Academic Press. 303-333.

Keenan, Edward L. 1985. Passive in the world's languages. In Timothy Shopen (ed.), Language Typology and Syntactic Description, Vol 1. Cambridge University Press. 243281.

Keenan, Edward \& Matthew Dryer. 2007. Passive in the world's languages. In Timothy Shopen (ed.), Language typology and syntactic description, vol. 1, 2nd edition. Cambridge University Press. 325-361.

Kemmer, Susan. 1993. The middle voice. Amsterdam / Philadelphia: John Benjamins.

Kibort, Anna. 2003. Passive and passive-like constructions in English and Polish: a constrastive study with particular reference to impersonal constructions. $\mathrm{PhD}$ dissertation. University of Cambridge.

Kibrik, Alexandr. 1996. Transitivity in Godoberi. In Kibrik, Alexandr (ed.), Godoberi. München: Lincom Europa.

Kibrik Aleksandr E. 1997, Beyond subject and object: Towards a comprehensive relational typology. Linguistic Typology 1. 279-346.

Kitagawa, C. \& A. Lehrer. 1990. 'Impersonal uses of personal pronouns'. Journal of Pragmatics 14. 739-759.

Kittilä, Seppo. 2002. Transitivity: towards a comprehensive typology. Turku: Åbo Akademis Tryckeri.

Kittilä, Seppo. 2005. Remarks on involuntary agent constructions. Word 56. 377-413.

Kittilä, Seppo. 2006. The anomaly of the verb 'give' explained by its high (formal and semantic) transitivity. Linguistics 44(3). 569-612.

Kittilä, Seppo. 2007. A typology of tritransitives. Alignment types and motivations. Linguistics45. 455-508.

Kittilä, Seppo. 2009. Causative morphemes as non-valence increasing devices. Folia Linguistica 43(1). 67-94.

Kittilä, Seppo. 2013. Causative morphemes as de-transitivizing devices: what do noncanonical instances reveal about causation and causativization. Folia Linguistica 43(1). 6794.

Kittilä, Seppo and Fernando Zúñiga (eds.). 2016. Advances in Research on Semantic Roles. Amsterdam / Philadelphia: John Benjamins.

Kiyosawa, Kaoru and Donna B. Gerdts. 2010. Salish Applicatives. Leiden / Boston: Brill.

Klaiman, M. H. 1980. Bengali dative subjects. Lingua 51. 275-295.

Klaiman, M. H. 1991. Grammatical voice. Cambridge: Cambridge University Press.

Klaiman, M. H. 1992. Inverse languages. Lingua 88(3/4). 227-261.

Klimov, Georgij. 1977. Tipologija jazykov aktivnogo stroja. Moskva: Nauka.

König, Christa. 2006. Marked nominative in Afrika. Studies in language 30(4), 705-82.

König, Christa. 2008. Case in Africa. Oxford University Press.

König, Ekkehard \& Volker Gast (eds.) Reciprocal and Reflexives, Theoretical and typological explanations. Mouton de Gruyter.

König, Ekkehard \& P. Siemund. 2000. Intensifiers and reflexives: a typological perspective. In Frajzyngier, Z. \& T. S. Curl (eds.), Reflexives: forms and functions. Amsterdam / Philadelphia: John Benjamins. 
Kœnig, Jean-Pierre. 1999. On a tué le président! The nature of passives and ultra-indefinites. In B. Fox, D. Jurafsky, \& L. Michaelis (eds.), Cognition and function in language. Stanford: CSLI. 256-272.

Kœnig, Jean-Pierre, \& G. Mauner. 1999. 'A-definites and the discourse status of implicit arguments'. Journal of Semantics 16(3). 207-236.

Kozinsky, I. Š., 5. P. Nedjalkov \& M. S. Polinskaya. 1988. Antipassive in Chukchee: oblique object, object incororation, zero object. In Shibatani, M. (ed.), Passive and voice. 651-706. Amsterdam / Philadelphia: John Benjamins.

Kratochvil, Frantisek. 2011. Transitivity in Abui. Studies in Language 35(3). 588-635.

Kratochvil, František, Alexander R. Coupe \& Randy J. LaPolla (eds.). 2011. Special thematic issue on Studies in Transitivity: Insights from Language Documentation. Studies in Language 35(3).

Kroeger, P. R. 1993. Phrase structure and grammatical relations in Tagalog. Stanford: CSLI Publications.

Krueger, John R. 1964. The Turco-Mongolian benefactive. Journal of the American Oriental Society 84/4. 410-1.

Kulikov, Leonid. 1993. The 'second causative': a typological sketch. In Bernard Comrie \& Maria Polinsky (eds.), Causatives and transitivity. Amsterdam / Philadelphia: John Benjamins.121-154.

Kulikov, Leonid. 2011. Voice typology. In Jae Jung Song (ed.), The Oxford Handbook of Linguistic Typology, 368-398. Oxford: Oxford University Press.

Kulikov, Leonid. 2013. Middle and reflexive. In Silvia Luraghi and Claudia Parodi (eds.), The Bloomsbury companion to syntax. Bloomsbury.

Kulikov, Leonid, Andrej Malchukov \& Peter de Swart (eds.). 2006. Case, valency and transitivity. John Benjamins.

Kwon, S.M. \& Anne Zribi-Hertz. 2006. Differential function marking and focus structure: some evidence from Korean. Manuscrit. Université de Paris 8.

Laka, Itziar. 1993. Unergatives that assign ergative, Unaccusatives that assign accusative. In Jonathan Bobaljik and Colin Phillips (eds.) Papers on case and agreement I. volume 18. MIT Working Papers in Linguistics. 149-172.

Laka, Itziar. 2000. Thetablind case: Burzio's generalisation and its image in the mirror. In Eric Reuland (ed.) Arguments and case: Explaining Burzio's generalisation. Amsterdam: John Benjamins. 103-129.

Lambrecht, Knud. 2000. When subjects behave like objects: an analysis of the merging of $S$ and $\mathrm{O}$ in sentence focus constructions across languages. Studies in Language 24. 611-682.

Langacker, Ronald, and Pamela Munro. 1975. Passives and their meaning. Language 51. 789830.

Larson, Martha. 2005. The Empty Object Construction and related phenomena. $\mathrm{PhD}$ thesis. Cornell University.

Larson, R. K. 1988. On the double object construction. Linguistic Inquiry 19. 335-392.

Latrouite, Anja. 2011. Voice and case in Tagalog: the coding of prominence and orientation. $\mathrm{PhD}$ thesis. Düsseldorf: Heinrich-Heine Universität.

Lavidas, Nikolaos. 2007. The diachrony of the Greek anticausative morphology. In Artemis Alexiadou (ed.), The morphosyntax of Modern Greek. Cambridge Scholars Publishing.

Lazard, Gilbert. 1985. Anti-impersonal verbs, transitivity continuum and the notion of transitivity. In Hansjakob Seiler \& Gunter Brettschneider, eds. Language invariants and mental operations. Tübingen: Gunter Narr Verlag, 115-123.

Lazard, Gilbert. 1994. L'actance. Paris: Presses Universitaires de France.

Lazard, Gilbert. 1995. Le géorgien: Actance duale ('active') ou ergative ? Typologie des verbes anti-impersonnels. Sprachtypologie und Universalienforschung 48: 275-293. 
Lazard Gilbert, 1997, 'Review of Ergativity by Robert Dixon', Linguistic Typology 1, p. 243268.

Lazard, Gilbert (ed.). 1997b. La typologie actancielle. Pisa: Pacini.

Lazard, Gilbert. 2001. Le marquage différentiel de l'objet. In Haspelmath, M., E. König, W. Österreicher \& W. Raible (eds.), Language typology and language universals. Vol. 2. 873885. Berlin: Mouton de Gruyter.

Lazard, Gilbert. 2002. Transitivity revisited as an example of a more strict approach in typological research. Folia Linguistica 36(3-4). 141-190.

Lazard Gilbert. 2003. Le sujet en perspective interlinguistique. In J.-M. Merle (ed.), Le sujet. Gap-Paris : Ophrys. 15-28.

Lazard Gilbert. 2008. Nouvelles remarques au sujet du sujet. BSL 103(1). 111-121.

Lazard Gilbert. 2009. Qu'est-ce qu'un sujet ? La linguistique 45(1). 151-158.

Legendre, G. \& A. Sorace. 2003. Auxiliaires et intransitivité en français et In les langues romanes. In Godard, D. (ed.), Les langues romanes, problèmes de la phrase simple. Paris: CNRS Editions. 185-233.

Lehmann, Christian. 1991. Predicate classes and PARTICIPATION. In Hansjakob Seiler \& Waldfried Premper (eds.), Partizipation: das sprachliche Erfassen von Sachverhalten, 183-239. Tubingen: G. Narr.

Lehmann, Christian. 1999. Possession in Yucatec Maya: Structures, functions, typology. Munich: Lincom.

Lehmann, Christian, Yong-Min Shin \& Elisabeth Verhoeven. 2004. Direkte und indirekte Partizipation. Zur Typologie der sprachlichen Reprasentation konzeptueller Relationen, 2nd revised edn. Erfurt: Seminar fur Sprachwissenschaft der Universitat (ASSidUE, 13).

Letuchiy, Alexander. 2006. Case marking, possession and syntactic hierarchies in Khakas causative constructions in comparison with other Turkic languages. In Leonid Kulikov, Andrej Malchukov \& Peter de Swart (eds.), Case, Valency, and Transitivity, 417-441. Amsterdam: John Benjamins.

Letuchiy, Alexander. 2009. Towards a typology of labile verbs: Lability vs. derivation. In Alexandre Arkhipov \& Patience Epps (eds.), New challenges in typology: Transcending the borders and refining the distinctions. 223-244. Berlin \& New York: Mouton de Gruyter.

Letuchiy, Alexander. 2012. Ergativity in the Adyghe system of valency-changing derivations. In Gilles Authier and Katharina Haude (eds.), Ergativity, valency and voice. De Gruyter.

Levin, Beth. 1993. English Verb Classes and Alternations. Chicago: University of Chicago Press. 372-428.

Levin, Beth \& Malka Rappaport. 1986. The formation of adjectival passives. Linguistic Inquiry 17. 623-61.

Levin, Beth \& Malka Rappaport Hovav. 1995. Unaccusativity. At the syntax-lexical semantics interface. Cambridge / London: The MIT Press.

Levin, Beth \& Malka Rappaport Hovav. 2005. Argument Realization. Cambridge: Cambridge University Press.

Li, Charles. 2007. Split ergativity and split intransitivity in Nepali. Lingua 117. 1462-1482.

Lichtenberk, František. 1985. Multiple uses of reciprocal constructions. Australian Journal of Linguistics 5. 19-41.

Lichtenberk, František. 1991. Reciprocal and depatientives in To'aba'ita. In Robert Blust (ed.), Currents in Pacific Linguistics: Papers on Austronesian languages and Ethnolinguistics in honour of George W. Grace. Canberra: Pacific Linguistics. 171-183.

Lichtenberk, František. 1999. Reflexives and reciprocals. In Keith Brown \& Jim Miller (eds.), Concise encyclopedia of grammatical categories. Oxford: Elsevier. 313-319. 
Lichtenberk, František. 2000. Reciprocals without reflexives. In Zygmunt Frjzyngier and Traci S. Curl (ed.), Reciprocals: forms and functions. John Benjamins. 31-62.

Lichtenberk, František. 2007. Reciprocals and related meanings in To'aba'ita. In Vladimir P. Nedjalkov (ed.), Reciprocal Constructions. Amsterdam: John Benjamins. 1547-1574.

Ljutikova, Ekaterina. 2001. Perexodnost' i diateznye preobrazovanija [Transitivity and diathetic transformations]. In Aleksandr E. Kibrik (ed.), Bagvalinskij jazyk (grammatika, teksty, slovari) [The Bagvalal language (grammar, texts, dictionaries]. Moscow: Nasledie. 377-400.

Lord, Carol, Foong-Ha Yap, \& Shoichi Iwasaki. 2002. Grammaticalization of 'give': African and Asian perspectives. In Ilse Wischer \& Gabriele Diewald (eds.), New reflections on grammaticalization. Amsterdam / Philadelphia: John Benjamins. 217-235.

Lüpke, Friederike. 2005. A grammar of Jalonke argument structure. Doctoral thesis. University of Nijmegen.

Lüpke, Friederike. 2007. Vanishing Voice - the Morphologically Zero-Coded Passive of Jalonke. Linguistische Berichte 14. 173-90.

Luraghi, Silvia \& Heiko Narrog. 2014. Perspectives on semantic roles. John Benjamins.

Lyngfelt, Benjamin \& Torgrim Solstad. 2006. Demoting the agent: Passive, middle, and other voice phenomena. John Benjamins.

Mabugu, Patricia R. 2002. Polysemy and applicative verb construction in Chishona. Doctoral thesis. University of Edinburgh.

Macfarland Talke. 1995. Cognate objects and the argument/adjunct distinction in English. PhD dissertation. Evanston, Illinois: Northwestern University.

Malchukov, Andrej. 1993. The syntax and semantics of adversative constructions in Even. Gengo Kenkyu 103. 1-36.

Malchukov, Andrej. 2005. Case pattern splits, verb types, and construction competition. In Mengistu Amberber \& Helen de Hoop (eds.), Competition and Variation in Natural Languages: The Case for Case, 73-117. Amsterdam: Elsevier.

Malchukov, Andrej. 2008. Split intransitives, experiencer objects and 'transimpersonal' constructions: (re-) establishing the connection. In Mark Donohue \& Soren Wichmann (eds.), The Typology of Semantic Alignment, 76-101. Oxford: Oxford University Press.

Malchukov, Andrej. Forthcoming. "Ambivalent voice": markedness effects in valency change. In Taro Kageyama \& Wesley M. Jacobsen (eds.), Transitivity and Valency Alternations: Studies on Japanese and Beyond. Berlin: De Gruyter Mouton.

Malchukov, Andrej and Bernard Comrie (eds.). 2015. Valency Classes in the World's Languages, Vol. 1. Berlin: De Gruyter Mouton.

Malchukov, Andrej and Bernard Comrie (eds.). 2015. Valency Classes in the World's Languages, Vol. 2. Berlin: De Gruyter Mouton.

Malchukov, Andrej, Martin Haspelmath \& Bernard Comrie (eds.). 2010a. Studies in Ditransitive Constructions: A Comparative Handbook. Berlin: De Gruyter Mouton.

Malchukov, Andrej, Martin Haspelmath \& Bernard Comrie (eds.). 2010b. Ditransitive constructions: a typological overview. In Andrej Malchukov, Martin Haspelmath \& Bernard Comrie (eds.), Studies in ditransitive constructions: a comparative handbook. Berlin / New York: De Gruyter Mouton. 1-64.

Malchukov, Andrej \& Peter de Swart. 2009. Differential case marking and actancy variation. In Andrej Malchukov \& Andrew Spencer (eds.), Handbook of Case. Oxford: Oxford University Press. 339-356.

Malchukov Andrej \& Akio Ogawa. 2011. Towards a typology of impersonal constructions: A semanctic map approach. In Andrej Malchukov \& Anna Siewierska (eds.), Impersonal constructions, a cross-linguistic perspective. Amsterdam / Philadelphia: John Benjamins. 19-56. 
Malchukov, Andrej \& Anna Siewierska (eds.) (2011), Impersonal constructions: a crosslinguistic perspective, Amsterdam /Philadelphia: John Benjamins.

Malchukov, Andrej \& Andrew Spencer (eds.) 2009. The Oxford handbook of case. Oxford University Press.

Maling, J. 2001. Dative: the heterogeneity of the mapping among morphological case, grammatical functions, and thematic roles. Lingua 111. 419-464.

Manninen, S. \& D. Nelson. 2004. 'What is a passive? The case of Finnish'. Studia Linguistica 58(3). 212-251.

Manning Christopher D. 1996. Ergativity: Argument structure and grammatical relations. Stanford, CA, CSLI Publications.

Maran, Raw La \& John F. Clifton 1976. The causative mechanism in Jinghpaw. In Masayoshi Shibatani (ed.), The grammar of causative constructions. New York: Academic Press. 443458.

Marandin Jean-Marie. 2001. Unaccusative inversion in French. In d'Hulst Y., J. Rooryck \& J. Schroten, Going Romance 1999: selected papers. Amsterdam: John Benjamins.

Marantz Alec, 1984, On the nature of grammatical relations, Cambridge, MIT Press.

Marantz, Alec. 1993. Implications of asymmetries in double object constructions. In Mchombo, S. A. (ed.), Theoretical aspects of Bantu grammar. Stanford: CSLI Publications. 113-150.

Marelj, Marijana. 2004. Middles and argument structure across languages. $\mathrm{PhD}$ thesis. University of Utrecht: LOT.

Margetts, Anna \& Peter K. Austin. 2007. Three-participant events in the languages of the world: towards a crosslinguistic typology. Linguistics 45(3). 393-450.

Marten, Lutz. 2003. The dynamics of Bantu applied verbs: an analysis at the syntaxpragmatics interface. In Kézié K. Lébikaza (ed.), Actes du 3e Congrès Mondial de Linguistique Africaine Lomé 2000. Cologne: Köppe. 207-221.

Marten, Lutz. 2006. Locative inversion in Otjiherero: More on morphosyntactic variation in Bantu. ZAS Papers in Linguistics 43. 97-122.

Marten, Lutz and Jenneke van der Waal. 2014. A typology of Bantu subject inversion. Linguistic Variation 14(2). 318-368.

Massam, Diane. 1990. Cognate objects as thematic objects. Canadian Journal of Linguistics 1990. 161-190.

Mchombo, Sam A. 1999. Argument structure and verbal morphology in Chichewa. Malilime: Malawian Journal of Linguistics 1. 57-75.

Melis, Ludo. 1980. La voie pronominale. Louvain: Duculot.

Merlan, Francesca. 1985. Split intransitivity: functional oppositions in intransitive inflection. In Nichols, Johanna. \& A. Woodbury (eds.), Grammar inside and outside the clause: some approaches to theory from the field. Cambridge: Cambridge University Press. 324-62.

Miller, C. L. \& L. G. Gilley. 2001. Evidence for ergativity in Shilluk. Journal of African Languages and Linguistics 22(1). 33-68.

Mithun, Marianne. (1984). The evolution of noun incorporation. Language 60(4). 847-895.

Mithun, Marianne. (1986). On the nature of noun incorporation. Language 62(1). 32-38.

Mithun, Marianne. 1991. Active/agentive case marking and its motivations. Language 67: 510-546.

Mithun, Marianne. 2001. Understanding and explaining applicatives. Chicago Linguistic Society 37(2). 73-97.

Mithun, Marianne. 2008. The Emergence of Agentive Patient Systems in Core Argument Marking. In Donohue, Mark and Søren Wichmann (eds.), The typology of semantic alignment. Oxford: Oxford University Press. 
Mithun Marianne \& Wallace Chafe. 1999. What are S, A, and O? Studies in Language 23. 569-596.

Mittwoch, Anita. 1971. Optional and obligatory verbal complements in English. PhD thesis. SOAS, London.

Mittwoch, Anita. 1982. On the difference between eating and eating something: activities versus accomplishments. Linguistic Inquiry 13. 113-122.

Mittwoch, Anita. 1998. Cognate objects as reflections of Davidsonian event arguments. In S. Rothstein (ed.), Events and grammar. Dordrecht: Kluwer.

Mittwoch, Anita. 2005. Unspecified arguments in episodic and habitual sentences. In Nomi Erteschik-Shir \& T. Rapoport (eds.), The syntax of aspect. Oxford University Press.

Miyamoto, Tadao. 2000. The light verb construction in Japanese. Amsterdam \& Philadelphia: John Benjamins.

Mohanan, T. 1994. Argument structure in Hindi. Stanford: CSLI Publications.

Montaut, Annie. 1997a. L'ergativité en indo-aryen. Faits de langues 10. 57-64.

Montgomery-Anderson, B. 2006. Light verbs and split ergativity in Western Cholan languages. Kansas Working Papers in Linguistics 28.

Moravcsik, Edith A. 1978. On the distribution of ergative and accusative patterns. Lingua 45: 233-279.

Morin, Y.C. \& E. Tiffou. 1988. Passives in Burushaski. In Shibatani (ed.), Passive and voice. Amsterdam / Philadelphia: John Benjamins. 493-524.

Moser, Rosmarie. 2005. Grammaticalization chains of the verb kàre 'to give' in Kabba. In Erhard F. K. Voeltz (ed.), Studies in African linguistic typology. Amsterdam / Philadelphia: John Benjamins. 277-301.

Moshi, Lioba. 1998. Word order in multiple object constructions in KiVunjo-Chaga. Journal of African Languages and Linguistics 19. 137-152.

Mounole, Céline. 2012. The evolution of transitive verbs in Basque and the emergence of dative-marked patients. In Gilles Authier and Katharina Haude (eds.), Ergativity, valency and voice. De Gruyter. 355-380.

Moyse-Faurie, Claire. 2003. The ergative features of Papuan and Austronesian languages. In Francisco Queixalos, ed. Ergatividade na Amazônia II. Paris: CELIA \& Brasília: Laboratório de línguas indígenas, 39-60.

Moyse-Faurie, Claire. 2007. Reciprocal, sociative, middle, and iterative constructions in East Futunan. In Vladimir P. Nedjalkov (ed.). 2007. Reciprocal Constructions. Amsterdam: John Benjamins. 1511-1543.

Moyse-Faurie, Claire. 2008. Constructions expressing middle, reflexive and reciprocal situations in some Oceanic languages. In Ekkehard König \& Volker Gast (eds.) Reciprocal and Reflexives, Theoretical and typological explanations. Mouton de Gruyter. 105-168.

Moyse-Faurie, Claire. 2010. L'ambitransitivité: exemples océaniens. In Frank Floričić (ed.) Essais de typologie et de linguistique générale. Mélanges offerts à Denis Creissels. Lyon: ENS Editions. 505-525.

Moyse-Faurie, Claire \& Françoise Ozanne-Rivierre. 1983. Subject case markers and word order in New Caledonia and Loyalty Islands Languages. In A. Halipm, L. Carrington \& S. Wurm (eds.) Papers from the Third International Conference on Austronesian Linguistics, vol. 4: Thematic variation. Pacific Linguistics, C-77. 113-152.

Muller-Gotama, Franz. 1994. Grammatical Relations: A Cross-Linguistic Perspective on their Syntax and Semantics. Berlin: Mouton de Gruyter.

Munro, Pamela. 2007. Oblique subjects in Garifuna. In Austin, P. \& A. Simpson (eds.), Endangered languages. Hamburg: Helmut Buske. 113-41.

Næss Åshild, 2007, Prototypical Transitivity, Amsterdam and Philadelphia, John Benjamins. 
Napoli, Donna Jo. 1999. Resultatives. In Keith Brown \& Jim Miller (eds.), Concise encyclopedia of grammatical categories. Oxford: Elsevier. 324-329.

Nash, Léa and Pollet Samvélian (eds.). 2015. Approaches to complex predicates. Brill.

Ndayiragije, Juvénal. 2003. Théories linguistiques et réciprocité en chichewa: la leçon du kirundi. In Sauzet, P. \& A. Zribi-Hertz (ed.), Typologie des langues d'Afrique et universaux de la grammaire. Vol. 1. Paris: L'Harmattan. 169-210.

Nedjalkov, Vladimir P. 1964. O svjazi kauzativnosti i passivnosti. [On the relation between causatives and passives]. In J. M. Skrebnev (ed.), Voprosy ob̌̌čego i romano-germanskogo jazykoznanija [Problems of Romance and Germanic linguistics], 301-310. Ufa: Baškirskoe knižnoe izdatel'stvo.

Nedjalkov, Vladimir P. (ed.). 2007. Reciprocal Constructions, 5 vols. Amsterdam: John Benjamins.

Nedjalkov, Vladimir P. \& Georgij G. Sil'nitskij. 1969. Tipologija morfologičeskogo i leksičeskogo kauzativov [Typology of morphological and lexical causatives]. In Alexandr A. Xolodovič (ed.), Tipologija kauzativnyx konstrukcij. Morfologičeskij kauzativ, 5-50. Leningrad: Nauka.

Nedjalkov, Vladimir P. and Sergej Je. Jaxontov (eds.). 1988. Typology of resultative constructions. Amsterdam and Philadelphia: John Benjamins.

Nichols, Johanna. 1986. Head-marking and dependent-marking grammar. Language 62, 56119.

Nichols, Johanna. 2008. Why are stative-active languages rare in Eurasia? A typological perspective on split-subject marking. In Mark Donohue \& Soren Wichmann (eds.), The Typology of Semantic Alignment. Oxford: Oxford University Press. 121-139.

Nichols Johanna, David Peterson, and Jonathan Barnes. 2004. Transitivizing and detransitivizing languages. Linguistic Typology 8. 149-211.

Noonan, Michael. 1994. 'A tale of two passives in Irish'. In Hopper, P. \& B. Fox (eds.), Voice: form \& function. Amsterdam / Philadelphia: John Benjamins.

Noonan, Michael. 2001. 'Subjectless clauses in Irish'. Paper presented at the International Symposium on Non-nominative Subjects. Tokyo: Institute for the Study of Languages and Cultures of Asia and Africa.

Nouguier, Sylvie. 2002. Relations entre fonctions syntaxiques et fonctions sémantiques en wolof. Thèse de doctorat. Université Lyon 2.

Nouguier, Sylvie. 2003. Un syncrétisme causatif / applicatif en wolof? In Patrick Sauzet. \& Anne Zribi-Hertz (ed.), Typologie des langues d'Afrique et universaux de la grammaire. Vol. 2. Paris: L'Harmattan. 185-203.

Onishi, Masayuki. 2001. Non-canonically marked S/A in Bengali. In Alexandra Aikhenvald, Robert Dixon \& Masayuki Onishi (eds.), Non-canonical marking of subjects and objects. Amsterdam / Philadelphia: John Benjamins. 113-47.

Operstein, Natalie \& Aaron Huey Sonnenschein (eds.). 2015. Valency changes in Zapotec. Synchrony, diachrony, typology. John Benjamins.

Oyharçabal, Bernard. 2007. Basque light verb constructions. In Joseba A. Lakarra and José Ignacio Hualde (eds.) Studies in Basque and Historical Linguistics. In Memory of R. L. Trask. Bilbao: Diputacion Foral de Gipuzkoa - Gipuzkoako Foru Aldundia and Universidad de Pais Vasco - Euskal Herriko Unibertsitatea, Bilbao. 787-806.

Öztürk, Balkiz. 2003. Complex predicates in Turkish. In Conor Quinn, Claire Bowern \& Gülsat Aygen, eds. Harvard University Working Papers in Linguistics (Papers from the Harvard University/Dudley House Light Verb Workshop) Vol. 9. 171-192.

Palmer Frank R. 1994. Grammatical roles and relations. Cambridge University Press.

Paramasivam, K. 1979. Effectivity and causativity in Tamil. International Journal of Dravidian Linguistics 8. 71-151. 
Payne, J., 1980. The decay of ergativity in Pamir languages. Lingua 51. 147-186.

Payne, Doris L. \& Immanuel Barshi. 1999. External possession. Amsterdam / Philadelphia: John Benjamins.

Perez, C. 1983. Locative pseudo-subjects in Shona. Journal of African Languages and Linguistics 5. 131-155.

Perlmutter, David. 1978. Impersonal passives and the Unaccusative Hypothesis. Proceedings of the Fourth Annual Meeting of the Berkeley Linguistics Society. Berkeley: University of California. 157-89.

Perlmutter, David. 1983. Personal vs. impersonal constructions. Natural Language and Linguistic Theory 1(...). 141-198.

Perlmutter, David \& John Moore. 2002. Language-internal explanation: the distribution or Russian impersonals. Language 78(...). 619-650.

Peterson, David A. 2007. Applicative constructions. Oxford: Oxford University Press.

Peterson, J. 1998. Grammatical relations in Pali and the emergence of ergativity in IndoAryan. München: LINCOM.

Petruck, Miriam. 1996. Semantic frames. In J. Verschueren, J. Ostman, J. Blommaert \& C. Bulcaen (eds.), Handbook of pragmatics. John Benjamins.

Pinker, Steven. 1989. Learnability and cognition: The acquisition of argument structure. Cambridge MA: MIT Press.

Plank Frans (ed.), 1979, Ergativity: Towards a theory of grammatical relations, London \& New York, Academic Press.

Plank, Frans. 1984. Objects: towards a theory of grammatical relations. Londres / New York: Academic Press.

Polinsky, Maria. 1995. Double objects in causatives: towards a study of coding conflict. Studies in Language 19(1). 129-221.

Polinsky, Maria. 2005. Antipassive constructions. In Haspelmath, M., M. Dryer, D. Gil, \& B. Comrie (eds.), The World Atlas of Language Structures. Oxford: Oxford University Press.

Porterie-Gutierrez, L. 1980. Les relations actancielles en Aymara. Amerindia 5. 7-29.

Postal, Paul. 1997. Antipassive in French. Linguisticae Investigationes. Revue de Linguistique Française et de Linguistique Générale 1(2). 333-374.

Prasithrathsint, Amara. 2004. The adversative passive marker as a prominent areal feature of Southeast Asian languages. In Somsonge Burusphat (ed.), Papers from the Eleventh Annual Meeting of the Southeast Asian Linguistics Society, Tempe, Arizona: Arizona State University, Program for Southeast Asian Studies, Monograph Series Press. 583-598.

Primus, Beatrice. 1999. Cases and Thematic Roles. Tubingen: Niemeyer.

Prince, E. 2006. 'Impersonal pronouns in French and Yiddish: Semantic reference vs. discourse reference'. In B. Birner \& G. Ward (eds.), Drawing the boundaries of meaning. Amsterdam / Philadelphia: John Benjamins. 295-315.

Pülkkänen, Liina. 2002. Introducing arguments. Cambridge MA: MIT Press.

Pustet, R. 1995. Obviation and subjectivization: the same basic phenomenon? A study of participant marking in Blackfoot. Studies in Language 19. 37-72.

Pustet, Regina. 2002. Split intransitivity revisited: comparing Lakota and Osage. International Journal of American Linguistics 68(4). 381-427.

Queixalós Francesc, 2013, L'ergativité est-elle un oiseau bleu?, Munich, LINCOM.

Quesada, Diego. 1998. Transitivity, voice, and the middle: Spanish se revisited. Romanische Forschungen 110. 1-36.

Quizar, R. 1994. Split ergativity and word order in Ch'orti'. International Journal of American Linguistics 60(2). 120-38.

Rappaport Hovav, Malka, Edit Doron \& Ivy Sichel (eds.). 2010. Lexical semantics, syntax, and event structure. Oxford University Press. 
Reinhart, Tanya \& Eric Reuland. 1993. Reflexivity. Linguistic Inquiry 24(4). 657-720.

Renaudier, Marie. 2012. Dérivation et valence en sereer, variété de Mar Lodj (Atlantique, Sénégal). $\mathrm{PhD}$ thesis. University of Lyon.

Renault-Lescure, Odile. 2001-2002. Dynamique des relations actancielles en kali'na de Guyane française (ou galibi). Amerindia 26/27. 67-84.

Reuland, Eric, Tanmoy Bhattacharya \& Giorgos Spathas (eds.). 2007. Argument structure. John Benjamins.

Rezac, Milan. 2008a. The syntax of eccentric agreement: The person case constraint and Absolutive displacement in Basque. Natural Language and Linguistic Theory 26. 61-106.

Rezac, Milan. 2008b. The forms of Dative displacement. From Basauri to Itelmen. In Xabier Artiagoitia and Joseba A. Lakarra (eds.) Gramatika jaietan: Patxi Goenagaren omenez. Universidad del País Vasco - Euskal Herriko Unibertsitatea. 709-724.

Rivero, M. 2004. Spanish quirky subjects, person restrictions, and the person-case constraint. Linguistic Inquiry 35. 494-502.

Rivière, N. 1981. La construction impersonnelle en français contemporain. Paris: JeanFavard.

Roberts, I. 1999. Passive and related constructions. In Keith Brown \& Jim Miller (eds.), Concise encyclopedia of grammatical categories. Oxford: Elsevier. 284-290.

Roberts, J. 2001. Impersonal constructions in Amele. In Alexandra Aikhenvald, Robert Dixon \& Masayuki Onishi (eds.), Non-canonical marking of subjects and objects. Amsterdam / Philadelphia: John Benjamins. 201-250.

Rousseau, André, Didier Bottineau \& Daniel Roulland (eds.). 2007. L'énoncé réfléchi. Rennes: Presses Universitaires de Rennes.

Saccon, G. 1993. Postverbal subjects: A study based on Italian and its dialects. PhD dissertation. Harvard University.

Samvelian, Pollet. 2012. Grammaire des predicats complexes: Les constructions nom-verbe. Paris: Lavoisier.

Sands, K. \& L. Campbell. 2001. Non-canonical subjects and objects in Finnish. In Alexandra Aikhenvald, Robert Dixon \& Masayuki Onishi (eds.), Non-canonical marking of subjects and objects. Amsterdam / Philadelphia: John Benjamins. 251-305.

Sapir, Edward. 1917. Review of C. C. Uhlenbeck, Het passieve karakter van het verbum transitivum and van het verbum actionis in talen van Noord-Amerika. International Journal of American Linguistics 1: 82-86.

Sansò, Andrea, and Anna Giacalone Ramat. 2016. Deictic motion verbs as passive auxiliaries. The case of Italian andare 'go' (and venire 'come'). Transactions of the Philological Society 114. 1-24.

Saj, Sergej. 2008. K tipologii antipassivnyx konstrukcij: Semantika, pragmatika, sintaksis [Towards a typology of antipassive constructions: Semantics, pragmatics, syntax]. PhD dissertation. St.Petersburg: Institute of Linguistic Studies.

Say, Sergey. 2014. Bivalent verb classes in the languages of Europe. A quantitative typological study. Language Dynamics and Change 4(1). 116-166.

Schachter, P. 1976. The subject in Philippine languages: Topic, actor, actor-topic or none of the above. In Li, C. (ed.), Subject and topic. New York: Academic Press. 491-518.

Schlund, Katrin. 2013. Russian adversity impersonals and split ergativity. In Irina KorChahine (ed.), Current studies in Slavic languages. John Benjamins. 247-263.

Seidl, A. \& A. Dimitriadis. 2003. Statives and reciprocal morphology in Swahili. In Sauzet, P. \& A. Zribi-Hertz (ed.), Typologie des langues d'Afrique et universaux de la grammaire. Vol. 1. Paris: L'Harmattan. 239-284.

Serbat, Guy. 1981. Cas et fonctions. Paris: Presses Universitaires de France. 
Seržant, Ilja A. 2012. The so-called possessive perfect in North Russian and the CircumBaltic area. A diachronic and areal account. Lingua 122. 356-385.

Shibatani, Masayoshi. (ed.). 1976. The grammar of causative constructions. New York: Academic Press.

Shibatani, Masayoshi. 1977. Grammatical relations and surface cases. Language 53. 789-809.

Shibatani, Masayoshi. 1985. Passives and related constructions: a prototype analysis. Language 61. 821-848.

Shibatani, Masayoshi. 1988. Voice in Philippine languages. In Masayoshi Shibatani. (ed.), Passive and voice. Amsterdam / Philadelphia: John Benjamins. 85-142.

Shibatani, Masayoshi. (ed.). 1988. Passive and voice. Amsterdam / Philadelphia: John Benjamins.

Shibatani, Masayoshi. 1999. Dative subject constructions twenty-two years later. Studies in the Linguistic Sciences 29(2). 45-76.

Shibatani, Masayoshi. 2001. Non-canonical constructions in Japanese. In Alexandra Aikhenvald, Robert W. M. Dixon \& Masayuki Onishi (eds.), Non canonical marking of subjects and objects. Amsterdam: Benjamins. 307-355.

Shibatani, Masayoshi (ed.). 2002. The Grammar of Causation and Interpersonal Manipulation. Amsterdam: John Benjamins.

Shibatani, Masayoshi. \& Praashant Pardeshi (eds.). 2001. The grammar of causation and interpersonal manipulation. Amsterdam / Philadelphia: John Benjamins.

Shibatani, Masayoshi \& Prashant Pardeshi. 2002. The causative continuum. In Masayoshi Shibatani (ed.), The Grammar of Causation and Interpersonal Manipulation. Amsterdam: John Benjamins. 85-126.

Shopen, Timothy \& M. Konaré. 1970. Sonrai causatives and passives: Transformational versus lexical derivations for propositional heads. Studies in African Linguistics 1. 211254.

Shore, S. 1988. On the so-called Finnish passive. Word 39. 151-76.

Siewierska, Anna. 1984. The passive: a comparative linguistic analysis. Londres: Croom Helm.

Siewierska, Anna. 1988. The passive in Slavic. In Masayoshi Shibatani (ed.), Passive and voice. Amsterdam / Philadelphia: John Benjamins. 243-89.

Siewierska, Anna. 2010. From third plural to passive: Incipient, emergent and established passives. Diachronica 27(1). 73-109.

Siewierska, Anna. (ed.). 2008. Special thematic issue on Impersonal constructions. Transactions of the Philological Society 106(2).

Siewierka, Anna. 2008. Introduction: Impersonalization: An agent-based vs. a subject-based perspective. Transactions of the Philological Society 106(2). 115-137.

Sigurðsson, H. 2002. To be an oblique subject: Russian vs. Icelandic. Natural Language and Linguistic Theory 21. 89-155.

Silverstein, Michael. 1976. Hierarchy of features and ergativity. In Robert M. W. Dixon (ed.), Grammatical Categories in Australian Languages. Canberra: Australian Institute of Aboriginal Studies. 112-171.

Słoń, A. 2003. Impersonal constructions in English and Polish, a Cognitive Grammar analysis. PhD dissertation. Lublin: Marie Curie-Skłodowska University.

Smeets, Rieks. 1992. On valencies, actants and actant coding in Circassian. In B. George Hewitt (ed.), Caucasian perspectives. München / Newcastle : LINCOM Europa. 98-114.

Smith, M. 2004. Light and heavy reflexives. Linguistics 42(3). 573-615.

Song, Jae Jung. 1996. Causatives and causation: a universal-typological perspective. Londres / New York: Longman. 
Sonnenschein, Aaron Huey. 2015. Indirect object 'lowering' in San Bartolomé Zoogocho Zapotec. In Natalie Operstein \& Aaron Huey Sonnenschein (eds.), Valency changes in Zapotec. Synchrony, diachrony, typology. John Benjamins. 281-295.

Spreng, Bettina. 2005. Third person arguments in Inuktitut. In Solveiga Armoskaite and James J. Thompson (eds.), Workshop on the structure and constituency of the languages of the Americas. University of British Columbia: UBC Working Papers in Linguistics. 215225.

Spreng, Bettina. 2010. On the conditions for antipassives. Language and Linguistics Compass 4(7). 556-575.

Stefanini, Jean. 1962. La voix pronominale en ancien et en moyen français. Aix-en-Provence: Ophrys.

Stilo, Donald. 2009. Case in Iranian: from reduction and loss to innovation and renewal. In Andrej Malchukov \& Andrew Spencer (eds.), Handbook of Case. Oxford: Oxford University Press. 700-715.

Stroński, Krzysztof. 2010. Variation of ergativity patterns in Indo-Aryan. Poznań Studies in Contemporary Linguistics. 46(2). 237-253.

Stroński, Krzysztof. 2011. Synchronic and diachronic aspects of ergativity in Indo-Aryan. Poznań: Wydawnictvo Naukowe UAM.

Tchekhoff, Claude. 1987. Antipassif: Aspect imperfectif et autonomie du sujet. Bulletin de la Societe de Linguistique de Paris 82. 43-67.

Terada, Michiko. 1991. Incorporation and argument structure in Japanese. $\mathrm{PhD}$ thesis. University of Massachusetts, Amherst.

Terrill, Angela. 1997. The development of antipassive constructions in Australian languages. Australian Journal of Linguistics 17. 71-88.

Tesnière, Lucien. 1959. Eléments de syntaxe structurale. Paris: Klincksieck.

Thompson, Chad. 1989. Voice and obviation in Athabaskan and other languages. $\mathrm{PhD}$ dissertation. University of Oregon.

Thompson, Chad. 1994. Passive and inverse constructions. In Givón (ed.), Voice and inversion. Amsterdam: Benjamins. 47-63.

Torn, Reeli. 2002. The status of the passive in English and Estonian. In Hendriks, H. (ed.), Working Papers in English and Applied Linguistics 7. Cambridge: Research Center for English and Applied Linguistics. 81-106.

Tournadre, Nicolas. 1996. L'ergativité en tibétain. Louvain \& Paris: Peeters.

Trask, R. Larry. 1979. On the origin of ergativity. In Frans Plank (ed.), Ergativity. Toward a theory of grammatical relations. London: Academic Press. 385-404.

Tsunoda, Tasaku. 1981. Split case-marking in verb types and tense/aspect/mood. Linguistics 19. 389-438.

Tsunoda, Tasaku. 1985. Remarks on transitivity. Journal of Linguistics 21(2). 385-396.

Tsunoda, Tasaku. 1988. Antipassives in Warrungu and other Australian languages. In Masayoshi Shibatani (ed.), Passive and voice. Amsterdam / Philadelphia: John Benjamins. 595-649.

Tsunoda, Tasaku. 1999. 'Transitivity'. In Keith Brown \& Jim Miller (eds.), Concise encyclopedia of grammatical categories. Oxford: Elsevier. 383-391.

Tsunoda, Tasaku \& Taro Kageyama (eds.), Voice and grammatical relations: In honor of Masayoshi Shibatani. Amsterdam / Philadelphia: John Benjamins.

van der Wal, Jenneke. 2008. Agreement in thetic sentences in Bantu and Romance. In De Cat, C. \& K. Demuth (eds.), The Bantu-Romance connection: a comparative investigation of verbal agreement, DPs, and information structure. Amsterdam / Philadelphia: John Benjamins. 323-350. 
van Langendonck, W. \& W. van Belle (eds.). 1996-1998. The dative. 2 vols. Amsterdam / Philadelphia: John Benjamins.

Van Valin, Robert D. 1980. On the distribution of passive and antipassive constructions in Universal Grammar. Lingua 50: 303-327.

Van Valin, Robert D. 1981. Grammatical relations in ergative languages. Studies in Language 5: 361-394.

Van Valin, Robert D. 1990. Semantic parameters of split intransitivity. Language 66: 221260.

Vater, Heinz. 1978. On the possibility of distinguishing complements and adjuncts. In Werner Abraham Werner (ed.), Valence, Semantic Case, and Grammatical Relations. Amsterdam: Benjamins. 21-45.

Velázquez-Castillo, M. 1996. The grammar of possession: Inalienability, incorporation and possessor ascension in Guaraní. Amsterdam / Philadelphia: John Benjamins.

Velázquez-Castillo, M. 2002. Guaraní causative constructions. Typological Studies in Language 48. 507-553.

Velázquez-Castillo, M. 2003. Grammatical relations in active systems. Functions of Language 9. 133-167.

Verla, M. \& K.P. Mohanan (eds.). 2003. Experiencer subjects in South Asian languages. Stanford: CSLI Publications.

Vincent, Nigel. 1998. Competition and correspondence in syntactic change: null arguments in Latin and Romance. Paper delivered at the 5th Diachronic Generative Syntax Conference. University of York.

Voisin-Nouguier, Sylvie. 2011. Possessive voice in Wolof: a rare type of valency operator. In Jan Wohlgemuth \& Michael Cysouw (eds.), Rara and rarissima, documenting the fringes of linguistic diversity. De Gruyter Mouton. 377-400.

Welton-Lair, L. 1999. The evolution of the French indefinite pronoun on: a corpus-based study on grammaticalization. $\mathrm{PhD}$ dissertation. Cornell University.

Werner, Abraham (ed.). 1978. Valence, Semantic Case, and Grammatical Relations. Amsterdam: Benjamins.

Werner, Abraham \& Larisa Leisiö (eds.). 2006. Passivisation and typology: form and function. Amsterdam: Benjamins.

Wichmann, Soren. 2009. Case relations in a head-marking language: verb-marked cases in Tlapanec. In Andrej Malchukov \& Andrew Spencer (eds.), The Oxford Handbook of Case. Oxford: Oxford University Press. 797-807.

Wichmann, Søren (ed.). 2014. Special thematic issue on Arguments and Adjuncts CrossLinguistically. Linguistic Discovery 12(2).

Witzlack-Makarevich, Alena. 2011. Typological Variation in Grammatical Relations. Doctoral dissertation. University of Leipzig.

Witzlack-Makarevich, Alena, Taras Zakharko, Lennart Bierkandt, Fernando Zúñiga \& Balthasar Bickel. 2016. Decomposing hierarchical alignment: co-arguments and conditions on alignment. Linguistics 54(3). 531-561.

Woolford, Ellen. 1993. Symmetric and asymmetric passives. Natural Language and Linguistic Theory 11. 679-728.

Wouk, Fay \& Malcolm Ross (eds.). 2002. The history and typology of Western Austronesian voice systems. Canberra: Australian National University, Research School of Pacific and Asian Studies.

Xolodovič, Alexander A. (ed.) 1969. Tipologija passivnyx konstrukcij. Diatezy i zalogi. [Typology of passive constructions: Diatheses and voices]. Leningrad: Nauka. 
Xolodovič, Alexander A. (ed.) 1974. Tipologija kauzativnyx konstrukcij. Morfologičeskij kauzativ. [Typology of causative constructions: Morphological causative]. Leningrad: Nauka.

Xrakovskij, Viktor S. 1974. Passivnye konstrukcii. [Passive constructions]. In Viktor S. Xrakovskij (ed.) Tipologija passivnyx konstrukcij [Typology of passive constructions]. Leningrad: Nauka. 5-45.

Xrakovskij, Viktor. 1981. Diateza i referentnost' [Diathesis and Referentiality]. In Viktor Xrakovskij (ed.), Zalogovye konstrukcii v raznostrukturnyx jazykax. Leningrad: Nauka. 5-38.

$\mathrm{Xu}$, Jie. 2006. The nature of null objects in Chinese. Journal of Chinese Language and Computing 16(1). 1-15.

Zaenen, Annie, Joan Maling \& Höskuldur Thráinsson. 1985. Case and grammatical functions: the Icelandic passive. Natural Language and Linguistic Theory 15(4). 573-639.

Zifonun Gisela. 2001. «Man lebt nur einmal». Morphosyntax und Semantik des Pronomens man. Deutsche Sprache 28. 232-253.

Zribi-Hertz, Anne. 1982. La construction SE-moyen du français et son statut In le triangle: moyen-passif-réfléchi. Linguisticae Investigationes 6. 345-401.

Zribi-Hertz, Anne. 1987. La réflexivité ergative en français moderne. Le français moderne 55. 23-54.

Zribi-Hertz, Anne. 1995. Emphatic or reflexive? On the endophoric character of French luimême and similar complex pronouns. Journal of Linguistics 31. 333-374.

Zúñiga, Fernando. 2006. Deixis and Alignment. Inverse systems in indigenous languages of the Americas. John Benjamins, Amsterdam.

Zuñiga, Fernando \& S. Kittilä. 2010. Benefactives and Malefactives. Typological perspectives and case studies. Amsterdam / Philadelphia: John Benjamins. 